\title{
The influence of semiochemicals on the co-occurrence patterns of a global invader and native species
}

by

\section{Fabian Ludwig Westermann}

\author{
A thesis submitted to \\ Victoria University of Wellington \\ in fulfilment of the requirements for the degree of \\ Doctor of Philosophy \\ in Ecology and Biodiversity
}

Victoria University of Wellington

Te Whare Wānanga o te Ūpoko o te Ika a Māui 

This thesis was conducted under the supervision of

\section{Professor Phil J. Lester (primary supervisor)}

Victoria University of Wellington

Wellington, New Zealand

and

\section{Dr. David M. Suckling (secondary supervisor)}

The New Zealand Institute for Plant \& Food Research Ltd.

Christchurch, New Zealand 
"Because it's there"

- Retort of George Mallroy to the question, why he wanted to climb Mount Everest 


\section{ABSTRACT}

The success of invasive species in their introduced range is often influenced by interactions with resident species communities. Chemical communication is one the factors which contributes to a variety of aspects of a species life cycle, ranging from mating, to food localization and interactions with members of the same and other species. In my thesis, I investigate the effects of venoms and semiochemicals on interactions between the invasive Argentine ant (Linepethima humile) with other resident ant species and demonstrate how pheromones can potentially be utilized as an area wide control mechanism of this species, by disrupting their foraging success.

I studied the effects of venom composition, their toxicity and utilization on the outcome of aggressive interactions between the Argentine ant and the four Monomorium species in New Zealand occurring. The toxicity of the venom of the two species co-occurring with Argentine ants was significantly higher than the toxicity of the species which do not. However, no correlation between venom toxicity and Monomorium survival was found. For M. antipodum a significant relationship between venom utilization and its mortality was found, indicating that the way venom is used might be an important aspect of these interactions. Physical Aggression between Monomorium and Argentine ants also had strong effects on Monomorium worker mortality, which provided evidence that a variety of factors and strategies contribute to the ability of interacting organisms to withstand the pressure of a dominant invader at high abundance.

I conducted bioassays with food sources and synthetic trail pheromones, providing a proof of concept on disrupting the foraging ability of Argentine ants. Other resident species benefited from the reduced success of Argentine ants, but to a varying degree. Behavioural variations between the resident species provided an explanation for observed differences in foraging 
success and how much each of these individual competitors was able to increase their foraging. The mechanism for the observed increase in resource acquisition of resident species appeared to be a decrease in aggressive behaviour displayed by Argentine ants.

I expanded the usage of the synthetic pheromone to a commercial vineyard, were Argentine ants can have negative effects on crop development by dispersing and tending to homopteran pest species. Argentine ants' access to the crop canopy could be significantly reduced by placing pheromone dispensers at the base of the vine plant, while dispensers in the plant canopy had little effect on Argentine ant numbers. Doubling the amount of pheromone did not result in an additional reduction of ant activity.

Lastly incorporating the knowledge gained in the previous chapter, I extended the application of the pheromone to a large field trial over a three month period. Argentine ant activity and foraging success was significantly supressed compared to untreated control plots, providing evidence that this form of large scale application might be a possible way to control large invasive ant populations by disrupting their trail following and foraging behaviour for a prolonged period of time. While initial calculations have suggested that the treatment is currently not feasible (13.3 US\$/mg/ha), I found a significant reduction in body fat in workers collected from treated plots compared with untreated plots, suggesting adverse effects on nest fitness.

My findings provide new insights into chemical communication between invasive and resident species, support existing dominance hierarchy models in ant populations, and help to establish a target specific potential management technique of wide-spread invasive ant species. 


\section{ACKNOWLEDGEMENTS}

Many different individuals contributed to my success throughout the journey of my $\mathrm{PhD}$. Unfortunately, it is impossible to list everybody who supported me over the years to this point and I wish to apologize if you feel that I have forgotten to include your name in this list; I am still grateful for your support.

My decision to start a PhD at Victoria University of Wellington was primarily based on my good impressions of my primary supervisor Professor Dr. Phil Lester. He has supported me greatly throughout my $\mathrm{PhD}$, often beyond what I would have expected of him and I consider myself to be exceptionally lucky to have had him as my supervisor. I would like to thank you for your guidance when I got stuck, your patience when something took (waaaaaay) longer than expected and your support for all the challenges I had to overcome during the period of my $\mathrm{PhD}$. I wouldn't have made it without you.

I would like to thank my secondary supervisor Dr. Max Suckling for his ideas and encouragements to add additional details to experiments. I very much appreciated your expertise on pheromone work and feedback for manuscripts.

I thank Dr. Vaughn Bell for our collaboration as well as his kindness and friendship in times of troubles. I am very grateful for all your help, ideas, advice, let alone countless cups of coffee!

I am grateful to colleagues who made suggestions that improved my critical thinking, analysis and writing. In particular I wish to thank Dr. Monica Gruber and Dr. Rafael Barbieri for their very helpful comments, but a thanks also goes to all other members of my research group. 
I thank Mr. H. Senoh of Shin Etsu Fine Chemicals, Tokyo for supplying me with the formulated trail pheromone dispensers, which made Chapters 4 and 5 of this thesis possible.

I thank Dr. Andrew Twidle his support with the GC-MS analysis of the pheromone dispensers and the time he gave me during my stay with Plant \& Food Lincoln.

I'd like to thank my friends on all sides of the planet, who supported me with motivation and advice when it was needed. There are many things from many people for which I am grateful, but I'll constrain myself to a single sentence for each person.

I thank Dr. Tamsen Byfield for advice and talks when needed. I thank Meghan Cooling for giving advice, being cheerful and some damn fun movie nights. I thank Julia Loepelt for sharing her pineapple-coconut tea and sharing misery during the $\mathrm{PhD}$ journey. I thank Tanya Karst for being awesome (Seriously). I thank Dr. Susanne Krejcek who has supplied me with information about Wellington before I even arrived here and supported me throughout my $\mathrm{PhD}$ in many ways. I thank Christina Roberts for coffee, fun emails and distractions from work. I thank Davide Santoro and Varun Venkatesh for advice on all matters of live. I thank Kirsty Yule for fun chats.

I thank Nihal Aktas for sharing her PhD experiences with me, and sticking with me through debates about the world. I thank Heiko Barho for supporting me on my way towards my $\mathrm{PhD}$ application; sorry I was a stubborn oaf. I thank Sandy Fisher for our long friendship, ever since I met you in the tram on that bloody rainy day. I thank Vanessa Fourcaudot who, unknowingly, set me on the path to my research carrier. I thank Vanessa Herrmann for discussions and fun Q\&As on many subjects throughout my life and all the time together. I thank Dr. Kevin Lüthy for his invaluable advice in the many years throughout my studies. I thank Thi Kim Yen Phan 
for our long internet friendship and long chats on the interesting matters of life. I thank Sebastian Reusch for being an awesome and reliable friend; I truly miss library study times. I thank Natalie Schwan for her absolutely unmatchable and amazing way to motivate me with a single txt message, as well as coaching me for my TOEFL test before the start of my $\mathrm{PhD}$. I thank Benjamin Stegmann for motivational talks, video game discussions and a long friendship. I thank Sebastian Winkler for endless videogame debates, as well as spellchecking the motivation letter (albeit mocking me for it with the words "It tugs my heartstrings that you've found your destiny") which eventually led to this $\mathrm{PhD}$. I thank Larana Walen for being my healer in STO PvE battles against the Borg, inappropriate jokes on the bridge and fun chats when nobody else would listen.

I am very grateful for the financial support of a VUW PhD Scholarship and the VUW Completion scholarship, which allowed me to conduct my research.

I thank the people who aim to inspire and communicate Science in the public and have also influenced me to some degree in my pursuit of Science, specifically I thank Richard Dawkins, Neil deGrasse Tyson and Stephen Hawkins for their work.

I thank SmoothMcGroove for providing some damn fine background music during the write-up of this thesis.

Most importantly, my gratitude goes to my amazing mother Andrea Westermann, who has been hugely supportive throughout this degree and the preceding one and my awesome brother Zimmermannsmeister David Westermann, who had to cope with my long absence and manage 


\section{Acknowledgements}

things at home while I wasn't around. Their encouragement and faith in me has made all the difference to this journey and gave me the confidence to proceed when it all seemed too much. 


\section{CONTENTS}

ABSTRACT I

CONTENTS

VII

LIST OF FIGURES

XI

LIST OF TABLES

XV

Chapter 2: Toxicity and utilization of chemical weapons: Is toxicity and venom utilization a strong force in the formation of species communities? 


\section{Contents}

2.1. ABSTRACT

2.2. INTRODUCTION

2.3. MATERIALS AND METHODS

2.3.1. ANT SAMPLES.

2.3.2. ARENA Fight AND VENOM uSAGE.

2.3.3. VENOM SURVIVABILITY.

2.3.4. STATISTICAL ANALYSIS

2.4. RESULTS

2.5. DISCUSSION

Chapter 3: Disruption of foraging by a dominant invasive species to decrease its competitive ability

3.1. ABSTRACT.

3.2. INTRODUCTION

3.3. METHODS 40

3.3.1. LOCATION 40

3.3.2. RESOURCE COMPETITION EXPERIMENTS

3.3.3. BEHAVIOURAL SCORING

3.4. RESULTS

3.4.1. RESOURCE COMPETITION EXPERIMENTS

3.4.2. BEHAVIOURAL SCORING

Chapter 4: Synthetic Pheromones as a management technique - Dispensers decrease 
Chapter 5: The effects of reduced foraging success on an invasive ant - pheromone disruption 
Contents

5.3.7. STATISTICAL ANALYSIS

5.4. RESULTS

5.4.1. CANOPY TRAFFic.

5.4.2. FOOD SOURCE RECRUITMENT.

5.4.3. EdGE EFFECTS.

5.4.4. FAT ANALYSIS.

5.5. DISCUSSION

6.2. SYNTHESIS 


\section{LIST OF FIGURES}

Figure 2.1: Structural formula of venom and illustrations of the four Monomorium species. M. antarcticum

(1) (5Z,8E)- 3,5-di-(5-hexen-1-yl)-pyrrolizidine (2) 2-butyl-5-(8-nonenyl)pyrrolidine; $M$. smithii (3)

(5Z,8E)-3-heptyl-5-methylpyrrolzidine, (4) (5Z,8E)-3-methyl-5-(8-nonenyl)pyrrolizidine and (5) trans-2-

butyl-5-heptylpyrrolidine in a 1:2:2 ratio; $M$. antipodum (6) trans-2-ethyl-5-nonylpyrrolidine and (7)

trans-2-ethyl-5-(10-undecenyl)pyrrolidine in a 1:1 ratio; $M$. sydneyense (8) trans-2-butyl-5-

undecylpyrrolidine and (9) trans-2-butyl-5-(12-tridecenyl) pyrrolidine in a $1: 2$ ratio from. Sketches of

Monomorium species represent different ant workers (sketches not to scale). LD50 values are results

from venom survival experiments.

Figure 2.2: Monomorium toxicity and ant survival. Overall survival time of Argentine ant workers in arena fights against four Monomorium species correlated with the LD50 of the venom of that Monomorium species (upper) and the overall survival time of Monomorium workers in arena fights against Argentine ants correlated with the LD50 of the venom of that Monomorium species (lower).

Figure 2.3: Monomorium mortality in arena fights. Mortality of Monomorium workers in arena fights against Argentine ants depending on Average Individual Aggression within the same replicate (open squares) and Average Maximum Aggression within the same replicate (closed triangles). Behaviour scores were taken as follows: $\mathbf{0}=$ no interest or aggression; 1 = interest shown via antennation; $\mathbf{2}$ = ant retreats quickly; 3 = lunging, biting or leg-pulling, raising of gaster and exuding venom; 4 = prolonged (> 5 s) incidences of aggression, individuals locked together and fighting.

Figure 2.4: Argentine ant mortality in arena fights. Mortality of Argentine ant workers in arena fights against Monomorium species depending on Average Individual Aggression within the same replicate (open squares) and Average Maximum Aggression within the same replicate (closed triangles). Behaviour scores were taken as follows: $\mathbf{0}$ = no interest or aggression; $\mathbf{1}=$ interest shown via antennation; $\mathbf{2}=$ ant retreats quickly; 3 = lunging, biting or leg-pulling, raising of gaster and exuding venom; 4 = prolonged (> $5 \mathrm{~s}$ ) incidences of aggression, individuals locked together and fighting.

Figure 3.1: Food items taken by ants. Percentage of average number of food items taken in trials $(n=6$ per treatment and site) by M. antarcticum, $O$. glaber and $T$. jocosus from Argentine ants depending on the 


\section{List of Figures}

treatment at increasing concentrations of synthetic trail pheromone (Z)-9-hexadecanal (measured in $\mu g$ pheromone per $\mu$ l solvent). Error bars represent standard error of average \% food items taken. 45

Figure 3.2: Relative percentage of behavioural scores during interactions. (A) Argentine ants towards $M$. antarcticum, $O$. glaber and $T$. jocosus and (B) M. antarcticum, $O$. glaber and $T$. jocosus towards Argentine ants. Numbers surrounding each graph $(0-4)$ represent the displayed behaviours during interactions, which was scored as $\mathbf{0}=$ no interest or aggression; $\mathbf{1}=$ interest shown via antennation; $\mathbf{2}=$ ant retreats quickly; 3 = lunging, biting or leg-pulling, rising of gaster and exuding venom; 4 = prolonged (> $5 \mathrm{~s}$ ) incidences of aggression, individuals locked together and fighting. Small numbers and dashed lines mark intervals of $0,25,50,75$ and 100 for the percentage of interactions during which these behaviours were being displayed.

Figure 3.3: Average aggression scores of ants. Average aggression of (A) Argentine ants towards $M$. antarcticum, 0 . glaber and $T$. jocosus and (B) M. antarcticum, 0 . glaber and $T$. jocosus towards Argentine ants depending on the treatment with different concentrations of synthetic trail pheromone (Z)-9-hexadecanal (measured in $\mu \mathrm{g}$ pheromone per $\mu \mathrm{l}$ solvent). Aggression was scored as $0=$ no interest or aggression; 1 = interest shown via antennation; 2 = ant retreats quickly; $\mathbf{3}$ = lunging, biting or leg-pulling, rising of gaster and exuding venom; 4 = prolonged (> $5 \mathrm{~s}$ ) incidences of aggression, individuals locked together and fighting. Error bars represent Standard Error of average aggression scores.

Figure 4.1: Overview of experimental site and design. A) Argentine ants approaching mesh pockets with mealybugs in vine canopy before placement of pheromone dispensers. B) Experimental setup of a single grapevine, placed in a bucket under the irrigation line. C) Experimental setup of the trial. D) A close-up of the canopy treatment with pheromone disperser (brown wire) attached to the vine (left) and white mesh pocket containing mealybugs on a segment of seed potato (right). E) Argentine ant tending to a citrophilus mealybug on one of the experimental plants.

Figure 4.2: Mean ( \pm SEM) numbers of Argentine ants recorded in pitfall traps established in the Hawke’s Bay vineyard study block. Assessments were undertaken between 15 February (before pheromone treatment) and 29 April 2013 ( $n=12$ pitfall traps next to $G ; n=11$ pitfall traps next to UE, C and GC; $n=$ 10 pitfall traps next to UI). C = canopy; G = ground; GC = ground plus canopy; UI = untreated internal control; UE = untreated external control. 
Figure 4.3: Mean ( $\pm \mathrm{SEM}$ ) numbers of Argentine ants recorded during 1-min counts in the Hawke's Bay vineyard study block ( $n=12$ mealybug-inoculated Pinot Noir grapevines per treatment). Assessments were undertaken between 25 February and 29 April 2013. $C=$ canopy; $G=$ ground; GC = ground plus canopy; UI = untreated internal control; UE = untreated external control.

Figure 5.1: Schematic representation (not to scale) of the experimental layout. Each square represents one experimental plot with $\mathrm{T}=$ Treated and $\mathrm{C}=$ Control plots with the dimensions of $28 \times 32 \mathrm{~m}$. Each plot contained a monitoring area with $12 \times 16 \mathrm{~m}$.

Figure 5.2: Mean ( \pm SEM) numbers of Argentine ants recorded during 1-minute counts in the canopy of grapevines in treated and untreated monitoring plots. Assessments were undertaken between $4^{\text {th }}$ February (before pheromone treatment) and 25 $5^{\text {th }}$ March 2014 (with $n=30$ per plot and monitoring interval).

Figure 5.3: Mean ( \pm SEM) numbers of Argentine ants recorded at randomly placed food sources in the canopy of grapevines after 1 hour in treated and untreated monitoring plots. Assessments were undertaken between $4^{\text {th }}$ February (before pheromone treatment) and $25^{\text {th }}$ March 2014 (with $n=4$ per plot and monitoring interval).

Figure 5.4: Argentine ant activity along transects. Mean \% ( \pm SEM) of Argentine ants recorded during 1minute counts along transects through treated monitoring plots, relative to the mean number $(10.27 \pm$ 1.15) of Argentine ants counted during 1-minute counts along transects through untreated monitoring plots. The x-Axis represents the distance from the centre of the plot in meters, with the edge of the monitoring plot after the 6.4 meter mark and the edge of the treated plot, where the last dispensers were located, after the $\mathbf{1 2 . 8}$ meter mark. The dotted line represents a fitted curve with the function $y$ $=215.926 /\left(1+\mathrm{e}^{(-0.205 \times(\mathrm{x}-24.246)}\right)$. Assessments were undertaken between $4^{\text {th }}$ February (before pheromone treatment) and $25^{\text {th }}$ March 2014 (with $n=15$ per plot and monitoring interval).

Figure 6.1: Proposed feedback cycle initiated and supported by the application of synthetic Argentine ant trail pheromone in an environment with at least one sub dominant ant community species competing with the Argentine ant for food sources. Minus-signs represent a negative feedback i.e. a reduction of the following descriptor by the previous one for instance "reduction of trails and foraging of the Argentine ant by synthetic pheromone". Plus-signs represent a positive feedback i.e. an increase of the following descriptor by the previous one in the same manner. 


\section{LIST OF TABLES}

Table 2.1: Monomorium venom usage depending on Argentine ant density. Number of observed occurrences of venom utilization of four Monomorium species in arena trials, corresponding with the Argentine ant density encountered. The table displays the species (venom toxicity from venom survival trials included for reference), Argentine ant worker density, number of displayed venom behaviours (No venom, Gaster flagging or spraying, stinging) and the total number of behaviour observations during trials with the corresponding density.

Table 2.2: Monomorium venom usage depending on Monomorium mortality. Number of observed occurrences of venom utilization of four Monomorium species in arena trials, corresponding with the Monomorium mortality rates in arena trials. The table displays the species (venom toxicity from venom survival trials included for reference), Monomorium mortality (Low = 0 - 4; Medium = 5-8; High = 9-12), the sum of all displayed venom behaviours in that category (No venom, Gaster flagging or spraying, stinging) and the total number of behaviour observations during trials with the corresponding Monomorium mortality.

Table 2.3: Concise summary of experimental results and proposed interpretation. Columns display the four Monomorium species occurring in New Zealand, the observed co-occurrence patterns with the invasive Argentine ant, relative toxicity and LD50 of Monomorium venom against Argentine ants found in venom toxicity tests, most common means of venom application by Monomorium observed in arena trials as well as observed changes of behaviour with increased Argentine ant abundance, Aggression levels in arena trials, Argentine ant mortality in arena trials, Monomorium mortality in arena trials and proposed interpretation of the combined factors in regards to the observed spatial patterns.

Table 3.1: Statistics for number of food items taken. Logistic regression on the number of food items taken in trials by Argentine ants versus $M$. antarcticum, $O$. glaber and $T$. jocosus. First two rows show the difference between food items taken by Argentine ants from a species, with $M$. antarcticum as reference. The next three rows show the difference of food items taken by Argentine ants depending on pheromone concentration with the control treatment as a reference. $B$ is the log-odds units, S.E. 


\section{List of Tables}

the standard errors associated with the coefficients, Wald the Wald chi-square value, df the degrees of freedom, $P$ the statistical significance and $\operatorname{Exp}(ß)$ the odds ratio.

Table 3.2: Total number of behavioural observations. Total number of observations of non-aggressive (behaviour scores 0, 1 and 2) and aggressive (behaviour scores 3 and 4) behaviour displayed by Argentine ants towards each competing species and observations for this species in return, as a function of pheromone concentration or no treatment.

Table 3.3: Statistics for aggression by Argentine ants. Logistic regression on displayed aggression by Argentine ants towards $M$. antarcticum, $O$. glaber and $T$. jocosus. The first two rows show the difference between aggressions of Argentine ants towards a species, with $M$. antarcticum as reference. The next three rows show aggression of Argentine ants depending on pheromone concentration with the control treatment as a reference. $ß$ is the log-odds units, S.E. the standard errors associated with the coefficients, Wald the Wald chi-square value, df the degrees of freedom, $P$ the statistical significance and $\operatorname{Exp}(ß)$ the odds ratio.

Table 3.4: Statistics for aggression by $M$. antarcticum, $O$. glaber and $T$. jocosus towards Argentine ants. Logistic regression on displayed aggression by $M$. antarcticum, $O$. glaber and $T$. jocosus towards Argentine ants. The first two rows show the difference between aggressions by a species towards Argentine ants, with $M$. antarcticum as reference. The next three rows show aggression depending on pheromone concentration with the control treatment as a reference. $B$ is the log-odds units, S.E. the standard errors associated with the coefficients, Wald the Wald chi-square value, df the degrees of freedom, $P$ the statistical significance and $\operatorname{Exp}(ß)$ the odds ratio.

Table 4.1: Mean difference, standard error, $p$-values and confidence intervals between treatments from the repeated measures linear model for the ground assessment (Games Howell post hoc test) and canopy assessment (Fishers LSD post hoc test). $\mathrm{C}=$ canopy; $\mathbf{G}=$ ground; $\mathrm{GC}=$ ground plus canopy; $\mathrm{UI}=$ untreated internal control; UE = untreated external control. Statistically significant differences between treatments during each assessment are denoted by one asterix $(\alpha=0.05)$. 


\section{STATEMENT OF AUTHORSHIP}

I hereby declare that this thesis is my own work and that all sources quoted, paraphrased or otherwise referred to have been properly acknowledged in the references at the end of each respective chapter. To the best of my knowledge, this thesis neither contains material previously published or written by another person, nor material which to a substantial extent has been accepted for the award of any other degree or diploma of the university or other institutes of higher learning, except where due to acknowledgement it has been made clear in the text.

Chapters 2 to 5 of this thesis were written as independent manuscript intended for publication and were written in first person plural tense, as they included contributions of collaborators. In all cases, the manuscripts were written by me. Professor Phil J. Lester provided advice throughout and contributed to editing of the manuscripts and is therefore coauthor on all manuscripts. The contribution of other collaborators and co-authors to each chapter are outlined below, indicated by author initials. ${ }^{1}$

Chapter 2 was accepted for publication in Ecology and Evolution on June $14^{\text {th }} 2015$. Author contributions: FW and PL formulated the research questions and designed the research based on earlier work of PL. PL provided data on effects of venom on ant mortality from the earlier work. FW and LM conducted venom survival experiments. FW analysed the data and

\footnotetext{
${ }^{1}$ Author initials and names: VB Vaughn Bell; TJ Tappey Jones; PL Phil Lester; IM Ian McPherson, LM Lesley Milicich; DMS David Suckling; FW Fabian Westermann;
} 
interpreted the results. TJ and IM provided synthetic venom and contributed to editing of the manuscript.

Chapter 3 was accepted for publication in PLoS One 9(3): e90173 on January $27^{\text {th }} 2014$. Author contributions: FW and PL formulated the research questions and designed the research based on earlier work of DMS. FW conducted the resource competition experiments and behavioural assays, data analysis and interpreted the results. DMS provided synthetic pheromone and contributed to editing of the manuscript.

Chapter 4 was accepted for publication in Pest Management Science on May $21^{\text {st }} 2015$. Author contributions: FW, VB, DMS and PL formulated the research questions and designed the research. FW and VB set up the experimental design. FB conducted pitfall trapping, data analysis and interpreted the results. VB conducted 1 minute canopy counts and contributed to editing of the manuscript. PL provided synthetic pheromone.

Chapter 5 was written for intended publication to Agriculture, Ecosystems and Environment but is yet to be submitted. Author contributions: FW and VB formulated the research questions and designed the research. FW and VB set up the experimental design. FB conducted pitfall trapping, 1 minute canopy counts, data analysis and interpreted the results. DMS provided synthetic pheromone and contributed to editing of the manuscript. 


\section{Chapter 1: General Introduction}

\subsection{Invasive Species}

In the last century global biodiversity has been on a continuous decline. Recent studies suggest that earth's sixth mass extinction may be indeed already well underway (Barnosky et al. 2011; Pimm et al. 2014), with current extinction rates being 100 to 1000 times their prehuman levels (Pimm et al. 1995, 2014). Ecologists are trying to understand many of the factors and processes involved in ecosystem deterioration and biodiversity decline in order to develop strategies to protect the remaining habitats, decrease the impact on already disturbed systems and restore damaged environments to their original state. Climate change (Thomas et al. 2004), pollution (Worm et al. 2006), habitat loss, fragmentation and modification (Pimm et al. 1995) are all major drivers of biodiversity decline. Invasive species are another important driver of biodiversity loss, which only started to receive more attention in the last decades (Richardson \& Pyšek 2008; Gurevitch et al. 2011; Ricciardi et al. 2013). While I am aware that the concept of invasive species has been criticized (for example Davis et al. 2011; Valéry, Fritz \& Lefeuvre 2013), I believe that appropriate and comprehensive rebuttals to this criticism has already been provided by other authors (Simberloff 2003; Lövei et al. 2012; Simberloff \& Vitule 2014) and will therefore not discuss it further in the scope of this thesis.

Divergent definitions of the criteria and terminology for invasive species among researchers exist (Colautti \& MacIsaac 2004; Occhipinti-Ambrogi \& Galil 2004; Colautti \& Richardson 2009). Here the term 'invasive species' in the context of this thesis shall be defined, in accordance with Lockwood et al. (2007), as an organism which: 
1) has been translocated via human actions from its original habitat and normal geographical ranges to a location where it did not previously occur, and

2) has demonstratively established a successfully reproducing and spreading population in a new habitat, and

3) negatively effects the native species community and/or ecosystems to a significant extent in this habitat or bioregion.

Not all introduced species necessarily become invasive, some may even facilitate diversity by coexisting with native species (Rodriguez 2006) and can adapt to their new ecosystems without having any noticeable impact. Others, however, increase vastly in abundance, changing the ecosystem and disassembling communities around them (Sanders et al. 2003). Even after their initial population incline, not all invasive species necessarily persist indefinitely in their newly occupied habitat after a successful establishment and population explosion. Simberloff (2004) reviewed 17 population crashes of invasive species and their causes in detail. Several species populations crashed without any observed causes (for example Elodea canadensis, Bufo marinus, Acridotheres cristatellus) while others exhausted local resources (Rangifer tarandus) or were outcompeted by other introduced species (Mustela nivalis, Ceratitis capitata, Aedes aegypti, Cakile edentula).

Despite these results and the ongoing dispute whether invasive species are passengers or drivers of ecosystem change (MacDougall \& Turkington 2005; Didham et al. 2005) it appears more and more apparent that invasive species are an important factor in environmental change. In many occasions, invasive species appear to be at least "back seat drivers" of ecosystem change, taking advantage of disturbed habitat to establish themselves and then continuously spread from there (Bauer 2012), with additional synergy and cascade effects coming together to degrade a habitat (Brook, Sodhi \& Bradshaw 2008). Simberloff \& Von Holle (1999) introduced the concept of an "invasional meltdown" which was revised later (Simberloff 2006) 
and has been used by other authors (for example Green et al. 2001; O’Dowd et al. 2001, 2003). The underlying hypothesis is that multiple invasions could have a cumulative disturbance effect, which lowers the resistance of the habitat and makes it more vulnerable to subsequent invasive species. This is then hypothesized to produce a catalytic process which accelerates the replacement of native communities and the degradation of the local ecosystems. Ecosystems that have been invaded by one species become destabilized, by opening up niches through the disruption of the original food web, which makes it much easier for secondary invaders to establish. Subsequently, the accumulative impacts of the primary, secondary and following invasions shift the original ecosystem to a "meltdown" point, where the original species community is changed and destabilized to a degree that makes it very difficult to recover.

A number of studies has attempted to provide estimates for the environmental and economic impact of invasive species in detail for different ecosystems and regions (Pimentel et al. 2000; Pimentel, Zuniga \& Morrison 2005; Yan et al. 2001; Andersen et al. 2004; Lovell, Stone \& Fernandez 2006; Olson 2006). Determining economic costs of environmental concerns, particularly invasive species, is no easy task under the best of circumstances (Lovell et al. 2006). Calculating the values for human health or a particular ecosystem service and providing empirical estimates of the damage done by a certain invasive species are difficult, however a number of studies have provided estimates for terrestrial (Olson 2006) and aquatic (Lovell et al. 2006) ecosystems. Concrete estimates for the economic losses through decreased agricultural productivity and costs of control measures in the United States, have amounted to approximately 137 billion US dollars per year at the time of the study (Pimentel et al. 2000, 2005). Pimentel et al. (2005) also estimated that about $42 \%$ of endangered species are primarily threatened because of invasive species, illustrating the importance to act and contain the spread of invasive species, even if they don't cause any immediate economic loss or threat. For these reasons, a number of studies have been conducted to identify pathways (Ward et al. 2006; 
Kaluza et al. 2010), develop management and risk assessment tools (Horan et al. 2002; Leung et al. 2002; Keller, Lodge \& Finnoff 2007; Ricciardi et al. 2013) and to provide recommendations to policymakers (Yan et al. 2001; Horan et al. 2002; Keller et al. 2007).

Invasive species are often adaptive generalists, for example they are frequently omnivores that do not shy away from unknown food sources if none of their usual plant/prey items can be acquired (Sol, Timmermans \& Lefebvre 2002), frequently paired with high aggressiveness (Duckworth \& Badyaev 2007) or other behavioural traits, which increase their invasion success (Sih, Bell \& Johnson 2004; Sih et al. 2012). Insects among all others appear to be particularly well suited to become invaders. Being small they can, for instance, easily be translocated completely unnoticed by humans and make use of planes or cargo ships to reach almost any point on earth (Kaluza et al. 2010). Additionally, their small food demands usually ensures that they survive even longer transports and their high rates of reproduction and rapid adaptiveness to changing environmental conditions increases their chances of survival in the new habitat (Speight, Hunter \& Watt 2008).

Invasive ants have been particularly successful in spreading worldwide with severe consequences for the invaded habitats, causing havoc to native biodiversity including negative effects on other ant species, other invertebrates and vertebrates, particularly birds and lizards, in addition to substantially influencing ecosystem function, economy, animal and human health (McGlynn 1999; Holway et al. 2002a; Krushelnycky \& Gillespie 2008; Pejchar \& Mooney 2009; Rabitsch 2011). Species like the Red Imported Fire Ant (Solenopsis invicta Buren), the Little Fire Ant (Wasmannia auropunctata Roger), the Yellow Crazy Ant (Anoplolepis gracilipes Smith), the Big Headed ant (Pheidole megacephala Fabricius) or the Argentine Ant (Linepithema humile Mayr) are globally wide spread 'tramp species' with strong negative impacts on the native communities (Porter \& Savignano 1990; Holway et al. 2002; Hoffmann \& Parr 2007; Savage et al. 2011, but see King \& Tschinkel 2008). For example, the Red 
Imported Fire Ant has been linked to declining bird populations, as well as damage to seeds, seedlings, and root systems of a variety of agricultural crops (Holway et al. 2002a). Furthermore Fire Ants deploy a powerful venom which is not only very painful to humans, but can have serious negative health effects (Howell et al. 2005; Pejchar \& Mooney 2009). Similarly, the Little Fire Ant delivers a powerful and painful sting, because of which it is sometimes commonly referred to as 'electric ant', and has wreaked havoc for biodiversity and human populations on island ecosystems (Lubin 1984; Wetterer \& Porter 2003; Causton, Sevilla \& Porter 2005; Vonshak, Dayan \& Hefetz 2012). Extreme population explosions have been described outside the native range of little fire ants and it "is capable under some circumstances of wiping out entire ant faunas over large areas ... forming in many places a living blanket of ants that kill and eat nearly all other ants in their path" (Holldobler \& Wilson 1994). The Yellow Crazy Ant has also caused serious problems and disruption on islands (O’Dowd et al. 2003; Abbott et al. 2007; Bos et al. 2008; Davis et al. 2008, 2010), as has the Big Headed Ant (Holway et al. 2002a; Hoffmann \& Parr 2008).

Several factors have been hypothesized to contribute to the invasion success of particular ant species and their ability to reach high abundance in new habitats. For example release from predators (Keane \& Crawley 2002; but see Colautti et al. 2004), competitors, parasites or pathogens (Mitchell \& Power 2003; Torchin \& Mitchell 2004), which could limit their abundance within their natural range. Genetic bottlenecks imposed on a founder population may facilitate unicoloniality (Tsutsui et al. 2000), which blurs the nest-mate discrimination between colonies and allows multiple queens and nests to work together over an entire landscape resulting in higher population densities, hypothesized to occur because intraspecific competition between colonies is annulled (Tsutsui et al. 2000; Pedersen et al. 2006; Corin et al. 2007; Suarez, Holway \& Tsutsui 2008; Heller, Ingram \& Gordon 2008). Unicoloniality is considered to be one of the most important traits promoting the abundance and ecological success of many invasive ants 
(Krushelnycky \& Holway 2010). Two other aspects contributing to ants success is their efficient recruitment system (Stuart 1981; Aron, Pasteels \& Deneubourg 1989; Deneubourg et al. 1990; Pratt et al. 2002; Cerdá et al. 2008; Dussutour et al. 2009; Flanagan et al. 2013; Shaffer, Sasaki \& Pratt 2013) and their usage of venom for defence and repellent purposes (Schmidt 1978; Don et al. 2001; Greenberg et al. 2008; Sorrells et al. 2011; Lebrun, Jones \& Gilbert 2014).

A key part of ant success is their pheromone system, which encompasses information processing both on the individual and the communal level (Detrain \& Deneubourg 2006; Cerdá et al. 2008; Jeanson \& Weidenmüller 2014). These pheromones allow, for example, an ability to quickly alert other individuals to dangers (Wilson, Jr \& Regnier Jr. 1971; Wilson 1975; Ali \& Morgan 1990), recruit nest-mates to defend the nest from aggressors (Stuart 1981; Ali \& Morgan 1990), reach a communal decision when selecting a new nest (Pratt et al. 2002), or recruit towards a newly discovered food source (Stuart 1981; Ravary et al. 2007; Cerdá et al. 2008; Dussutour et al. 2009). The efficiency of the recruitment system of the Argentine ant has been particularly noted in connection to its invasion success. Argentine ants have a trail pheromone with a comparatively short half-life (Deneubourg et al. 1990; Holway et al. 2002a) and direct recruitment from existing trails, instead of recruiting from the nest itself (Flanagan et al. 2013), which both allow for rapid reallocation of the worker force for optimal resource exploitation. This system has been studied in great detail and has been hypothesized to give Argentine ants a profound competitive advantage when engaging with other ant species in exploitative competition (Aron et al. 1989; Deneubourg et al. 1990; Human \& Gordon 1996; Rowles \& O’Dowd 2007). As such, trail pheromones may be one of the most important aspects of their ecology to be investigated for management and containment efforts. 


\subsection{Study organism - The Argentine ant}

The Argentine ant is native in South America but has spread to many countries worldwide, becoming a global invader (Holway et al. 2002a). It can currently be found in North and South America, Europe, South Africa, Japan, Australia, Hawaii and New Zealand (Lester et al. 2003; Ward, Harris \& Stanley 2005; Ward 2007; van Wilgenburg, Torres \& Tsutsui 2010). In New Zealand it was first encountered 1990 on Mt. Smart in Auckland (Green 1990) and has been spreading since then in and around urban areas (Ward et al. 2010). The Argentine ants form unicolonial structures in new habitats (Heller \& Gordon 2006; Corin et al. 2007), which enables them to pool resources, achieve high population densities and overpower nests of competing ant species, even larger ones, with relative ease, either overrunning them quickly through physical aggression, numerical supremacy and by deploying repellent chemicals in combat or by monopolising all local resources (Harris 2002; Holway et al. 2002a).

The Argentine ant exhibits high territoriality, displacing other ant species from invaded areas (Human \& Gordon 1996; Rowles \& O’Dowd 2009a) and has impacts across different trophic levels (Suarez \& Case 2002; Suarez, Yeh \& Case 2005), for instance it affects a variety of seed dispersing ants (Gómez \& Oliveras 2003; Carney, Byerley \& Holway 2003), pollinating arthropods (Blancafort \& Gómez 2005; Lach 2007) and attacks frugivorous birds (Davis et al. 2010). However, some ant species prevail and coexist with Argentine ants (Blight et al. 2010; Sorrells et al. 2011). For example, the native winter ant, Prenolepis impairs (Say) in California, utilizes its venom to effectively repel and kill Argentine ant workers (Sorrells et al. 2011). Furthermore, a number of Monomorium species, have been found to co-occur with the Argentine ant, for example M. antipodum (Forel) (Lester et al. 2003), M. ergatogyna (Wheeler) (Holway 1999), M. rothsteini (Forel) (Andersen, Blum \& Jones 1991) and M. sydneyense (Forel) (Rowles \& O’Dowd 2009b), which has led to the hypothesis that chemical interactions 
might be an important factor for biological resistance against this invasive ant (Andersen et al. 1991; Jones, Andersen \& Kenny 2009).

\subsection{Chemical Communication}

Animals rely on different senses to evaluate their surroundings and to interact with their environment. Many animals use chemical cues to search for food or mates, identify family/nest members (Carlin \& Hölldobler 1986; Heth, Todrank \& Johnston 1998) or to find their way while foraging and when returning back to their nesting place (Traniello 1982). Chemical communication can be defined as the utilization of a substance, frequently air- or waterborne molecules, but also stationary anchored to a membrane, to carry a message from a sender to a receiver, with the receiver subsequently reacting based on the content of the message. This communication system plays an important role in the development of complex social systems in arthropods where eusocial insects represent the highest form of sociality (Ross \& Keller 1995).

Eusociality is mostly characterized by a colonial structure with overlapping generations, reproductive and non-reproductive castes and a strict division of labour for special tasks like building, food harvesting, defence and brood care (Regnier \& Wilson 1971; Thorne 1982). It has developed independently in various groups of insects (Wilson 1971; Lin \& Michener 1972; Wilson \& Hölldobler 2005; Nowak, Tarnita \& Wilson 2010), for instance termites (Thorne 1997), beetles (Kent \& Simpson 1992) and a variety of Hymenoptera (Wilson 1971). To organize and administer this complex system, an effective chemical communication system has evolved. Information is transmitted by semiochemicals which can be divided into allomones and pheromones (Dicke et al. 1990; Schulz 2005; Sbarbati \& Osculati 2006; Barrows 2011). Allomones transmit information between species, while pheromones specifically transmit information within a species. Pheromones are further divided into releaser pheromones, which 
elicit a specific behaviour, for example trail following in ants (Deneubourg et al. 1990) and primer pheromones which affect physiological processes, for instance the suppression of fertile workers in the presence of a queen (Keller \& Nonacs 1993). Although 'eavesdropping' exists, wherein some animals can understand and take advantage of the pheromones of other species (classified as Kairomones) (Sbarbati \& Osculati 2006), the majority of animal pheromones are species specific (Ali \& Morgan 1990; Schulz 2005; Sbarbati \& Osculati 2006). As such, they can either not be registered by other species, which do not have the receptors to perceive them, or have no meaning to them, as the message of the pheromone can only be understood by members of the same species. Therefore, pheromones can be used for target specific management of individual species, as for instance pheromone traps only attract one individual pest species (Nesbitt et al. 1975; Witzgall, Kirsch \& Cork 2010; Brockerhoff et al. 2012), while leaving other animals unaffected.

\subsection{Pheromone based management techniques for invasive species}

Once an invasive species has been discovered to have successfully established a foothold in a new habitat, different management methods can be deployed to eliminate, slow its advance or exert some form of control. Common pest management techniques range from poisoned baits and traps (Su 1979; Harris, Rees \& Toft 2002a; Cooper et al. 2008) installed at specific locations, to widespread aerial distribution of toxic baits to achieve huge area of effect population control (Towns \& Broome 2003; Cook, Khan \& Pickett 2007; Witzgall et al. 2010). While the latter has been proven to be effective, it can also be unspecific with deleterious side effects on a wide range of non-target species (Matsumura 1985; Littrell 1990; Cresswell 2011; Whitehorn et al. 2012; Blacquière et al. 2012), soil and water organisms (Kreuger 1998; Belfroid et al. 1998; Weston, You \& Lydy 2004), as well as accumulation in the food chain (Brown 1978; Zehnder et al. 2007). More modern and sophisticated management techniques 
frequently involve non-lethal and target specific behaviour manipulation like chemical, visual and auditory stimuli (Foster and \& Harris 1997). These techniques utilize push-pull strategies which include luring pest species or invaders into traps, repel the pest species, or attract suitable predators which decimate them (Cook et al. 2007). For example, sex pheromones have been shown to effectively manage pest species in agriculture and horticulture (Witzgall et al. 2010; Brockerhoff et al. 2012), for instance by disrupting mating success (Nesbitt et al. 1975; Brockerhoff et al. 2012)

Attempts to manage invasive ant species with pheromones have only become more frequent in recent years, but have shown promising potential. As the efficient foraging of ants is one of their distinct features (Traniello 1989), and often one which is hypothesized to be an important factor of their invasion success (Human \& Gordon 1996), it is worthwhile investigating if and how ant foraging system might be manipulated. Promising results have been found. For example, in Monomorium pharaonis, it has been shown that negative trail pheromone communicates a 'no entry' signal to workers, leading them to turn back on the current trail (Robinson et al. 2005). For the Red Important Fire Ant, aerosol application of its trail pheromone Z,E- $\alpha$-farnesene has reduced arrival success of workers following trails, as well as trail integrity (Suckling et al. 2012). Therefore, specific trail pheromones, if applied on a large scale, may offer management opportunities for specific invasive ant species. Studies have shown that it is possible to disrupt Argentine ant trail following behaviour with the application of the synthetic pheromone (Z)-9-hexadecenal (Suckling et al. 2008, 2010; Nishisue et al. 2010). While perhaps not a part of the Argentine ants natural pheromone trail (Choe, Villafuerte \& Tsutsui 2012, but see Deneubourg et al. 1990), first trials showed point pheromone sources of this synthetic pheromone can cause Argentine ant trails to lose their integrity (Suckling et al. 2008) and decreases their abundance at bait cards (Suckling et al. 2010). 


\subsection{Chemical Weapons}

Venoms are biotoxines used by animals. They are deployed by a wide range of vertebrate and invertebrate species in order to hunt for prey or defend themselves against predators or competitors (Mebs 2001, 2002; Zimma et al. 2003; Hodgson 2012). While biotoxins are commonly injected by means of a bite, sting or other sharp body features which are able to penetrate the body cavity, they can also be utilized as a long distance weapon by shooting or squirting (Mebs 2002; Warrell 2007) effectively becoming a semiochemical (allomone) with the purpose of changing the recipients behaviour (Barrows 2011; Hodgson 2012). It is known that venom can play an essential role in invasions and give the invader an overpowering advantage which native species cannot deal with because they are not coevolved to have any suitable counter measures, as has been reported with predators of the cane toad Bufo marinus in Australia (Michael Crossland \& Alford 1998) or competitors of the red imported fire ant Solenopsis invicta (Holway et al. 2002a). On the other hand there are also several reported occasions, where the utilization of venom has helped native animals to successfully withstand the competition from invasive species (Blight et al. 2010; Sorrells et al. 2011; Lebrun et al. 2014).

What allows one species to resist the impact of an invasive species when others fail to do so? One possible answer may lie in chemical interactions between competing species, which may give one species a distinct advantage in interference competition. A number of ant species have been previously described to use their chemical weaponry as propaganda, repellent and appeasement allomones (Schmidt 1978; Blum 1985; D’Ettorre et al. 2000; Lenoir et al. 2001). The venom of several species has been previously associated with co-occurrence in ant communities and as means of biotic resistance against invasive species (Andersen et al. 1991; Sorrells et al. 2011). Repellent properties of Monomorium rothsteini venom, for example, has 
been hypothesised to be key in their success in Australian ant communities (Andersen et al. 1991). A range of active alkaloids in Monomorium species appear to offer an explanation for their competitive success (Blum et al. 1985; Blum 1985). Indeed, the usage of venom has been shown to play an important role in a varierty of interactions between the Argentine ant and other ant species. While the invasive Argentine ant has been shown to win one on one battles by spraying chemicals on competing ant species (Holway 1999), venom of the invasive Red Imported Fire ant (Solenopsis invicta) has been reported to be very effective against Argentine ants (Lebrun et al. 2007; Kabashima et al. 2007; Greenberg et al. 2008), leaving them to win interactions and subsequently displace the Argentine ant. The Tawny Crazy ant (Nylanderia fulva) has been shown to be able to detoxify venom of the Red Imported Fire ant, by coating itself with its own venom (Lebrun et al. 2014). The winter ant (Prenolepis infaris) deployed highly toxic venomous secretions which caused up to 79\% mortality among Argentine ants, enabling them to fight off the invaders even when vastly outnumbered (Sorrells $e$ al. 2011) and allowed them to resist displacement. Similarly, Tapinoma nigerrimum was able to successfully limit the spread of the Argentine ant (Blight et al. 2010). It appears therefore, that not only the type of venom, but also the application technique, for example spraying or coating oneself (Lebrun et al. 2014), are factors to be considered in the outcomes of these competitive interactions.

\subsection{Thesis aims}

In this thesis I investigated the effects of natural and synthetic semiochemicals on Argentine ants. My overall aim was to gain a better understanding of the influences of semiochemicals on interactions between Argentine ants and other ant species, and to determine whether pheromone recruitment mechanisms which control ant communities, can be used as tools to 
manage Argentine ants. Each chapter of my thesis investigated one aspect towards this objective.

Chapter 2 investigates the utilization of venom as chemical weapons and examines different utilization methods of venom (short distance versus long distance) in aggressive interactions between the four Monomorium species that occur in New Zealand and the invasive Argentine ant, in order to evaluate how these factors may explain the co-occurrence of some of these species with Argentine ants, while others have not been found to co-occur.

Chapter 3 presents evidence on how the disruption of foraging reduces the competitive ability of the invasive Argentine ant and how this disruption can benefit other community species to increase their own foraging activity. Furthermore, I propose that the mechanism for the observed increase in resource acquisition of resident species is a decrease in aggressive behaviour displayed by the Argentine ant, which may create an opportunity for other resident species to forage more successfully

Chapter 4 transfers the pheromone management system of Argentine ants to a trial setting on a commercial vineyard and investigates what would be the most effective way to apply the synthetic pheromone to grapevines. By experimenting with placements of pheromone dispensers at different locations around grapevines, I show which placement is the most likely to prevent the Argentine ants' access to vine canopy in a commercial vineyard.

Chapter 5 expands previous findings and the application of trail pheromones to a long term and large scale setup as a management technique. I tested the effects of the setup which has previously been found to be the most effective, on the ants foraging success within the vine canopy. Furthermore, I used the body fat content of ant workers as a surrogate measurement to evaluate whether the impaired foraging activity of Argentine ants translates into a measurable fitness effect in nests within the area of the pheromone trial. Additionally, I provide an initial assessment of the feasibility of the presented approach. 
General Introduction

Chapter 6 summarises and synthesises the main findings of my thesis, outlines any encountered constraints and discusses opportunities for further research. 


\section{Chapter 2: Toxicity and utilization of chemical weapons: Does toxicity and venom utilization contribute to the formation of species communities?}

\subsection{Abstract}

Toxicity and the utilization of venom is an essential feature in the ecology of many animal species and have been hypothesized to be an important factor contributing to the assembly of communities through competitive interactions. Ants of the genus Monomorium utilize a variety of venom compositions, which have been reported to give them a competitive advantage. Here we investigate two pairs of Monomorium species, which differ in the structural compositions of their venom and their co-occurrence patterns with the invasive Argentine ant. We looked at the effects of Monomorium venom toxicity, venom utilization and aggressive physical interactions on Monomorium and Argentine ant survival rates during arena trials. The venom toxicity of the two species co-occurring with the invasive Argentine ants was found to be significantly higher than the toxicity of the two species which do not. There was no correlation between venom toxicity and Monomorium survival, however three of the four Monomorium species displayed significant variability in their venom usage which was associated with the number of Argentine ant workers encountered during trials. Average Monomorium mortality varied significantly between species and in $M$. smithii and $M$. antipodum aggressive interactions with Argentine ants had a significant negative effect on their mortality. Our study demonstrates that different factors and strategies can contribute to the ability of a species to withstand the pressure of a dominant invader at high abundance and venom chemistry appears to be only one of several strategies utilized. 


\subsection{Introduction}

Venom toxicity and utilization mode are two important features in the ecology of many animal species. A wide range of organisms produce and utilize toxins to hunt for prey or defend themselves and their kin from predators or competitors (Halstead \& Courville 1988; Mebs 2001, 2002). Venom may also give invasive species a substantial advantage against native species due to lack of co-evolutionary history (Michael Crossland \& Alford 1998; Holway, Suarez \& Case 2002b; Albins \& Hixon 2008; Greenberg et al. 2008). The means of venom deployment differs between organisms and includes, injection, passive application on the skin or shooting/squirting over a distance (Mebs 2002; Warrell 2007).

Biotic resistance is an important factor limiting invaders' impacts on a community, hindering their establishment and spread. Such biotic resistance has been found in invasive fish (Baltz \& Moyle 1993), birds (Blackburn \& Duncan 2001), crabs (DeRivera \& Ruiz 2005) and ants (Rowles \& O’Dowd 2007; Blight et al. 2010). To date only few studies have investigated closely whether venom toxicity, or its application strategy, might be an important factor in understanding why certain native species are able to successfully resist an otherwise dominant invader, while other species are displaced.

Ant venom has been associated with co-occurrence patterns in ant communities (Holway 1999) and has also been reported as means of biotic resistance against invasive species such as the Argentine ant, Linepithema humile (Mayr) (Sorrells et al. 2011). One study reported venom of Monomorium rothsteini (Forel) to be highly repellent against three Iridomyrmex species and the authors concluded that venom alkaloids may be a potent yet poorly appreciated force in interference competition and possibly play an important role in the structure of ant communities (Andersen et al. 1991). 
The Argentine ant is considered one of the world's most invasive species and has established widespread colonies in many Mediterranean and subtropical regions worldwide (Suarez, Holway \& Case 2001; Holway et al. 2002a; Wild 2004). It has been linked with population declines in a variety of organisms (Cole et al. 1992; Sanders et al. 2003; Rowles \& O’Dowd 2009a) as well as damage to agricultural crops by supporting herbivorous pest species (Ward et al. 2010). Populations quickly reach high abundance and estimates of 50,000-600,000 ants on a trail have been reported (Vega \& Rust 2001). Such high abundances allows them to eliminate even comparatively large species (De Kock 1990). In New Zealand, the Argentine ant was first observed near Auckland (Green 1990) and has since spread to several locations around the country (Ward et al. 2010).

One ant genus, which has repeatedly been reported to successfully withstand other competitively strong ant competitors, is Monomorium (Adams \& Traniello 1981; Andersen \& Patel 1994; Holway 1999). For example, in Australia Monomorium was observed to occupy baits regardless of the presence or absence of the otherwise competitively dominant 'meat ant' Iridomyrmex purpureus (Smith), potentially because of its usage of venom alkaloids (Andersen \& Patel 1994). In competitive tests between seven native ants and the Argentine ant, Monomorium ergatogyna (Wheeler), which was the smallest species, won $100 \%$ of the interactions (Holway 1999). Another study showed that Monomorium minimum (Buckley) uses chemical interference to delay competitors (Adams \& Traniello 1981).

Monomorium ants utilize a range of venom alkaloids. Available evidence suggests that the venom chemistry of each alkaloid-producing species of Monomorium has a qualitatively characteristic signature (Jones et al. 2009), likely resulting in varying venom toxicity. In New Zealand, the native Monomorium species M. antarcticum (Smith) and M. smithii (Forel) have not been observed to co-occur with Argentine ants on larger scales, with only slight overlaps at the borders of their occupied ranges. However, the two exotic species M. antipodum (Forel) 
and M. sydneyense (Forel) have been observed to co-occur with Argentine ants in New Zealand (Lester et al. 2003) or elsewhere (Rowles \& O'Dowd 2009b). The venom compositions of the native and non-native Monomorium species differ in one important aspect. While the venom of $M$. antarcticum and M. smithii contains both pyrrolizidine and pyrrolidine alkaloids, the venoms of M. antipodum and $M$. sydneyense contain only the pyrrolidines $\mathbf{6 , 7 , 8}$, and 9 (Don et al. 2001). The differences in the venom chemistry between those two Monomorium groups, may result in a general mechanism by which venom chemistry influences distribution patterns of those species and their co-occurrence with Argentine ants. Illustrations of the four study species and structural formulae of their venoms are given in Fig. 2.1.
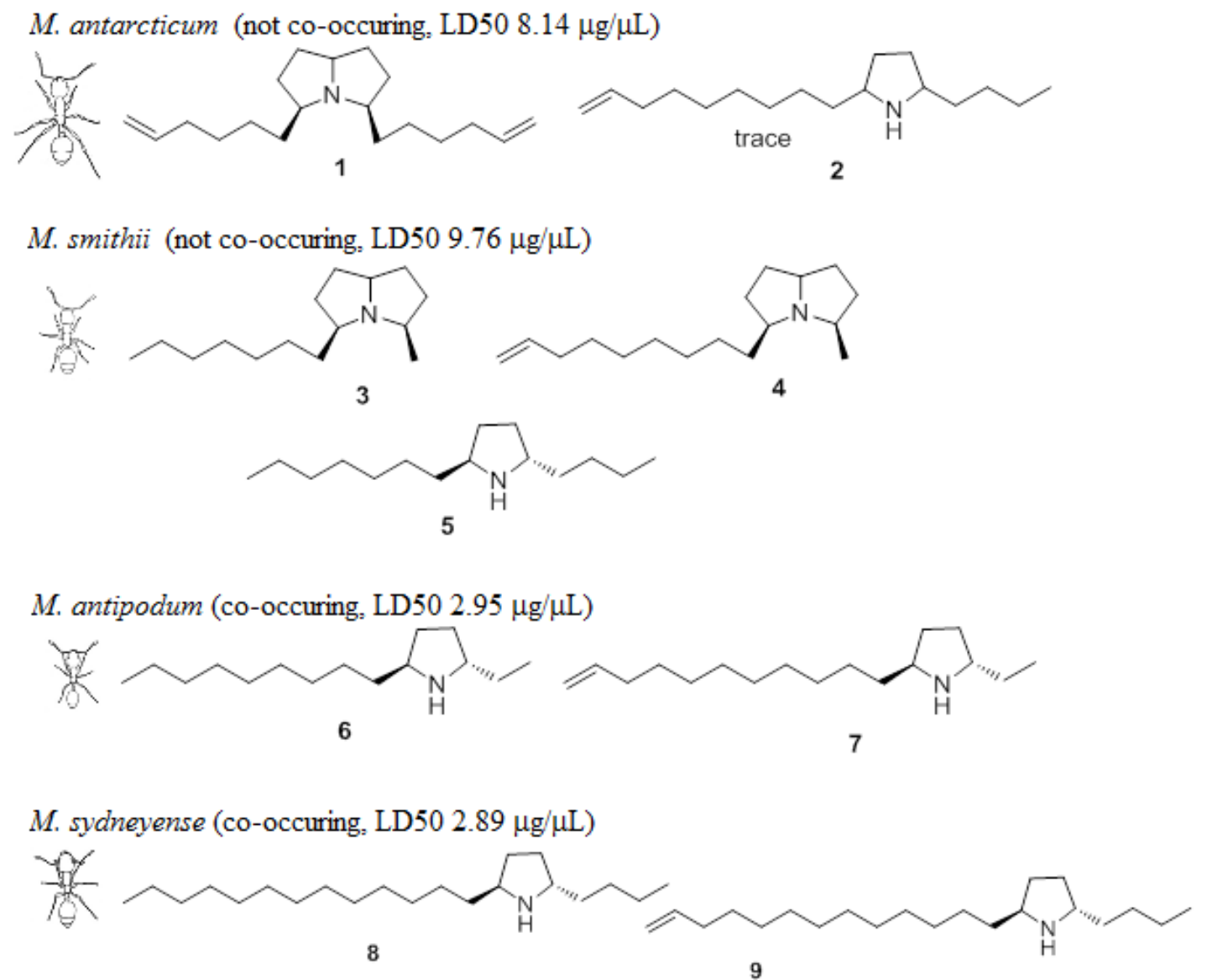

Figure 2.1: Structural formula of venom and illustrations of the four Monomorium species. M. antarcticum (1) (5Z,8E)- 3,5-di-(5-hexen-1-yl)-pyrrolizidine (2) 2-butyl-5-(8-nonenyl)pyrrolidine; M. smithii (3) (5Z,8E)-3heptyl-5-methylpyrrolzidine, (4) (5Z,8E)-3-methyl-5-(8-nonenyl)pyrrolizidine and (5) trans-2-butyl-5heptylpyrrolidine in a 1:2:2 ratio; $M$. antipodum (6) trans-2-ethyl-5-nonylpyrrolidine and (7) trans-2-ethyl-5-(10- 
undecenyl)pyrrolidine in a 1:1 ratio; $M$. sydneyense (8) trans-2-butyl-5-undecylpyrrolidine and (9) trans-2-butyl5-(12-tridecenyl) pyrrolidine in a $1: 2$ ratio from. Sketches of Monomorium species represent different ant workers (sketches not to scale). LD50 values are results from venom survival experiments.

Here we report the results of a mechanistic study to understand the observed patterns of cooccurrence and determine the importance of chemical weapons in community patterns and biotic resistance. We performed a series of behavioural assays and venom effectiveness assessments between the invasive Argentine Ant and the four Monomorium species that occur in New Zealand. Our goal was to investigate whether patterns of co-occurrence previously observed in the field are related to venom toxicity and composition or its deployment method. We based our investigations on the assumption that the two Monomorium species $(M$. antarcticum and M. smithii) not co-occurring with Argentine ants may be able to exclude the Argentine ant from their habitat through biotic resistance by means of venom application as had been indicated by other studies (Adams \& Traniello 1981; Andersen \& Patel 1994; Holway 1999). Therefore we hypothesized that: (1) Monomorium species with higher venom toxicity to Argentine ants have higher survival rate when engaging Argentine ants; (2) The mortality of Monomorium species engaging Argentine ants should differ depending on venom utilization; and (3) In the absence of venom, aggressive interactions result in a lower survival rate of the Monomorium species engaging Argentine ants.

\subsection{Materials and methods}

\subsubsection{Ant samples.}

We collected nests of all four Monomorium species currently found in New Zealand at locations around the North Island: M. antarcticum (Ohariu Bay; -41.219, 174.710) M. antipodum (Palmerston North; -40.354, 175.606), M. smithii (Ohariu Bay; -41.219, 174.710) and M. sydneyense (Sulfur Point; -38.130, 176.265), as well as of the invasive Argentine ant $L$. humile (Petone; -41.222, 174.872). All nests were housed in nest boxes at a constant 
temperature of $20^{\circ} \mathrm{C}$ and a day/night cycle of $12 / 12$ hours. Walls of the nest boxes were covered with Fluon (DuPont ${ }^{\mathrm{TM}}$ Teflon ${ }^{\circledR}$ PTFE DISP 30) and ants were fed a diet of $20 \%$ honey water and two mealworms three times a week. Nesting tubes, consisting of a glass tube with water covered with a cotton plug and surrounded with aluminium foil, were provided.

\subsubsection{Arena fight and venom usage.}

Fighting experiments were conducted between November 2010 and June 2011. Twelve worker ants of one of the four species (M. antarcticum, M. smithii, M. antipodum and $M$. sydneyense) were placed in a small container together with 20,40, 80, or 120 Argentine ants. Six replicates were conducted for each combination of the four Monomorium species and the four Argentine ant densities. The mortality of Monomorium and Argentine ants was assessed after one, four and 24 hours. In the first 15 minutes a randomly chosen Monomorium ant was observed and the displayed behaviour in each interaction with Argentine ants scored (= individual aggression). Behaviour scores were taken as follows: $0=$ no interest or aggression; $1=$ interest shown via antennation; 2 = ant retreats quickly; 3 = lunging, biting or leg-pulling, raising of gaster and exuding venom; $4=$ prolonged (> 5 s) incidences of aggression, individuals locked together and fighting (Rowles \& O’Dowd 2007). If prolonged fighting occurred, another ant was chosen. This was done, to achieve a maximum of twenty behavioural observations, as the observed Monomorium ant did not always survive the interaction. Within the first hour, all ants were also scanned at random intervals for a maximum of twenty observations, and the interaction with the highest observable aggression at this given moment scored (= maximum aggression). This was done for comparison, in case the interactions of a randomly chosen individual ant were not representative of the general aggression displayed within the arena (for instance if individuals selected would have been exceptionally docile 
compared to the others). For each observation the type of venom usage by the Monomorium ants was noted either as stinging, gaster flagging/spraying or no venom usage.

\subsubsection{Venom survivability.}

Venom survival experiments were conducted between November 2011 and February 2012. Gas Chromatography-Mass Spectrometry (GC-MS) analyses were carried out in the EI mode using a Shimadzu QP-2010 GC-MS equipped with an RTX-5, $30 \mathrm{~m}$ x $0.25 \mathrm{~mm}$ i.d. column. The instrument was programmed from $60{ }^{\circ} \mathrm{C}$ to $250{ }^{\circ} \mathrm{C}$ at $10 \% \mathrm{~min}$. The major alkaloids of the four ant species were identified by direct comparison with synthetic samples available from previous studies, or prepared by the usual method of reductive amination of the appropriate 1,4-diketones, to form pyrrolidines, or 1,4,7-triketones to form pyrrolizidines (Jones et al. 1980a; b, 1988). These were (1) (5Z,8E)- 3,5-di-(5-hexen-1-yl)-pyrrolizidine from $M$. antarcticum; (3) (5Z,8E)-3-heptyl-5-methylpyrrolzidine, (4) (5Z,8E)-3-methyl-5-(8nonenyl)pyrrolizidine, and (5) trans-2-butyl-5-heptylpyrrolidine in a 1:2:2 ratio from $M$. smithii; (6) trans-2-ethyl-5-nonylpyrrolidine and (7) trans-2-ethyl-5-(10undecenyl)pyrrolidine in a 1:1 ratio from $M$. antipodum; and (8) trans-2-butyl-5undecylpyrrolidine and (9) trans-2-butyl-5-(12-tridecenyl)pyrrolidine in a $1: 2$ ratio from $M$. sydneyense. Alkaloid (2) 2-butyl-5-(8-nonenyl)pyrrolidine from M. antarcticum was only identified as a trace component of the venom and was therefore not included. It should also be mentioned that the venom composition of $M$. smithii differed from venom alkaloids identified in a previous study (Jones et al. 1990). The structural formulae of the venom components are given in Fig. 2.1.

We used concentrations of $1,5,10,15$ and $20 \mu \mathrm{g} / \mu \mathrm{l}$ of the respective venoms in ethanol, as well as a control with the pure solvent. Argentine ant workers were randomly picked from a nest box, placed in a glass vial. We anaesthetised them by aerating them with ether vapour for 
10 seconds and then closing the vial for 50 seconds. Subsequently, twenty anaesthetised ants were then placed on filter paper in a glass Petri dish and each ant was treated with $1 \mu \mathrm{l}$ of venom solution. The droplet was observed to flow over the body and engulfed the ant for a moment before being soaked by the filter paper, which ensured the animals did not drown in the liquid. Ants were consequently placed into small plastic containers to awake from anaesthesia. Status of the treated animals was assessed after one and four hours. Ants were scored as dead if they were immobile and gentle prodding with the tip of forceps did not elicit any reaction. Ants were counted as alive if any reaction (leg or antennae movement) could be observed or when they were moving normally.

\subsubsection{Statistical analysis}

To investigate if Monomorium species with higher venom toxicity to Argentine ants have higher survival rate when engaging Argentine ants, we combined the data from our arena tests and our venom toxicity assessments. A Kaplan Meier survival analysis was used to determine differences in survival times in the arena fights between the four Monomorium species and Argentine ants by pooling the mortality rates over all densities. A Probit analysis was used to assess the mortality rates of Argentine ants treated with venom of the Monomorium species and calculate the median lethal dosage (LD50) of the respective venoms on Argentine ants. A Linear regression analysis was then used to analyse the impact of venom toxicity on survival of the respective Monomorium species and the Argentine ants they encountered.

To investigate if survival chances of Monomorium species engaging Argentine ants differed depending on venom utilization, we analysed the occurrence of the three venom displays: "no venom", "gaster flagging or spraying" and "stinging". We examined if these behaviours were related to the number of Argentine ant workers encountered and to Monomorium survival in 
each trial, which was categorized as "low" (0-4 workers died), "medium" (5-8 workers died) or "high" (9-12 workers died) using Pearson Chi-Square tests.

To determine whether aggressive interactions resulted in a lower survival rate of the species engaging Argentine ants in arena fights, we used Generalized Linear Models with the following setup: Relative Monomorium mortality (number of deceased Monomorium workers divided by the number of Monomorium workers in the arena) and relative Argentine ant mortality (number of deceased Argentine ants divided by the number of Argentine ants in the arena) as dependent variable; individual aggression (displayed behaviour of individual ant in each interaction with Argentine ants) and maximum aggression (interaction with the highest observable aggression at this given moment) as factors; and Argentine ant density as a Covariate. The models were run as a full factorial model to investigate any interactions between the Argentine ant density and aggression. We also used a Generalized Linear Model to look for differences in the mortality between the four Monomorium species, with Relative Monomorium mortality (number of deceased Monomorium workers divided by the number of Monomorium workers in the arena) as dependent variable, Monomorium species as factor and Argentine ant density as a Covariate.

All data analysis was conducted using IBM SPSS Statistics v. 20.0, Figures were created using OriginPro v. 8.6. The level of significance was defined at $\mathrm{P}<0.05$.

The data package associated with this manuscript has been made available at the Dryad data depository (Dryad access number: doi: 10.5061/dryad.7g02r).

\subsection{Results}

Our first hypothesis was that species with higher venom toxicity would have a higher rate of survival when engaging Argentine ants. The Kaplan Meier survival analysis showed significant differences (Mantel-Cox: Chi-Square 336.77, $\mathrm{df}=3, \mathrm{p}<0.001$ ) in the survival times 
of the four Monomorium species in arena fights against Argentine ants. Monomorium antarcticum (mean 24 hours \pm 0 ) and Monomorium antipodum (Mean 23.77 hours \pm 0.12 ) survived longer than Monomorium sydneyense (Mean 21.63 hours \pm 0.35 ) and Monomorium smithii (Mean 20.72 hours \pm 0.41$)$.

The Probit analysis of Argentine ant mortality rates when treated with venom of the four Monomorium species showed significant differences in lethality of venoms four hours after treatment. While the venom of co-occuring $M$. sydneyense and $M$. antipodum had a relatively low LD50 $(2.89 \mu \mathrm{g} / \mu \mathrm{l}$ and $2.95 \mu \mathrm{g} / \mu \mathrm{l})$, the venom of the two Monomorium species, which do not co-occur with Argentine ants (M. antarcticum and M. smithii) have a much higher LD50 for Argentine ant workers $(8.14 \mu \mathrm{g} / \mu \mathrm{l}$ and $9.76 \mu \mathrm{g} / \mu \mathrm{l})$. We found no significant correlation between Monomorium survival and the toxicity of Monomorium venom (Pearson correlation, 1-tailed, $\mathrm{R}=-0.279, \mathrm{p}=0.36$ ), however there was a significant negative correlation between Argentine ant survival and the toxicity of Monomorium venom (Pearson correlation, 1-tailed, $\mathrm{R}=-0.954, \mathrm{p}=0.023)$ (Fig. 2.2). 

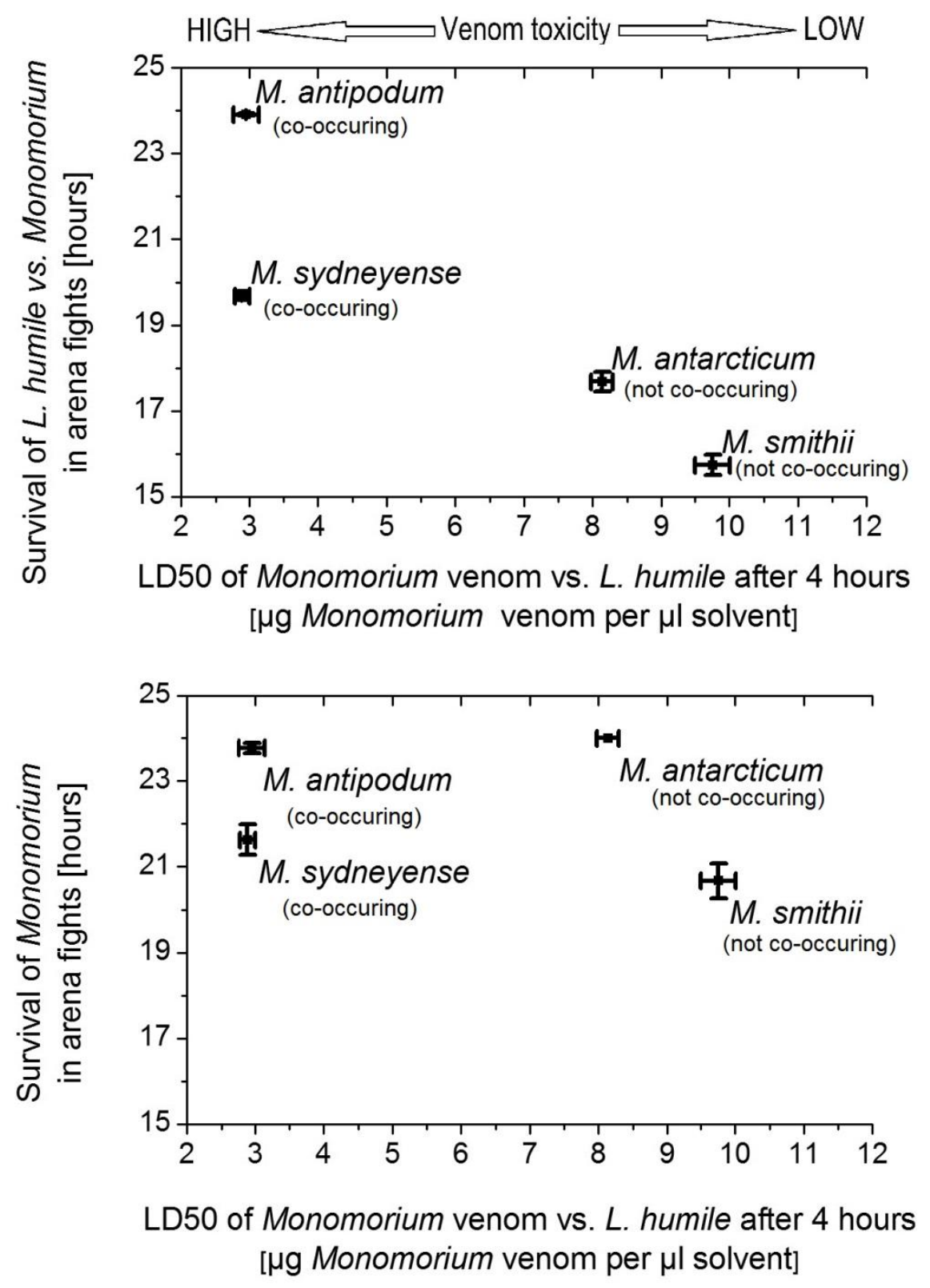

Figure 2.2: Monomorium toxicity and ant survival. Overall survival time of Argentine ant workers in arena fights against four Monomorium species correlated with the LD50 of the venom of that Monomorium species (upper) and the overall survival time of Monomorium workers in arena fights against Argentine ants correlated with the LD50 of the venom of that Monomorium species (lower).

We hypothesized that survival chances of species engaging Argentine ants would differ depending on venom utilization. Three of the four Monomorium species displayed significant variability in venom usage (Table 1) depending on the number of Argentine ant workers encountered $(M$. antarcticum; $\mathrm{N}=444$; Chi-Square 44.02; $\mathrm{df}=6 ; \mathrm{p}<0.001 ;$ M. smithii; $\mathrm{N}=$ 474; Chi-Square 36.80; $\mathrm{df}=6 ; \mathrm{p}<0.001 ;$ M. antipodum; $\mathrm{N}=484$; Chi-Square 32.52; $\mathrm{df}=6 ; \mathrm{p}$ 
$<0.001 ;$ M. sydneyense; $\mathrm{N}=229 ;$ Chi-Square 2.64; $\mathrm{df}=6 ; \mathrm{p}=0.853)$. For the species which have not been observed to co-occur with Argentine ants (M. antarcticum and M. smithii) venom usage shifted from no venom usage or gaster flagging and spraying, to a high usage of stinging.

For M. antipodum an immediate increase in gaster flagging and spraying was observed with an increase in Argentine ant numbers.

Table 2.1: Monomorium venom usage depending on Argentine ant density. Number of observed occurrences of venom utilization of four Monomorium species in arena trials, corresponding with the Argentine ant density encountered. The table displays the species (venom toxicity from venom survival trials included for reference), Argentine ant worker density, number of displayed venom behaviours (No venom, Gaster flagging or spraying, stinging) and the total number of behaviour observations during trials with the corresponding density.

\begin{tabular}{|c|c|c|c|c|c|}
\hline \multirow[t]{2}{*}{ Species } & \multirow[t]{2}{*}{ Density } & \multicolumn{3}{|c|}{ Venom } & \multirow[b]{2}{*}{ Total } \\
\hline & & No Venom & Gaster & Stinging & \\
\hline \multirow{5}{*}{$\begin{array}{l}\text { M. antarcticum } \\
\text { (does not co-occur; } \\
\text { LD50 } 8.14 \mu \mathrm{g} / \mu \mathrm{l} \text { ) }\end{array}$} & 20 & 7 & 24 & 77 & 108 \\
\hline & 40 & 6 & 16 & 85 & 107 \\
\hline & 80 & 0 & 17 & 91 & 108 \\
\hline & 160 & 0 & 0 & 121 & 121 \\
\hline & Total & 13 & 57 & 374 & 444 \\
\hline \multirow{5}{*}{$\begin{array}{l}\text { M. smithii } \\
\text { (does not co-occur; } \\
\text { LD50 } 9.76 \mu \mathrm{g} / \mu \mathrm{l} \text { ) }\end{array}$} & 20 & 12 & 46 & 60 & 118 \\
\hline & 40 & 13 & 49 & 58 & 120 \\
\hline & 80 & 7 & 44 & 67 & 118 \\
\hline & 160 & 4 & 17 & 97 & 118 \\
\hline & Total & 36 & 156 & 282 & 474 \\
\hline \multirow{5}{*}{$\begin{array}{l}\text { M. antipodum } \\
\text { (co-occurs; } \\
\text { LD50 } 2.95 \mu \mathrm{g} / \mu \mathrm{l} \text { ) }\end{array}$} & 20 & 89 & 12 & 0 & 101 \\
\hline & 40 & 78 & 53 & 3 & 134 \\
\hline & 80 & 82 & 42 & 0 & 124 \\
\hline & 160 & 78 & 42 & 5 & 125 \\
\hline & Total & 327 & 149 & 8 & 484 \\
\hline \multirow{5}{*}{$\begin{array}{l}\text { M. sydneyense } \\
\text { (co-occurs; } \\
\text { LD50 } 2.89 \mu \mathrm{g} / \mu \mathrm{l} \text { ) }\end{array}$} & 20 & 1 & 4 & 26 & 31 \\
\hline & 40 & 3 & 12 & 50 & 65 \\
\hline & 80 & 3 & 9 & 44 & 56 \\
\hline & 160 & 1 & 15 & 61 & 77 \\
\hline & Total & 8 & 40 & 181 & 229 \\
\hline
\end{tabular}


A significant relationship between venom utilization and mortality after 24 hours was only found in M. antipodum ( $\mathrm{N}=484$; Chi-Square 21.17; $\mathrm{df}=4 ; \mathrm{p}<0.001)$, where physical aggression was more common in trials which resulted in low mortality, while gaster flagging was $81 \%$ higher in trials which resulted in high mortality. No significant association was found in $M$. antarcticum $(\mathrm{N}=444 ;$ Chi-Square $5.27 ; \mathrm{df}=2 ; \mathrm{p}=0.07)$ or $M$. sydneyense $(\mathrm{N}=229$; Chi-Square $0.56 ; \mathrm{df}=4 ; \mathrm{p}=0.97$ ), while $M$. smithii could not be analysed since their mortality was always of the category "high" and therefore constant (Table 2.2).

Table 2.2: Monomorium venom usage depending on Monomorium mortality. Number of observed occurrences of venom utilization of four Monomorium species in arena trials, corresponding with the Monomorium mortality rates in arena trials. The table displays the species (venom toxicity from venom survival trials included for reference), Monomorium mortality (Low = 0-4; Medium = 5-8; High =9-12), the sum of all displayed venom behaviours in that category (No venom, Gaster flagging or spraying, stinging) and the total number of behaviour observations during trials with the corresponding Monomorium mortality.

\begin{tabular}{|c|c|c|c|c|c|}
\hline \multirow[t]{2}{*}{ Species } & \multirow[t]{2}{*}{ Mortality } & \multicolumn{3}{|c|}{ Venom } & \multirow[b]{2}{*}{ Total } \\
\hline & & No venom & Gaster & Stinging & \\
\hline \multirow{4}{*}{$\begin{array}{l}\text { M. antarcticum } \\
\text { (does not co-occur; } \\
\text { LD50 } 8.14 \mu \mathrm{g} / \mu \mathrm{l} \text { ) }\end{array}$} & High & 0 & 0 & 0 & 0 \\
\hline & Medium & 0 & 6 & 71 & 77 \\
\hline & Low & 13 & 51 & 303 & 367 \\
\hline & Total & 13 & 57 & 374 & 444 \\
\hline \multirow{4}{*}{$\begin{array}{l}\text { M. smithii } \\
\text { (does not co-occur; } \\
\text { LD50 } 9.76 \mu \mathrm{g} / \mu \mathrm{l} \text { ) }\end{array}$} & High & 36 & 156 & 282 & 474 \\
\hline & Medium & 0 & 0 & 0 & 0 \\
\hline & Low & 0 & 0 & 0 & 0 \\
\hline & Total & 36 & 156 & 282 & 474 \\
\hline \multirow{4}{*}{$\begin{array}{l}\text { M. antipodum } \\
\text { (co-occurs; } \\
\text { LD50 } 2.95 \mu \mathrm{g} / \mu \mathrm{l} \text { ) }\end{array}$} & High & 98 & 67 & 4 & 169 \\
\hline & Medium & 46 & 31 & 0 & 77 \\
\hline & Low & 183 & 51 & 4 & 238 \\
\hline & Total & 327 & 149 & 8 & 484 \\
\hline \multirow{4}{*}{$\begin{array}{l}\text { M. sydneyense } \\
\text { (co-occurs; } \\
\text { LD50 } 2.89 \mu \mathrm{g} / \mu \mathrm{l} \text { ) }\end{array}$} & High & 5 & 27 & 122 & 154 \\
\hline & Medium & 2 & 8 & 42 & 52 \\
\hline & Low & 1 & 5 & 17 & 23 \\
\hline & Total & 8 & 40 & 181 & 229 \\
\hline
\end{tabular}


Our third hypothesis predicted that aggressive interactions would result in lower survival of the species engaging Argentine ants. Different patterns for mortality and behaviour were observed in all four species when encountering Argentine ants (Fig. 2.3). Monomorium mortality varied significantly between species (Generalized Linear Model, $\mathrm{N}=96, \mathrm{df}=3$, Wald Chi-Square $=92.67, \mathrm{p}<0.001)$. M. antarcticum had the lowest $($ average $2 \%)$ and $M$. smithii the highest mortality (average 96.8\%). Significant differences between the four Monomorium species were also found for the factors individual (Generalized Linear Model, $\mathrm{N}=96, \mathrm{df}=3$, Wald Chi-Square $=29.35, \mathrm{p}<0.0011)$ and maximum aggression $($ Generalized Linear Model, $\mathrm{N}=96, \mathrm{df}=3$, Wald Chi-Square $=154.23, \mathrm{p}<0.001)$ displayed in interactions with Argentine ants. Individual aggression had a significant effect on the mortality of $M$. antipodum (Generalized Linear Model, $\mathrm{N}=24, \mathrm{df}=1$, Wald Chi-Square $=5.89, \mathrm{p}=0.015$; Covariate Argentine ant density df $=3$, Wald Chi-Square $=5.85, \mathrm{p}=0.119)$ and $M$. smithii (Generalized Linear Model, $\mathrm{N}=24, \mathrm{df}=1$, Wald Chi-Square $=9.46, \mathrm{p}=0.002$; Covariate Argentine ant density $\mathrm{df}=3$, Wald Chi-Square $=1.99, \mathrm{p}=0.574$ ). Individual aggression had no effect on the mortality of M. antarcticum or M. sydneyense, in all cases Argentine ant density did not appear to have any significant effect. Similarly no effect of the maximum aggression on any of the Monomorium species survival was found, though here Argentine ant density was significant for M. antipodum Argentine ant density (Generalized Linear Model; N = 24, df = 1, Wald ChiSquare $=0.66, \mathrm{p}=0.417 ;$ Covariate Argentine ant density $\mathrm{df}=3$, Wald Chi-Square $=8.5, \mathrm{p}=$ $0.037)$. 

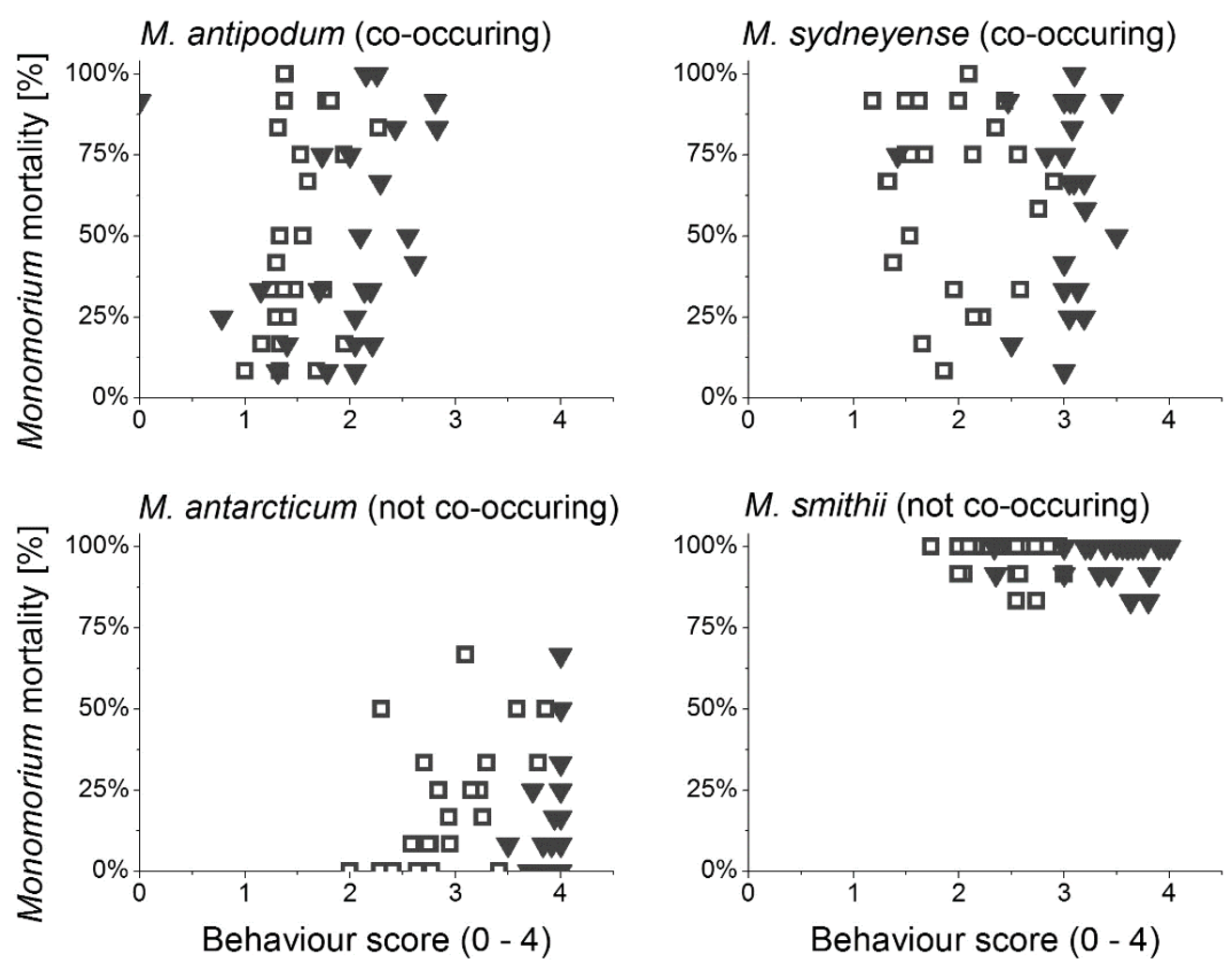

Figure 2.3: Monomorium mortality in arena fights. Mortality of Monomorium workers in arena fights against Argentine ants depending on Average Individual Aggression within the same replicate (open squares) and Average Maximum Aggression within the same replicate (closed triangles). Behaviour scores were taken as follows: $0=$ no interest or aggression; $1=$ interest shown via antennation; $2=$ ant retreats quickly; $3=$ lunging, biting or leg-pulling, raising of gaster and exuding venom; $4=$ prolonged ( $>5 \mathrm{~s}$ ) incidences of aggression, individuals locked together and fighting.

For Argentine ants, different patterns of mortality and behaviours for encounters with all four species were also observed (Fig. 2.4). Worker mortality varied significantly depending on the Monomorium species encountered (Generalized Linear Model, $\mathrm{N}=96$, df = 3, Wald ChiSquare $=170.54, \mathrm{p}<0.001)$. We observed the lowest mortality in Argentine ants when interacting with $M$. antipodum $(0.9 \%)$ and the highest mortality when encountering $M$. smithii (89\%). We only found an effect of individual aggression and Argentine ant density on Argentine ant mortality when facing $M$. antarcticum (Generalized Linear Model; $\mathrm{N}=24$, df = 1, Wald Chi-Square $=3.44, \mathrm{p}=0.063$; Covariate Argentine ant density df $=3$, Wald Chi-Square $=8.53, \mathrm{p}=0.036)$. 

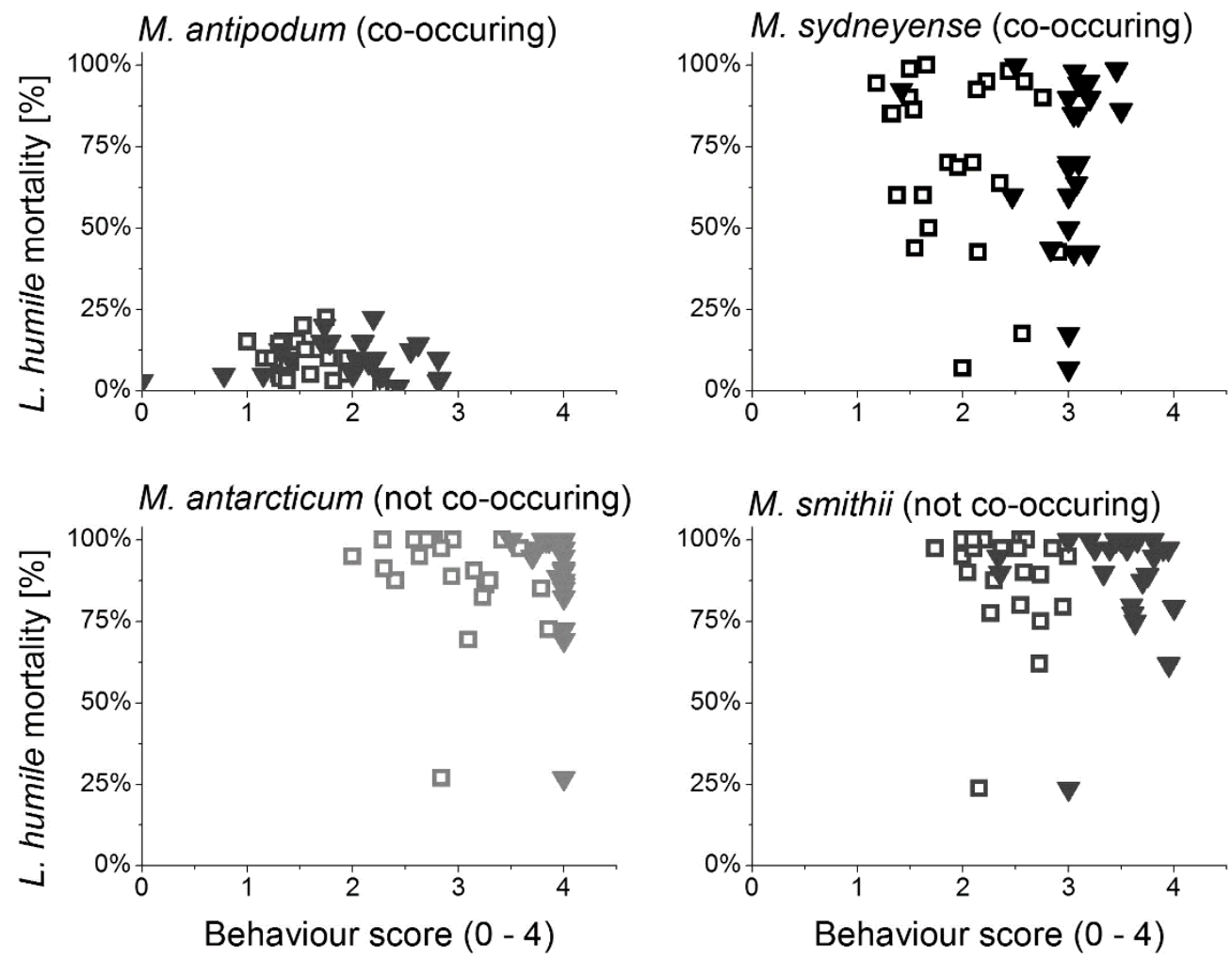

Figure 2.4: Argentine ant mortality in arena fights. Mortality of Argentine ant workers in arena fights against Monomorium species depending on Average Individual Aggression within the same replicate (open squares) and Average Maximum Aggression within the same replicate (closed triangles). Behaviour scores were taken as follows: $0=$ no interest or aggression; $1=$ interest shown via antennation; $2=$ ant retreats quickly; $3=$ lunging, biting or leg-pulling, raising of gaster and exuding venom; $4=$ prolonged $(>5 \mathrm{~s})$ incidences of aggression, individuals locked together and fighting.

\subsection{Discussion}

Our study showed differences in the behaviour of the two Monomorium species cooccurring with the invasive Argentine ant. The co-occurring species utilize much more potent venom and the aggression display between their workers and Argentine ants is lower than that of the two species which do not co-occur. A summary of our findings is presented in Tab. 2.3. 


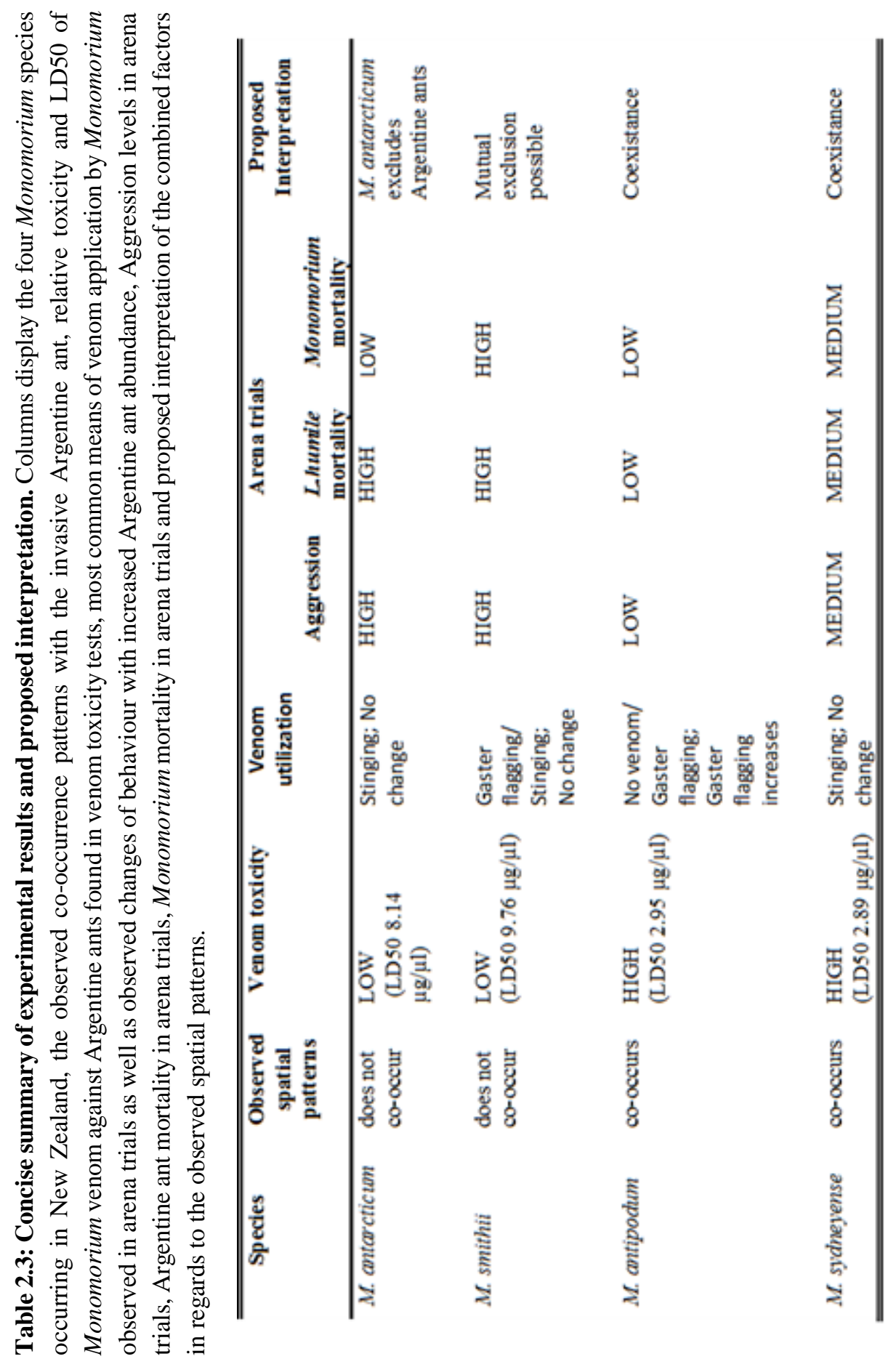


Our first hypothesis was that species with higher venom toxicity would have a higher survival rate when engaging Argentine ants. We based this initial hypothesis on the assumption that the two Monomorium species (M. antarcticum and $M$. smithii) displaying negative cooccurrence with Argentine ants might do so because Monomorium ants are able to exclude Argentine ants from their habitat through biotic resistance, by means of venom application. Our analysis of venom survival experiments showed that the venom of the two Monomorium species which do not co-occur (M. antarcticum, M. smithii), is less toxic to Argentine ants than the venom of the two Monomorium species that do co-occur (M. antipodum, M. sydneyenese). There is an alternative explanation for the venom toxicity/spatial patterns, which may also explain our results. Namely, it is possible that Monomorium species that display negative cooccurrence with Argentine ants do so, because they are poorly defended and are therefore excluded by the Argentine ant. Indeed, there are numerous examples of the Argentine ant competitively excluding other ant community species (Holway et al. 2002a). Species who have been reported to resist such exclusion, such as the winter ant (Prenolepis impairs), utilized high venom toxicity (Sorrells et al. 2011). However if the observed co-occurrence/exclusion patterns were primarily governed by venom toxicity, as we had initially hypothesized, we would have expected different mortality patterns for the two Monomorium species with lower venom toxicity (Fig. 2.2). Specifically, if Argentine ants excluded species with low venom toxicity, we would expect their survival to be much higher when interacting with $M$. antarcticum and $M$. smithii and as a corollary of this, would expect those species to have a higher mortality relative to the species which are better defended through their toxicity. This does not appear to be the case in our model, which indicates that other factors, such as aggression, are more influential in the outcome of interactions. Indeed, the counterintuitive significant negative correlation between Monomorium venom toxicity and Argentine ant survival, can very likely be explained by the differences in aggressiveness between those 
Monomorium species when interacting with Argentine ants. Comparing our results with studies which previously investigated physiological functionality of ant venoms (Lind 1982; Lebrun \& Cattaert 1997) further supports our findings, as it is highly plausible that the increased chain lengths of $M$. antipodum and $M$. sydneyense pyrrolidines $(\mathbf{6}, \mathbf{7}, \mathbf{8}$, and $\mathbf{9}$; Fig. 2.1) should result in increased toxicity. The differences we found in the venom composition of $M$. smithii compared to a previous study (Jones et al. 1990) is likely due to the possibility that there are two cryptic species, which are morphologically similar and given the current taxonomic keys, can only be identified to $M$. smithii. While it is a possibility that species with a less toxic venom might simply deliver more of it, this was not tested in this study. However, even if this were the case, a species delivering more of less effective venom, would consequently need more extensive venom reserves to mitigate the risk of exhausting them too quickly. Since all tested ants were of relatively similar size, we would expect them to have comparable venom reserves. The result that increased toxicity did not translate into an increase of survival of Monomorium and higher Monomorium toxicity was even correlated with higher Argentine ant survival suggests that venom toxicity is not the main factor driving the co-occurrence patterns between Monomorium and Argentine ants. However, toxicity may nonetheless play a still play a more limited role in mediating the outcome of aggressive interactions as has been shown by other studies (Andersen et al. 1991; Andersen \& Patel 1994). Given this result, other factors, like aggressive behaviour, must be taken into account to explain the interactions between these species and obtain a better understanding of how venom chemistry might influence community assembly.

We hypothesized that the likelihood of Monomorium species surviving aggressive interactions with Argentine ants would differ depending on venom utilization. While some animals primarily use their venom in close, physical interactions, some also have the ability to shoot or spit their venom over a larger distance (Warrell 2007). The way venom is utilized in 
different circumstances, or by certain species, might be an important aspect of venom efficacy, which was previously poorly investigated. Previous studies on the most effective way to use venom, have primarily focused on venom optimisation from a cost-benefit approach (Wigger, Kuhn-Nentwig \& Nentwig 2002; Longson \& Joss 2006; Morgenstern \& King 2013). However not only the metabolic costs of venom production need to be considered, but also the cost benefit of the utilisation. For example, two Monomorium species which have not been observed to co-occur with Argentine ants, M. antarcticum and M. smithii, both used their venom primarily in close encounters to sting Argentine ant workers while grappling them. Although the toxicity of their venom appeared to be lower in our trials, the direct injection into their opponents' body bypasses the bodies' outer barrier and seldom misses its target. On the other hand, using venom as a distance weapon bears less risk of injury if successful There are many instances of spray or squirt weapons in animals, although not all are venomous (Aneshansley et al. 1969; Sherbrooke \& Middendorf 2004; Westhoff, Tzschätzsch \& Bleckmann 2005; Suter \& Stratton 2009).

It has previously been shown that Argentine ants can subdue larger species in aggressive interactions through numerical superiority (De Kock 1990). We therefore expected that, if venom does not provide a significant advantage, aggressive interactions should result in a lower survival rate of the species engaging Argentine ants, especially at higher densities. Contrarily, our results showed that only in two of four Monomorium species did the increase in aggressive interactions actually result in an increase of Monomorium worker mortality. However, increased aggression also caused a great increase in mortality for Argentine ant workers when engaging $M$. antarcticum. Several non-mutually exclusive explanations exist for these results. For example, it is possible that other factors like size or physical prowess play an important role and Argentine ants are consequently only capable of dominating other ant species when occurring in overwhelming abundance (Walters \& Mackay 2005). Alternatively it is possible 
that not all species elicit the same strong aggressive response from Argentine ants. In a previous experiment, we showed that Argentine ants react differently to competitors in field experiments and may chose to ignore or avoid some species if met under natural conditions (Westermann, Suckling \& Lester 2014).

The combination of the factors we investigated (venom toxicity, venom utilization, aggression and survival during interactions) allows for a different explanation underlying the observed distribution patterns between Monomorium and Argentine ants (Table 3). For instance, in the case of $M$. antarcticum, the relatively low venom toxicity makes chemical interactions an unlikely explanation for biotic resistance. However our arena tests showed that M. antarcticum can successfully defend itself against Argentine ants, even when vastly outnumbered. This success may well lead to biotic resistance, but on the basis of physical aggression. For $M$. smithii, the pattern is unclear, as high aggression and mortality on both sides could lead to either side excluding the other. However, given the displacement of other species by Argentine ants (Holway 1999; Holway et al. 2002a; Rowles \& O’Dowd 2007) it appears likely that in this case the numerical superiority of the Argentine ant would lead to the exclusion of M. smithii. In M. antipodum the low aggression/mortality on both sides (Table 3) suggests little interference competition with the Argentine ant, therefore co-occurrence can be explained if niche/resource partitioning was to be assumed. For $M$. sydneyense the higher venom toxicity against Argentine ants may give workers an advantage when harassed, which allows $M$. sydneyense to co-occur with the Argentine ant.

Many different factors contribute to the success of an invasive species. Similarly, the ability of some species to co-occur and offer resistance against an invasive species is multifaceted. Previous studies have shown that venom plays an important role in ant community composition (Andersen \& Patel 1994; Holway 1999; Sorrells et al. 2011). The underlying mechanisms for the co-occurrence patterns cannot however be explained by venom toxicity alone, although we 
there is some evidence in $M$. antipodum that venom behaviour might influence survival chances.

Other studies have shown that the way species use their venom influences their competitive chances and determines community structure. For example, the tawny crazy ant (Nylanderia fulva) has been found to be able to detoxify the venom of its fiercest competitor, the red imported fire ant (Solenopsis invicta), by covering itself with its own venom (Lebrun et al. 2014). Aggressive interactions also contribute partially to the co-occurrence patterns. However, the overall success in engagements is likely determined by a multitude of intertwined factors like size and physical prowess, numerical abundance (Sagata \& Lester 2009), behaviour, defensive strategies (Barbieri, Grangier \& Lester 2013a) and toxicity, which are difficult to assess individually. Our study showed that different factors and strategies contribute to the ability of interacting organisms to withstand the pressure of a dominant invader at high abundance. While toxicity is one factor, other strategies like avoidance might also allow cooccurrence, while strong aggressive interactions likely result in territorial exclusion. 


\section{Chapter 3: Disruption of foraging by a dominant invasive species to decrease its competitive ability}

\subsection{Abstract.}

Invasive species are a major threat to biodiversity when dominant within their newly established habitat. The globally distributed Argentine ant Linepithema humile has been reported to break the trade-off between interference and exploitative competition, achieve high population densities, and overpower nests of many endemic ant species. We have used the sensitivity of the Argentine ant to the synthetic trail pheromone (Z)-9-hexadecanal to investigate species interactions for the first time. We predicted that disrupting Argentine ant trail following behaviour would reduce their competitive ability and create an opportunity for three other resident species to increase their foraging success. Argentine ant success in the control was reduced with increasing pheromone concentration, as predicted, but interactions varied among competing resident species. These behavioural variations provide an explanation for observed differences in foraging success of the competing resident species and how much each of these individual competitors can increase their foraging if the competitive ability of the dominant invader is decreased. The mechanism for the observed increase in resource acquisition of resident species appears to be a decrease in aggressive behaviour displayed by the Argentine ant, which may create an opportunity for other resident species to forage more successfully. Our demonstration of species interactions with trail pheromone disruption is the first known case of reduced dominance under a pheromone treatment in ants. 


\subsection{Introduction}

Invasive species are considered to be a major threat to biodiversity and can drive native species to extinction through competitive exclusion (Holway 1999) or niche displacement (Race 1982; Kenward \& Holm 1993). Invasive species can also have adverse effects on ecosystem functionality (Mack et al. 2000), and cause economic losses through decreased agricultural productivity and costs of control measures (Pimentel et al. 2000, 2005; Mack et al. 2000).

Several tramp ant species are among the 100 of the world's worst invasive species (Lowe, Browne \& Boudjelas 2000). Invasive tramp ants can drastically change the structure and community dynamic of an ecosystem (Holway et al. 2002a; O'Dowd et al. 2003). They have also been reported many times to replace native ant species (Barton, Gordon \& Sanders 2001; Sanders et al. 2003; Rowles \& O’Dowd 2007) without providing the same ecosystem services for plants and other community members (Gómez \& Oliveras 2003; Blancafort \& Gómez 2005).

In ants, a well-defined ecological classification of three competition hierarchy levels has been established (Vepsäläinen \& Pisarski 1982; Savolainen \& Vepsäläinen 1989), distinguishing among dominant, subdominant and subordinate species. Dominant species often place severe limitations on the foraging success of subordinate species at local food resources (Fellers 1987; Savolainen 1991; Andersen 1992; Andersen \& Patel 1994; Morrison 1996; Cerdá, Retana \& Cros 1998; Gibb 2005). Behavioural traits (Sih et al. 2004) play an important role for the success of invasive species (Pintor, Sih \& Kerby 2009; Sih et al. 2012) and may also be a factor for biotic resistance as the reactions of local community species influence the likelihood of native species to engage and interfere with the invader (Buczkowski \& Bennett 2008; Sorrells et al. 2011). 
Originally native to South America, the Argentine ant Linepithema humile has successfully become a global invader (Suarez et al. 2001; Holway et al. 2002a; Wild 2004; Roura-Pascual et al. 2006). It quickly monopolizes all resources in the local habitat (Harris, Ward \& Sutherland 2002b; Holway et al. 2002a) and causes large reductions in abundances of native ants. The mechanisms to explain the Argentine ants' ability to displace native ant has been attributed to their capability of breaking the trade-off usually involved between interference and exploitative capacities (Human \& Gordon 1996; Holway 1999), thus attaining ecological dominance (Tsutsui et al. 2000; Tsutsui \& Suarez 2003; Rowles \& O’Dowd 2007, 2009a). However there have also been reports of biotic resistance of native species against Argentine ants (Holway 1999; Sorrells et al. 2011), where native species successfully used physical aggression or chemicals to successfully defend themselves and their territory.

Like many social insects, Argentine ants utilize a trail pheromone-based communication system to mark routes to valuable resources and exploit them efficiently. This trail-pheromones signal was demonstrated to deteriorate within approximately 30 minutes (Deneubourg et al. 1990). It has been hypothesized that one of the causes for the Argentine ants' success and their high impact on native species is their effective recruitment system (Holway et al. 2002a). This recruitment allows them to quickly divert workers from almost-depleted to newly discovered and presumably more worthwhile resources, thus gathering more food and enabling/supporting greater population abundance and thereby exploitatively outcompeting other resident species.

Previous laboratory and field tests have demonstrated that the synthetic trail pheromone (Z)9-hexadecenal (Z9-16:Ald) disrupts Argentine ant trail-following behaviour by interfering with track angles to reduce foraging success (Suckling et al. 2008, 2010; Suckling, Stringer \& Corn 2011; Nishisue et al. 2010). High pheromone concentrations prevent Argentine ants from establishing stable trails and recruiting to resources in the area (Suckling et al. 2010), although existing heavy traffic requires more pheromone for disruption (Suckling et al. 2011). Study 


\section{Foraging disruption of an invasive species}

designs to measure the impacts of invaders usually focus on before/after and control/impact comparisons, supported by experimental manipulations to maintain or decrease invasive populations and observe the effects on the local ecosystem and communities (Parker, I.M., Simberloff, D., Lonsdale, W.M., Goodell, K., Wonham, M., Kareiva, P.M., Williamson, M.H., Holle, B. von, Moyle, P.B., Byers, J.E., Goldwasser 1999; Zavaleta, Hobbs \& Mooney 2001; Hejda, Pyšek \& Jarošík 2009; McNatty, Abbott \& Lester 2009). However, the Argentine ants and their sensitivity to synthetic trail pheromone provide an opportunity for a different approach to measure the impacts of an invasive species by altering their competitive abilities, rather than excluding them or comparing invaded with non-invaded areas.

Here, we attempt to reduce the competitive ability of the dominant Argentine ant using pheromones and assess the impact of these pheromones on the foraging success of competing community species. Firstly, we hypothesized that with increasing pheromone concentrations, Argentine ants would experience reduced resource acquisition, thus creating an opportunity for other resident species to increase their foraging success. Secondly, we hypothesized that increasing concentrations of synthetic pheromone would affect the foraging of co-occurring species differently, depending on the behavioural reactions between Argentine ants and the cooccurring species. Finally, as a mechanism for the increased foraging success of resident species in the presence of synthetic trail pheromone, we hypothesized that increasing pheromone concentrations could influence Argentine ant worker interactions with other species, with a variation in behavioural response between species.

\subsection{Methods}

\subsubsection{Location}

Experiments were conducted in an urban district of Lower Hutt, on the southern North Island of New Zealand, where Argentine ants have been well established since 2001. Three sites in 
the invasion zone $(-41.222,174.872 ;-41.221,174.872$ and $-41.219,174.879)$ were selected for competition experiments. No specific permissions were required to access the first two sampling sites, as they were on public land. The last site was the garden of a private property, the owners gave oral permission to use their garden. None of the experiments involved any endangered or protected species. A preliminary survey had detected the highest abundance of individual workers for Argentine ants and the presence of other resident species at these locations. The three ant species encountered to approach food items together with Argentine ants were the native Monomorium antarcticum, the introduced Ochetellus glaber and the introduced Technomyrmex jocosus, with relative species composition varying between the three sites. None of the species are endangered or protected. Experiments were conducted on dry and sunny days between November 2011 and April 2012.

\subsubsection{Resource Competition Experiments}

To assess the foraging success of $L$. humile under the influence of the pheromone treatment, 50 small marzipan pieces (average weight $0.024 \mathrm{~g} \pm 0.012 \mathrm{~g}$ ) were scattered on paper bait cards with $10 \mathrm{~cm}$ radius and placed haphazardly in an area of 10 x $10 \mathrm{~m}$ at the three sites. Marzipan (Odense Marzipan, Andre Prost, Inc.) was selected as the food because its compounds ( 30\% sugar, glycose syrup, almonds/almond oil) were found to be highly attractive for Argentine and a range of other ants in previous trials. Only one bait card was made available for foraging per plot at any point during the experiment. A fresh bait card was placed at a new location 5 minutes after the last experiment had concluded and was placed at least 3 meters away from the previous location to prevent habituation. Bait cards were treated with four droplets (25 $\mu 1$ each) of ethanol solutions of synthetic trail pheromone at concentrations of $100 \mu \mathrm{g} / \mu \mathrm{l}, 1 \mu \mathrm{g} / \mu \mathrm{l}, 0.01$ $\mu \mathrm{g} / \mu 1$ and a control with pure solvent. Six replicates were carried out in random order for each of the three treatments and the control on each of the three sites. One droplet was applied to 
each side of the bait card to provide an equal distribution of the pheromone. Bait cards were observed until all 50 food items had been picked up and carried over the edge of the bait card by ants (average time $85.9 \mathrm{~min} \pm 2.3 \mathrm{~min}$ ). For each individual food item that was being carried away by an ant worker from the bait card, the species of the worker carrying it was noted. Workers of all ant species were observed to be physically able to carry food items away. Due to differences in species abundance only one other resident species was primarily competing with Argentine ants at each location.

Logistic regression was used to compare the number of food items taken by each species with pheromone concentrations. The dependent response variable was whether an individual food item had been taken or not by Argentine ants at the end of each trial using pheromone concentration and competing ant species as explanatory variables. A binary logistic regression fits the data to give predicted probabilities (and odds) of whether a food item is taken, given particular values of the explanatory variables. For details see (Stringer, Haywood \& Lester 2007).

\subsubsection{Behavioural Scoring}

To assess the difference in how encountered species would be treated by the Argentine ant and assess differences in their reaction in return, Argentine ant and workers of competing species were scored individually for both participating ants during encounters. At times between 1 to 5 minutes, a worker ant of $M$. antarcticum, O. glaber or $T$. jocosus entering the bait card was randomly chosen and its behaviour during its next interaction scored, as well as the behaviour displayed by the Argentine ant worker it was interacting with. Behaviour scores were taken: $0=$ no interest or aggression; $1=$ interest shown via antennation; $2=$ ant retreats quickly; 3 = lunging, biting or leg-pulling, rising of gaster and exuding venom; 4 = prolonged 
(>5 s) incidences of aggression, individuals locked together and fighting (Rowles \& O’Dowd 2007). Ants were considered "meeting" each other when they either touched each other physically, or when they were in close proximity $(0.5 \mathrm{~cm})$ to each other and both parties could be observed to display behaviours which could reasonably assumed to be addressed towards the other worker ant (for example stopping, antennating towards the other ant, turning around and quickly retreating). For half of the bait cards for each treatment and location, interactions of at least 10 individual ant workers were scored. No behaviour scores were taken after all food items had been removed by ants.

To investigate if Argentine ant behaviour in interactions would be influenced by the synthetic pheromone, the average of the behavioural scores was analysed with a Kruskal-Wallis test. Logistic regression was then used to test how interactions differ depending on species. The dependent response variable was whether an interaction was non-aggressive (scores 0,1 and 2) versus aggressive behavioural (scores 3 and 4) with pheromone concentration and competing ant species as explanatory variables. Reactions of Argentine ant workers towards the competing species (M. antarcticum, O. glaber and T. jocosus) were tested as well as scores of the three species towards Argentine ant workers respectively. All data analysis was conducted using PASW Statistics v. 18.0. The data package associated with this manuscript has been made available at the Dryad data depository (Dryad accession number: doi: http://datadryad.org/resource/doi:10.5061/dryad.m64hs). 


\subsection{Results}

\subsubsection{Resource Competition experiments}

Our first hypothesis was that Argentine ants would experience reduced resource acquisition with increasing pheromone concentration, which disrupts their foraging. Argentine ant workers were observed to typically arrive first at the bait cards in all replicates, concurrent with the high exploitative abilities of these ants reported in previous publications (Human \& Gordon 1996; Holway 1999; Rowles \& O’Dowd 2007). The first scouts usually arrived within 2 to 18 minutes of the trial and substantially increased in number after that over the next 15 minutes. Although we did not quantify trail following behaviour or trail integrity, our observations indicate that Argentine ants always formed distinctive trails on and around the bait cards in controls, which were less distinctive in pheromone treatments of $1 \mu \mathrm{g} / \mu \mathrm{l}$ or higher. Furthermore in our observations during the experiment, Argentine ant workers appeared to take a slower approach on the bait card when pheromone was applied, often standing at the edge of the card for minutes and cleaning their antennae or walking in small circles before discovering food items. Workers of the three other species arrived much later, with the first worker ant picking up a food item between 14 to 31 minutes after the beginning of the experiment. By that time Argentine ants were nearly always already present in superior numbers and had started to retrieve food items, but this was reduced with increasing pheromone concentration.

Logistic regression indicated that the trail pheromone had a substantial impact on the competition between Argentine ants and the three tested species M. antarcticum, O. glaber and T. jocosus. The synthetic trail pheromone affected the Argentine ants' ability to dominate the bait cards and retrieve food items, but the effect was considerably stronger at higher pheromone concentrations. The number of food items retrieved by each of the three species was significantly higher with each increase in pheromone concentration (control vs. any of the pheromone treatments $P<0.001$ ). There was also a significant difference for the number of 
food items taken between species for each concentration level (Fig. 3.1, Tab. 3.1). The native ant $M$. antarcticum appeared to benefit the most from the pheromone treatment and increased the number of collected food items from an average of 4.6 in the controls to 28 at a treatment of $100 \mu \mathrm{g} / \mu \mathrm{l}$ (a $608 \%$ increase). The exotic ants $T$. jocosus increased their foraging success from an average of 4 to 20 (a 500\% increase) and $O$. glaber increased from an average of 1.6 retrieved food items to 6.7 (a $416 \%$ increase).

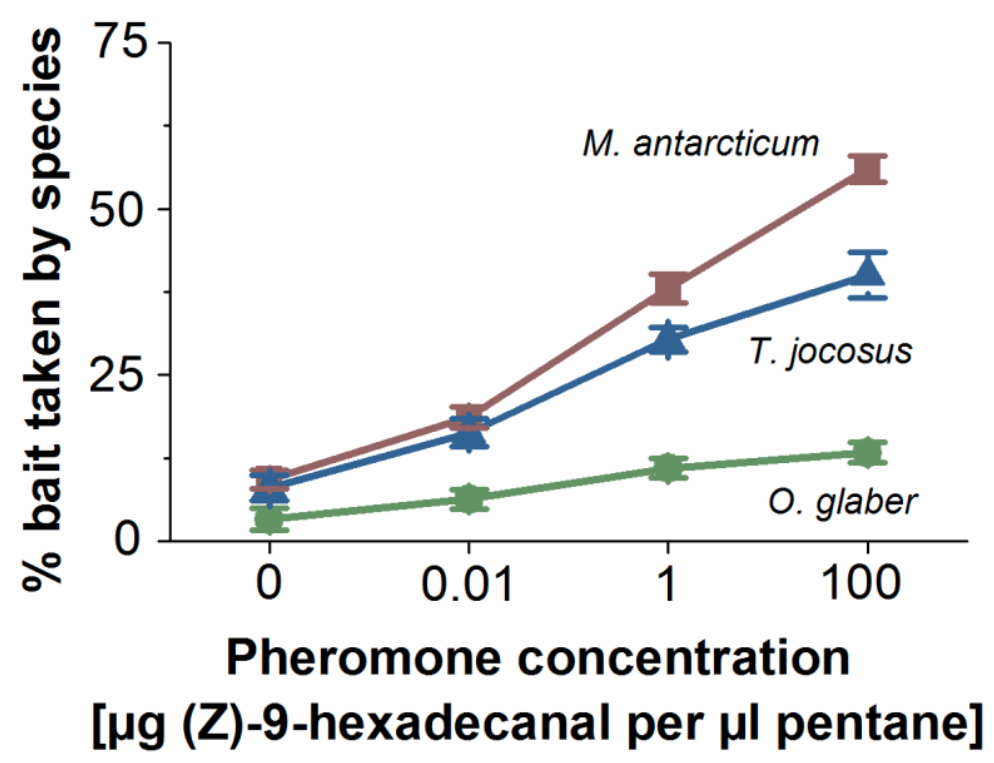

Figure 3.1: Food items taken by ants. Percentage of average number of food items taken in trials $(\mathrm{n}=6$ per treatment and site) by M. antarcticum, O. glaber and T. jocosus from Argentine ants depending on the treatment at increasing concentrations of synthetic trail pheromone (Z)-9-hexadecanal (measured in $\mu \mathrm{g}$ pheromone per $\mu$ l solvent). Error bars represent standard error of average $\%$ food items taken. 


\section{Foraging disruption of an invasive species}

Table 3.1: Statistics for number of food items taken. Logistic regression on the number of food items taken in trials by Argentine ants versus M. antarcticum, O. glaber and T. jocosus. First two rows show the difference between food items taken by Argentine ants from a species, with $M$. antarcticum as reference. The next three rows show the difference of food items taken by Argentine ants depending on pheromone concentration with the control treatment as a reference. $B$ is the log-odds units, S.E. the standard errors associated with the coefficients, Wald the Wald chi-square value, $\mathrm{df}$ the degrees of freedom, $P$ the statistical significance and $\operatorname{Exp}(B)$ the odds ratio.

\begin{tabular}{|c|c|c|c|c|c|c|}
\hline & B & S.E. & Wald & df & $P$ & $\overline{\operatorname{Exp}(\boldsymbol{B})}$ \\
\hline O. glaber vs. M. antarcticum & 0.39 & 0.10 & 15.77 & 1 & $<0.001 * *$ & 1.47 \\
\hline T. jocosus vs. M. antarcticum & 1.68 & 0.13 & 178.27 & 1 & $<0.001 * *$ & 5.35 \\
\hline $0.01 \mu \mathrm{g} / \mu \mathrm{l}$ vs. Control & -0.79 & 0.17 & 22.91 & 1 & $<0.001 * *$ & 0.45 \\
\hline $1 \mu \mathrm{g} / \mu \mathrm{l}$ vs. Control & -1.65 & 0.15 & 113.94 & 1 & $<0.001 * *$ & 0.19 \\
\hline $100 \mu \mathrm{g} / \mu \mathrm{l}$ vs. Control & -2.16 & 0.15 & 201.34 & 1 & $<0.001 * *$ & 0.12 \\
\hline Constant & 2.11 & 0.14 & 226.75 & 1 & $<0.001 * *$ & 8.23 \\
\hline
\end{tabular}

\subsubsection{Behavioural scoring}

We had hypothesized that behavioural interactions between Argentine ants and the cooccurring species would be different for each species, affecting foraging of co-occurring species differently. The average behavioural score for Argentine ant behaviour towards their interaction partner was significantly different between the three species (Kruskal-Wallis $P<$ 0.01), as was the reaction of M. antarcticum, O. glaber and T. jocosus in return (Kruskal-Wallis $P<0.01$ ) (Fig. 3.2). Workers of the native ant M. antarcticum were often avoided (aggression score 2) by Argentine ants, which retreated from $M$. antarcticum workers even when outnumbering it (Fig. 3.2A). In return, $M$. antarcticum workers were often observed to ignore Argentine ants (aggression score 0), often walking on the bait card without any sign of hesitation, picking up a food item and leaving again even when harassed (biting, leg pulling) by Argentine ant workers on rare occasions (Fig. 3.2B). 

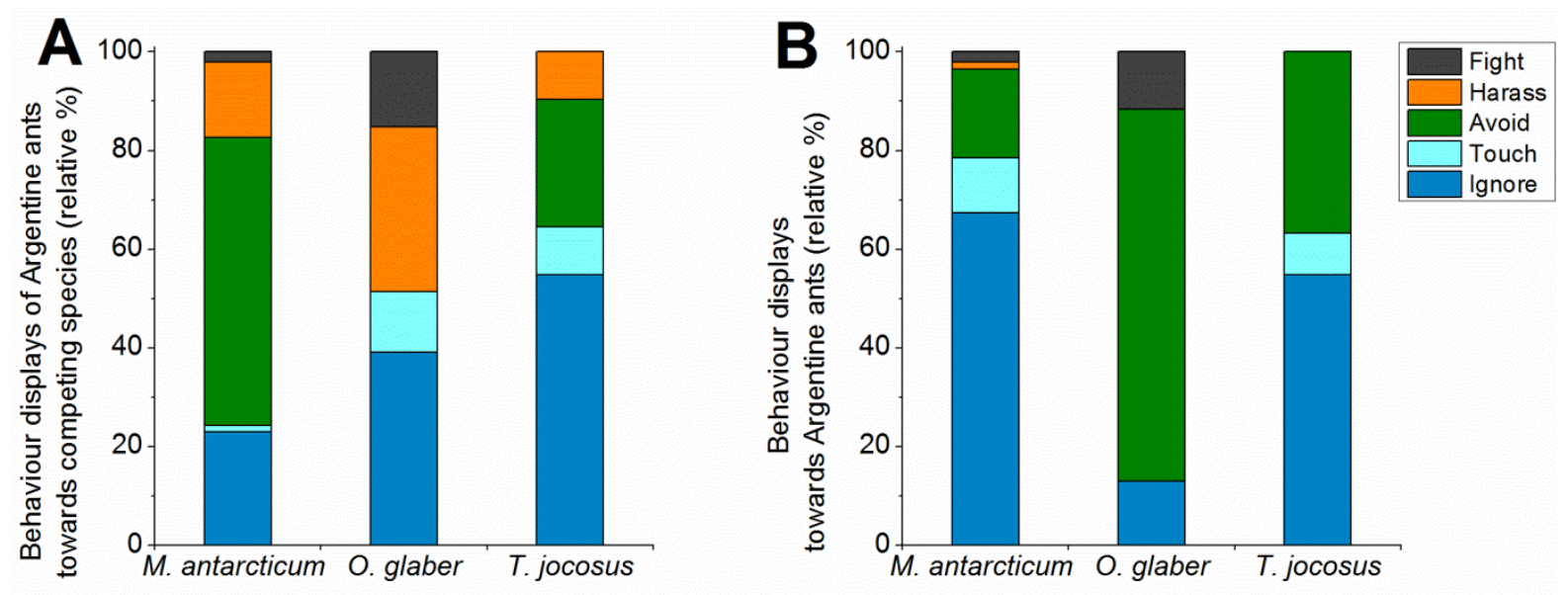

Figure 3.2: Relative percentage of behavioural scores during interactions. (A) Argentine ants towards $M$. antarcticum, O. glaber and T. jocosus and (B) M. antarcticum, O. glaber and T. jocosus towards Argentine ants. Numbers surrounding each graph $(0-4)$ represent the displayed behaviours during interactions, which was scored as $0=$ no interest or aggression; $1=$ interest shown via antennation; $2=$ ant retreats quickly; $3=$ lunging, biting or leg-pulling, rising of gaster and exuding venom; $4=$ prolonged ( $>5 \mathrm{~s}$ ) incidences of aggression, individuals locked together and fighting. Small numbers and dashed lines mark intervals of 0, 25, 50, 75 and 100 for the percentage of interactions during which these behaviours were being displayed.

Workers of the smaller exotic ant $O$. glaber were treated with considerably higher aggression by Argentine ants when encountered. The Argentine ants actively engaged and chased the smaller ants off the bait card. No occurrence of avoidance behaviour (aggression score 2) by Argentine ant workers towards $O$. glaber workers was ever observed (Tab. 3.2). In return the $O$. glaber workers never displayed any touching (aggression score 1) or harassment (aggression score 3) (Tab. 3.3) and appeared to show great hesitation to go near the food items when they appeared to perceive Argentine ant workers in the vicinity, often stopping and turning immediately when coming as close as $0.5 \mathrm{~cm}$ to an Argentine ant worker. 


\section{Foraging disruption of an invasive species}

Table 3.2: Total number of behavioural observations. Total number of observations of non-aggressive (behaviour scores 0,1 and 2) and aggressive (behaviour scores 3 and 4) behaviour displayed by Argentine ants towards each competing species and observations for this species in return, as a function of pheromone concentration or no treatment.

\begin{tabular}{llllll}
\hline \hline \multirow{2}{*}{ Species } & \multirow{2}{*}{ Treatment } & Argentine ants & \multicolumn{3}{c}{ Competitors } \\
\cline { 3 - 6 } & & Non Aggressive & Aggressive & Non Aggressive & Aggressive \\
\hline \multirow{2}{*}{ M. antarcticum } & 0 & 20 & 10 & 26 & 4 \\
& $0.01 \mu \mathrm{g} / \mu \mathrm{l}$ & 28 & 5 & 33 & 0 \\
& $1 \mu \mathrm{g} / \mu \mathrm{l}$ & 36 & 5 & 40 & 1 \\
& $100 \mu \mathrm{g} / \mu \mathrm{l}$ & 35 & 5 & 40 & 0 \\
O. glaber & 0 & 11 & 18 & 23 & 6 \\
& $0.01 \mu \mathrm{g} / \mu \mathrm{l}$ & 14 & 22 & 32 & 4 \\
& $1 \mu \mathrm{g} / \mu \mathrm{l}$ & 23 & 15 & 34 & 4 \\
& $100 \mu \mathrm{g} / \mu \mathrm{l}$ & 23 & 12 & 33 & - \\
& 0 & 25 & 6 & 31 & - \\
& $0.01 \mu \mathrm{g} / \mu \mathrm{l}$ & 35 & 3 & 38 & - \\
\hline \hline
\end{tabular}

Table 3.3: Statistics for aggression by Argentine ants. Logistic regression on displayed aggression by Argentine ants towards $M$. antarcticum, $O$. glaber and $T$. jocosus. The first two rows show the difference between aggressions of Argentine ants towards a species, with M. antarcticum as reference. The next three rows show aggression of Argentine ants depending on pheromone concentration with the control treatment as a reference. $B$ is the log-odds units, S.E. the standard errors associated with the coefficients, Wald the Wald chi-square value, df the degrees of freedom, $\mathrm{P}$ the statistical significance and $\operatorname{Exp}(ß)$ the odds ratio.

\begin{tabular}{|c|c|c|c|c|c|c|}
\hline & $\bar{B}$ & S.E. & Wald & $\overline{d f}$ & $P$ & $\overline{\operatorname{Exp}(ß)}$ \\
\hline O. glaber vs. M. antarcticum & 1.558 & 0.287 & 29.485 & 1 & $0.001 * *$ & 4.751 \\
\hline T. jocosus vs. M. antarcticum & -0.718 & 0.363 & 3.918 & 1 & $0.048 *$ & 0.488 \\
\hline $0.01 \mu \mathrm{g} / \mu \mathrm{l}$ vs. Control & -.0566 & 0.340 & 2.771 & 1 & 0.096 & 0.568 \\
\hline $1 \mu \mathrm{g} / \mu \mathrm{l}$ vs. Control & -1.108 & 0.352 & 9.921 & 1 & $0.002 * *$ & 0.330 \\
\hline $100 \mu \mathrm{g} / \mu \mathrm{l}$ vs. Control & -1.287 & 0.366 & 12.398 & 1 & $0.001 * *$ & 0.276 \\
\hline Constant & -0.836 & 0.297 & 7.933 & 1 & $0.005 * *$ & 0.433 \\
\hline
\end{tabular}


Workers of $T$. jocosus and the Argentine ant most frequently ignored and avoided each other, and while Argentine ant worker occasionally harassed T. jocosus, no occurrences of prolonged combat (aggression score 4) were observed between these species throughout the experiment. Additionally no instances of aggression from $T$. jocosus towards Argentine ants (behavioural score 3 or 4) were observed.

The results of the logistic regression (Tab. 3.3) analysing differences in non-aggressive versus aggressive behavioural reactions show significant differences between the aggression displayed by Argentine ants towards $M$. antarcticum and $O$. glaber $($ Wald $=29.485 ; \mathrm{df}=1 ; P$ $<0.001$ ), with $O$. glaber having a 4.75 times higher chance of being attacked than $M$. antarcticum. Between $M$. antarcticum and $T$. jocosus, the latter had an average of 0.49 chance of being attacked (Wald $=3.918 ; \mathrm{df}=1 ; P=0.048)$. There was also a significant difference in the reactions of these species towards Argentine ants. Displayed aggression differed significantly between $M$. antarcticum and $O$. glaber towards Argentine ants (Wald $=6.148$; df $=1 ; P=0.013)$. The difference in aggression between $M$. antarcticum and $T$. jocosus towards Argentine ants could not be tested for with logistic regression, due to the absence of any aggression displayed by T. jocosus (no instances of scores 3 or 4 observed; (Tab. 3.2).

In our third hypothesis, we investigated if increasing pheromone concentrations could influence Argentine ant worker interactions with other species. The treatment with synthetic trail pheromone had a substantial impact on the behaviour displayed by Argentines ants towards M. antarcticum, O. glaber and T. jocosus (Fig. 3.3A), lowering the average behavioural score (Kruskal-Wallis $P<0.01$ ). The behaviour displayed by $O$. glaber, $T$. jocosus and $M$. antarcticum appeared to be only slightly influenced by the application of pheromone, although all showed a small reduction (Fig. 3.3B). The results of the logistic regression (Tab. 3.3) analysing differences in non-aggressive versus aggressive behavioural reactions reveal a highly significant reduction of displayed aggression by Argentine ants with pheromone 
concentrations of $1 \mu \mathrm{g} / \mu \mathrm{l}(\mathrm{Wald}=9.921 ; \mathrm{df}=1 ; P<0.001)$ and $100 \mu \mathrm{g} / \mu \mathrm{l}(\mathrm{Wald}=12.398$; $\mathrm{df}$ $=1 ; P<0.001)$ compared to untreated controls. Furthermore, aggressive reactions of $M$. antarcticum, O. glaber and T. jocosus towards Argentine ants decreased with increasing pheromone treatments (Tab. 3.4).
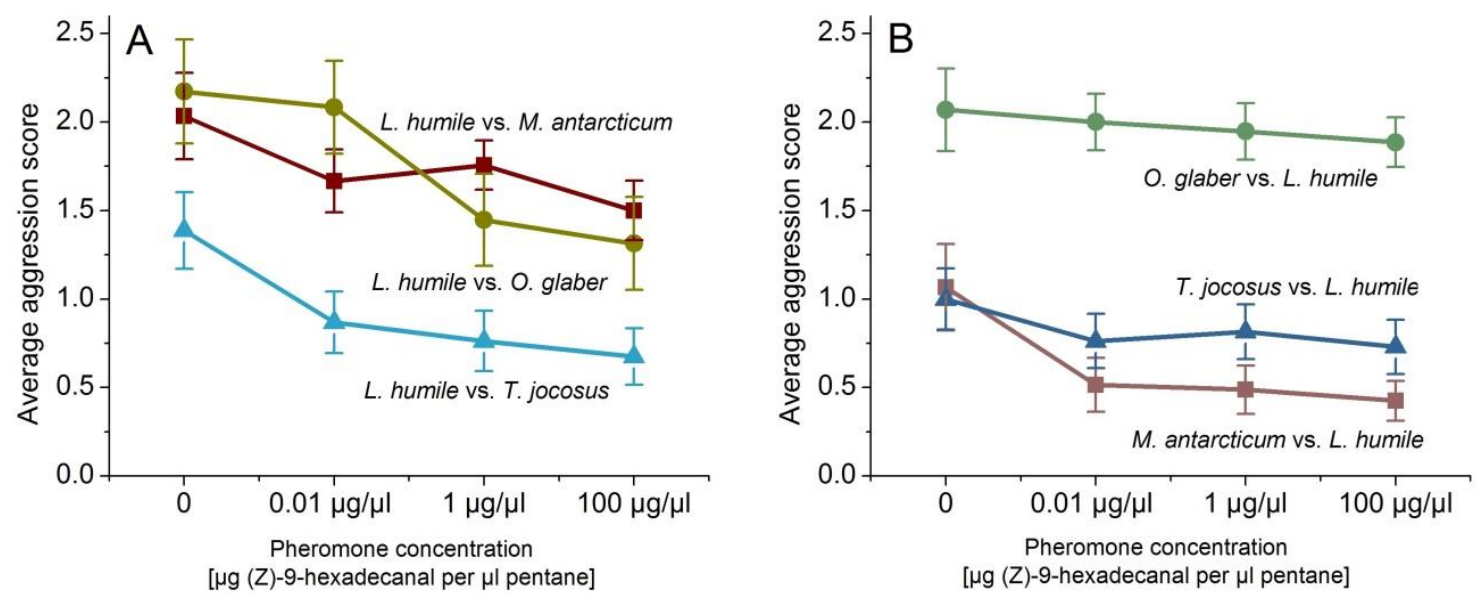

Figure 3.3: Average aggression scores of ants. Average aggression of (A) Argentine ants towards $M$. antarcticum, O. glaber and T. jocosus and (B) M. antarcticum, O. glaber and T. jocosus towards Argentine ants depending on the treatment with different concentrations of synthetic trail pheromone (Z)-9-hexadecanal (measured in $\mu \mathrm{g}$ pheromone per $\mu \mathrm{l}$ solvent). Aggression was scored as $0=$ no interest or aggression; $1=$ interest shown via antennation; 2 = ant retreats quickly; 3 = lunging, biting or leg-pulling, rising of gaster and exuding venom; 4 = prolonged (> $5 \mathrm{~s}$ ) incidences of aggression, individuals locked together and fighting. Error bars represent Standard Error of average aggression scores. 
Table 3.4: Statistics for aggression by M. antarcticum, $O$. glaber and T. jocosus towards Argentine ants. Logistic regression on displayed aggression by M. antarcticum, O. glaber and T. jocosus towards Argentine ants. The first two rows show the difference between aggressions by a species towards Argentine ants, with M. antarcticum as reference. The next three rows show aggression depending on pheromone concentration with the control treatment as a reference. $\beta$ is the log-odds units, S.E. the standard errors associated with the coefficients, Wald the Wald chi-square value, df the degrees of freedom, $\mathrm{P}$ the statistical significance and $\operatorname{Exp}(ß)$ the odds ratio.

\begin{tabular}{lrrrrrr}
\hline \hline & $\beta$ & S.E. & Wald & df & $P$ & $\operatorname{Exp}(\beta)$ \\
\hline O. glaber vs. $M$. antarcticum & 1.33 & 0.54 & 6.148 & 1 & $0.013 *$ & 3.78 \\
$T$. jocosus vs. M. antarcticum & -17.85 & 3251.82 & 0.000 & 1 & 0.996 & 0.000 \\
$0.01 \mu \mathrm{g} / \mu \mathrm{l}$ vs. Control & -1.278 & 0.632 & 4.090 & 1 & $0.043 *$ & 0.279 \\
$1 \mu \mathrm{g} / \mu \mathrm{l}$ vs. Control & -1.13 & 0.59 & 3.712 & 1 & 0.054 & 0.32 \\
$100 \mu \mathrm{g} / \mu \mathrm{l}$ vs. Control & -2.032 & 0.804 & 6.385 & 1 & $0.012 *$ & 0.131 \\
Constant & -2.388 & 0.520 & 21.062 & 1 & $0.000 * *$ & 0.092 \\
\hline \hline
\end{tabular}

$* P<0.05 ; * * P<0.01$

\subsection{Discussion}

Our data support the hypothesis that confusing a dominant invasive species and reducing its competitive ability can reduce its resource acquisition and create an opportunity for other resident species to increase their foraging. While dominating untreated bait cards, Argentine ants arrived sporadically and in a more disorganized manner, when cards were treated with synthetic pheromone. This is consistent with results in previous studies (Suckling et al. 2008, 2010, 2011; Nishisue et al. 2010), which had reported that trail-following behaviour of Argentine ants could be disrupted with synthetic pheromone. These studies provided a proof of concept for the pheromone disruption in Argentine ants by analysing trail integrity (Suckling et al. 2008) and providing evidence for a negative impact on their foraging (Suckling et al. 2010; Nishisue et al. 2010). However, it was previously unclear whether this interference with Argentine ants recruitment actually translates into an effect on the resident ant community, which could be used to support native species. In our experimental approach the trail disruption 


\section{Foraging disruption of an invasive species}

gave co-occurring species an opportunity to locate and remove baits much more successfully than without the pheromone.

Argentine ants reacted differently to each of the three species, showing a variety of patterns in frequency and type of non-aggressive and aggressive behaviours towards their competitors. Similar observations have been made in other ant species, which react differently towards certain competitors (Wilson 1975; Holldobler 1983). All three tested competing species $M$. antarcticum, O. glaber and T. jocosus were able to utilize the advantage arising through the previously reported confusion caused by the pheromone application and significantly increase their foraging success. However, the increase in the number of retrieved food items varied among species, with the relative increase of $M$. antarcticum being the most substantial. Comparatively with increasing pheromone concentration, $O$. glaber showed less dramatic increase.

The differences in foraging success can be well explained by the differences in behavioural traits (Sih et al. 2012) and their manifestations in interactions between Argentine ants and the three species. For example, M. antarcticum is frequently avoided by Argentine ants, which make way for approaching $M$. antarcticum workers even when Argentine ants outnumber $M$. antarcticum. Workers of $M$. antarcticum mostly seemed to ignore Argentine ants and single M. antarcticum workers were frequently observed to walk on the bait card and retrieve a food item without hesitation, apparently uninterested in present Argentine ant workers. These behaviour patterns are well within expected interaction ranges, as $M$. antarcticum workers are larger than Argentine ant workers and, unless dramatically outnumbered (Sagata \& Lester 2009), have been shown to annihilate Argentine ant workers in physical interactions by biting them in half. However, M. antarcticum are also slow moving and slower to recruit than Argentine ants, especially at higher temperatures (McGrannachan \& Lester 2013), which may explain why Argentine ants are still dominant at food sources. While $O$. glaber does benefit 
from the pheromone disruption, their foraging success increases less than the other species, since their workers are frequently harassed or attacked by Argentine ant workers. Workers of O. glaber were frequently observed to retreat when near Argentine ant workers, even when Argentine ants were walking in circles, apparently confused, and not directly interacting with O. glaber individuals. Workers of T. jocosus and Argentine ants display a similar pattern of ignoring and avoidance towards each other, with some harassment being exhibited by Argentine ant workers. The observed behavioural patterns are concurrent with aggression and avoidance patterns appropriate to dominance ranks of these species within the ant community (Vepsäläinen \& Pisarski 1982; Savolainen \& Vepsäläinen 1989), with the Argentine ant taking a dominant role, while $M$. antarcticum and T. jocosus are subdominant and $O$. glaber subordinate.

As a mechanism for increased foraging success of the three competing resident species, we observed decreased aggression being exhibited by dominant Argentine ant workers when treated with pheromone, combined with their reduced ability to locate the food items. Our data indicate a significant reduction in aggression displayed by Argentine ant workers with increasing pheromone concentrations. While previous studies have investigated changes of aggression in social insects related to cuticular hydrocarbons (Ruther, Sieben \& Schricker 2002; Smith, Hölldober \& Liebig 2009), queen pheromones (Alonso \& Vander Meer 2002) and alarm pheromones (Ali \& Morgan 1990), the impact on aggression due to experimental pheromone changes in a wider area are unexplored at this point. In the presence of synthetic pheromone, Argentine ants seemed to spread out more and no longer followed distinct trails, which could increase the chance of encounters between species. However, Argentine ant workers also more frequently stand around or move in small circles. This behaviour appeared to allow workers of the other species to pass them in close proximity $(\sim 0.5 \mathrm{~cm})$ without provoking any aggressive reaction and thus retrieving food more easily. We propose two non- 


\section{Foraging disruption of an invasive species}

mutually exclusive hypotheses to explain this reduction in aggressiveness. First the trail disruption caused by higher concentrations of trail pheromone could simply decrease the likelihood of Argentine ants workers being able to perceive the workers of other species, even at very close distance, thus ignoring them much more often. Alternatively high pheromone concentrations might alter the reactions of Argentine ants, making individual workers less aggressive. Ants frequently defend established trails to resources, so it might be possible that, due to the disruption of the trail, the territoriality of Argentine ants is reduced, which therefore decreases their aggressive behaviour within the area of the pheromones' influence.

We have demonstrated that it is possible to significantly reduce the foraging success and displayed aggression of the Argentine ant, a globally dominant invader (Suarez et al. 2001; Holway et al. 2002a; Wild 2004; Roura-Pascual et al. 2006). Argentine ants have been reported many times to competitively exclude subdominant and subordinate species due to their ability to quickly locate food and defend it efficiently (Human \& Gordon 1996; Holway 1999; Rowles \& O’Dowd 2007). Our experiments showed that it is possible to reduce the competitiveness of the Argentine ants by interfering with their ability to find and defend food sources. Species from a lower dominance hierarchy were able to take advantage of this opportunity. This provides evidence that pheromone-based control measures could help to stabilize or even increase local populations of native species that were previously being suppressed. Insecticides have often led to losses of non-target species (Whitehorn et al. 2012; Blacquière et al. 2012) and have recently shown to even have the potential of giving an advantage to invasive species (Barbieri et al. 2013b). Over a longer time, reduced foraging ability of Argentine ants could lead to reduced populations of this invader, potentially even to a point where the invaders' population collapses and they are replaced by other local species. Future experimental studies should focus on whether or not long-term reduction of competitive abilities of a dominant 
species is possible and results in anticipated changes in the species' community which could be utilized in invasive species management.

Our demonstration of species interactions with trail pheromone disruption is the first known case of reduced dominance from pheromone-based treatment in ants, and this area offers new prospects for behavioural interference in invasive species management. 



\section{Chapter 4: Synthetic Pheromones as a management technique - Dispensers decrease Linepithema humile activity in a commercial vineyard}

\subsection{Abstract}

Invasive ants, such as the Argentine ant, have often been reported to facilitate honeydewproducing hemipteran pests like mealybugs, which can be vectors of plant pathogens. Synthetic pheromones may offer a target-specific method to control such ants and consequently lower the abundance of honeydew producing pests. Here we report the results of a trial to suppress Argentine ants in grape vines using ant pheromone dispensers.

Compared with untreated controls, we observed a significant drop in Argentine ant activity on the ground, irrespective of whether pheromone dispensers were placed at ground level, within the canopy or in both locations. Ant counts in the canopy confirmed that Argentine ant abundance was reduced under the influence of the pheromone dispenser placed at ground level compared with untreated controls. However, placing dispensers only in the canopy did not reduce the numbers of ants within the canopy compared with untreated controls.

Our results showed that pheromone dispensers can significantly reduce Argentine ant foraging in grape vines, if they are positioned appropriately. This technique could potentially reduce the abundance of associated mealybugs and potentially attendant virus vectoring area wide. 


\section{Pheromone control of an invasive ant}

\subsection{Introduction}

Invasive species can impose economic losses through decreased agricultural productivity and the associated costs of control measures (Pimentel et al. 2000, 2005; Mack et al. 2000). For instance, invasive ant species have often been reported to facilitate honeydew-producing hemipteran pests like mealybugs (Johnson et al. 2001; Holway et al. 2002a), which can accelerate the distribution of plant pathogens like the virus causing Mealybug wilt of pineapple (Jahn, Beardsley \& Gonzalez-Hernandez 2003; Sether et al. 2005) or the Grapevine leafrollassociated virus 3 (GLRaV-3) (Tsai et al. 2008; Maree et al. 2013).

The invasive Argentine ant Linepithema humile M., native to South America, has successfully spread worldwide (Suarez et al. 2001; Holway et al. 2002a; Wild 2004; RouraPascual et al. 2006). Its success has been partly attributed to its strong association with honeydew-producing insect species (Shik \& Silverman 2013). In New Zealand, the invasive Argentine ant has been observed tending mealybugs in horticultural crops, and is therefore regarded as likely to be a significant pest in a variety of crops, (Lester \& Longson 2002; Lester et al. 2003) and has potential to spread significantly (Ward et al. 2010). Mealybugs are vectors of GLRaV-3 (Daane et al. 2012), an economically important disease of grapevines found throughout the world (Charles, Cohen \& Walker 2006). Estimated costs range from $\$ 25000$ to $\$ 40000$ per hectare for different scenarios of yield reduction and quality penalties (Atallah $e t$ al. 2012). Mealybug numbers on vine grapes could be significantly reduced simply by controlling Argentine ant numbers (Phillips \& Sherk 1991). Therefore, controlling these invasive ants is an important strategy to reduce the spread and impact of mealybugs and potentially, any associated plant pathogens.

While insecticides are often used for pest management, the reported negative impacts of insecticides on pollinators (Cresswell 2011; Whitehorn et al. 2012; Blacquière et al. 2012) and even potential facilitation of invasive species (Barbieri et al. 2013b), makes this a less and less 
desirable management approach. Pheromones may offer a target-specific and potentially more environmentally friendly approach for integrated pest management (Witzgall et al. 2010) and have become more prevalent over the years in push-pull strategies (Cook et al. 2007). Pheromone usage can be tailored to specific application methods, for instance on organic crops, if encapsulated in a dispenser (Zehnder et al. 2007) or for area-wide control if applied by aerial dispersion (Brockerhoff et al. 2012). More recently, pheromones have also been used to manipulate foraging of invasive ant species like Monomorium pharaonis (Robinson et al. 2005) or the Argentine ant (Nishisue et al. 2010).

The synthetic pheromone (Z)-9-hexadecenal (Z9-16:Ald) disrupts Argentine ant trail following behaviour (Suckling et al. 2008, 2010, 2011; Nishisue et al. 2010). High pheromone concentrations prevent Argentine ants from establishing stable trails, thus limiting their ability to successfully forage and recruit greater numbers of con-specifics to resources in the area (Suckling et al. 2010). Additionally, this treatment can also provide a competitive advantage for other resident ant species to increase their foraging, when directly competing with the Argentine ant for a specific food resource (Westermann et al. 2014). Therefore, the potential exists for this synthetic trail pheromone to provide a management technique which, if successful, could reduce the risk of disruption to mealybug biological control (Samways, Nel \& Prins 1982) and in doing so, reduce the risk of plant pathogen spread.

In previous trials on Argentine ants, a variety of different products have been used to deploy the trail pheromone in the field. Trail disruption had been previously demonstrated using a loaded canuba wax point source (Suckling et al. 2008), a micro-encapsulated sprayable product (Suckling et al. 2010) and pheromone diluted in ethanol (Suckling et al. 2011). Nishisue et al. (2010) reported a successful long-term control of Argentine ants and reduced foraging activity using a rope dispenser product by Shin-Etsu Chemical, Tokyo (Tatsuki, Terayama \& inventors; Shin-Etsu Chemical, Co., Ltd. 2005). These dispensers can be permanently deployed 


\section{Pheromone control of an invasive ant}

on an ant-infested site and continuously distribute pheromone to their immediate surroundings, without it being washed away by rain. Nishisue et al. (2010) tested the pheromone rope dispensers in an urban garden environment and deployed them on $\sim 40 \mathrm{~cm}$ poles. To our knowledge, however, a successful deployment of this technology in a commercial agricultural environment has not yet been demonstrated.

Mealybugs are primarily located in the canopy of vines. Argentine ants form trails to harvest honeydew and in so doing, the ants also effectively protect mealybugs from predators and parasitoids (Mgocheki \& Addison 2010). Because the different spatial scale of agricultural crops allows for much more three-dimensional-movement than in the urban grass environment in the previous trial (Nishisue et al. 2010), the deployment of a fixed pheromone dispenser also has to take into account the effect of pheromone placement within the crop. While a dispenser on the ground, around the crop might decrease the ability of ants to form a trail towards these plants, the effect might not extend into the canopy of a larger plant or fruit tree. This scenario could still allow ants that reach the upper parts of the plants to tend to mealybugs. On the other hand, a dispenser in the canopy of fruit plants could decrease the ability of ants to locate mealybugs.

Here we report the results of a trial to suppress Argentine ants in an agricultural environment using pheromone dispensers deployed in two ways to enable inferences about foraging and its disruption in a three dimensional space. Our aim was to lower ant abundance in the vine canopy, where mealybugs occur and assess the most effective management approach to achieve this goal. We tested the effects of artificial Argentine ant pheromone on ant abundance when the rope dispenser was placed on the ground and/or in the canopy. Previous studies reported a limit to the range of the pheromone (Suckling et al. 2008); therefore we predicted that, placing the dispenser near the ground would have the greatest impact on Argentine ant ground activity, 
while dispensers in the vine canopy would have a greater impact on Argentine ant numbers in the vine canopy.

\subsection{Methods}

\subsubsection{Study site}

The study was conducted in the late summer to autumn (20 February to 1 May 2013) on a commercial vineyard in Hawke's Bay $\left(39^{\circ} 63^{\prime} \mathrm{S}, 176^{\circ} 81^{\prime} \mathrm{E}\right)$, which is a winegrowing region on the east coast of New Zealand's North Island. The study block was planted in Cabernet Sauvignon vines in 2001. The trial was carried out within the block using an area of unplanted land sufficiently large enough to accommodate our experimental design. The entire Cabernet Sauvignon planted area had been colonised by the Argentine ant since at least 2009. The Argentine ant was abundant (Fig. 4.1A) and no other ant species could be found in the immediate trial area. Presence of the ant within the trial area was confirmed by preliminary pitfall trap sampling during early February 2013.

\subsubsection{Experimental setup}

We placed 60 potted Pinot Noir grapevines (approximately 1 year old) into plastic buckets (10 L) (Fig. 4.1B), which were buried under the irrigation lines in the unplanted vine rows. A single 10-mm diameter hole in each bucket c. $50 \mathrm{~mm}$ from its base allowed the outflow of excess water from the daily irrigation. A total of 48 vines (incorporating four treatments as described below) were set up in four rows (Fig. 4.1C); the distance between plants was $2.5 \mathrm{~m}$. A random numbers table was used to assign treatments as follows $(\mathrm{n}=12$ plants per treatment $)$ : Ground $(\mathrm{G})$ : one dispenser was wrapped around a short pole at a maximum height of $10 \mathrm{~cm}$ above ground. The pole was placed next to the vine, allowing pheromone to disperse without physically obstructing/preventing ants from walking up the vine; Canopy (C): one dispenser 


\section{Pheromone control of an invasive ant}

wrapped around the vine at a height of approximately $50 \mathrm{~cm}$ above ground; Ground + Canopy (GC): one dispenser on the ground and one in the vine canopy as described above; Untreated internal control (UI): brown electrical wire visually resembling the pheromone dispensers was tied in the canopy of the untreated internal control vines to account for any potential disturbance effects of the physical presence of these dispensers. To check for any potential area-wide effect of the pheromone, which might influence the untreated internal control, an additional 12 plants were established in a separate area at a distance of c. $20 \mathrm{~m}$ away from the main experimental area as an external untreated control (UE). Since individual plants were randomly assigned to treatment groups, we measured the length of the longest cane of each plant, to confirm whether a comparable amount of 'canopy space' between treatment groups was available.

We used a rope pheromone dispensers supplied by Shin-Etsu (Shin-Etsu Chemical, Tokyo, Japan; see details in Tanaka et al. 2009). It contained approximately $375 \mathrm{mg}$ of (Z)-9hexadecanal per meter, therefore each $20 \mathrm{~cm}$ dispenser contained $75 \mathrm{mg}$ of pheromone, which, under stable conditions, would release the pheromone at an estimated rate of $1.2 \mathrm{mg}$ per day (calculation based on constant temperature/delivery rate over 2 months; the manufacturer asserts a 2-month lifespan based on data for moth disruption. Dispensers were initially applied to vines in the field on 20 February 2013 and replaced on 15 March 2013.

To provide a natural food source for Argentine ants on the potted vines, plants were inoculated with 10-15 citrophilus mealybugs (Pseudococcus calceolariae) growing on a single piece of seed potato and placed into a cotton mesh bag $(15 \times 8 \mathrm{~cm})($ Fig. $4.1 \mathrm{D})$. The $2-4 \mathrm{~mm}$ diameter apertures throughout the fabric allowed mealybugs to naturally disperse onto the grapevine and to be picked up and tended by the Argentine ant. Before placement in the vineyard, mealybug colonies were reared on seed potatoes (cv. Karaka) in a laboratory $\left(23^{\circ} \mathrm{C}\right.$ $\left.\pm 1.0^{\circ} \mathrm{C}\right)$. 
Argentine ants were observed to approach the potted plants almost immediately after they had been dug in, walking over the side of the bucket and onto the plants trunks. Within 30 min of vine deployment, ants were observed investigating the cotton pockets containing the seed potatoes inoculated with mealybugs (Fig. 4.1A). Furthermore, mealybugs were observed moving out of the mesh pockets and onto the vines (Fig. 4.1E) within the same time.
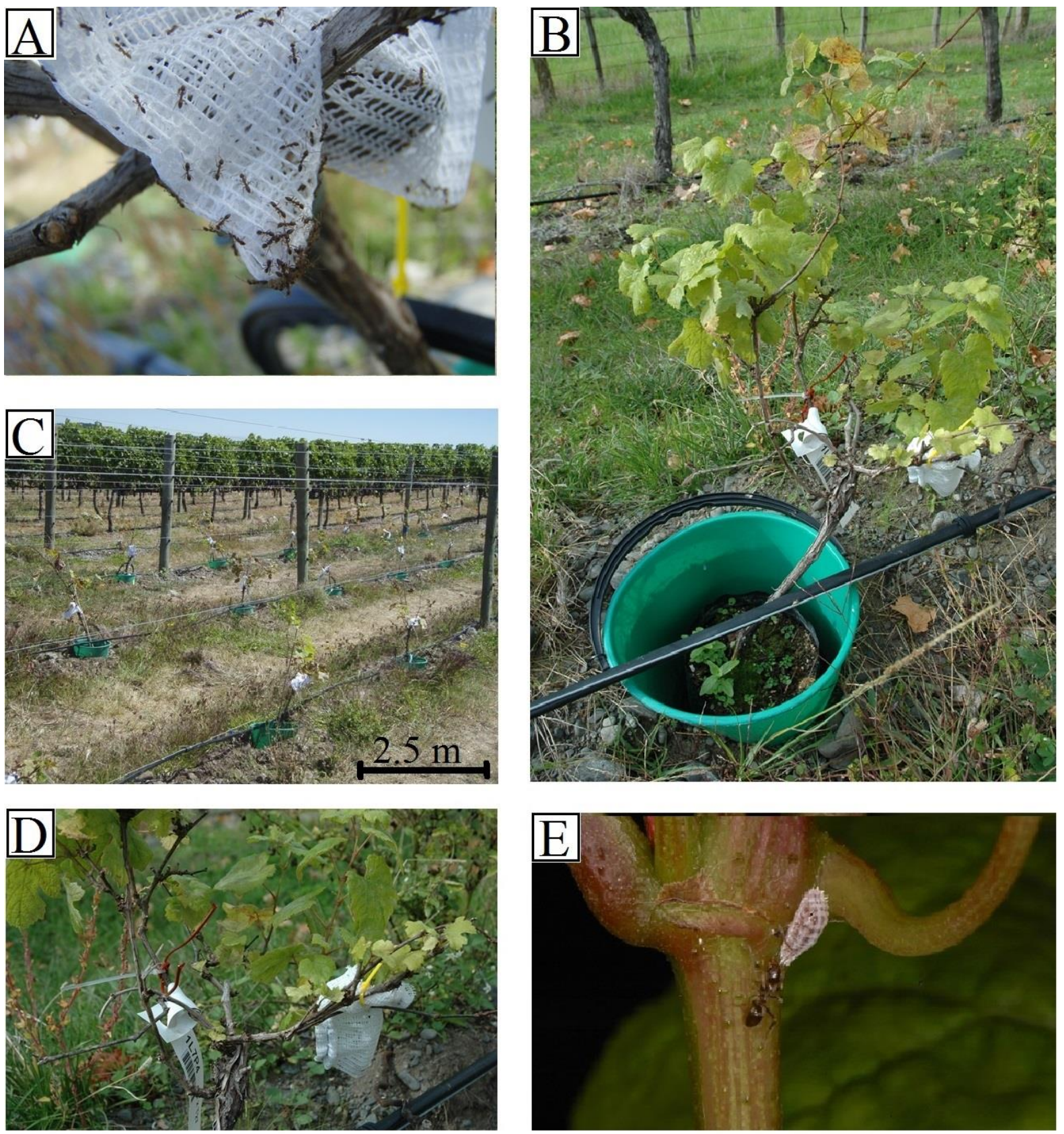

Figure 4.1: Overview of experimental site and design. A) Argentine ants approaching mesh pockets with mealybugs in vine canopy before placement of pheromone dispensers. B) Experimental setup of a single 


\section{Pheromone control of an invasive ant}

grapevine, placed in a bucket under the irrigation line. C) Experimental setup of the trial. D) A close-up of the canopy treatment with pheromone disperser (brown wire) attached to the vine (left) and white mesh pocket containing mealybugs on a segment of seed potato (right). E) Argentine ant tending to a citrophilus mealybug on one of the experimental plants.

\subsubsection{Ground assessments}

To assess if pheromone treatments would decrease Argentine ant abundance on the ground, we used pitfall traps to examine ant abundance. These traps were placed in the ground next to each plant on warm, dry and sunny days for $48 \mathrm{~h}$. In total, 23 traps were placed in the main experimental area and an additional 6 traps were positioned in the ground in the external control area. The traps were filled with approximately $30 \mathrm{ml}$ of water and propylene glycol at a ratio of 4:1 and a drop of dishwashing liquid to break the surface tension. The initial trapping was conducted on 15 February before the experiment was established. Subsequent trappings were undertaken on 15 March, 8 and 29 April.

\subsubsection{Canopy assessments}

To assess the effect on Argentine ant foraging in the vine canopy, we undertook 1-min counts of Argentine ant activity on each vine per treatment. Visual searches encompassed all parts of the vine, going methodically from bottom to top (trunk, crown, canes and leaves) and counting every ant seen within the allotted timeframe. Counts were undertaken on six separate occasions (25 February, 8, 16 and 26 March, 8 and 23 April 2013) on warm, dry and sunny days.

\subsubsection{Statistical analysis}

Statistical analyses were performed in IBM SPSS Statistics 20.00. Count data of pitfall traps and canopy counts were square root transformed. The pitfall trap dataset failed Levenes test for homogeneity of variance, which was accounted for by using a repeated measures linear general model (ANOVA) with a Games Howell post hoc test (Games \& Howell 1976) to 
analyse the data for differences between treatment groups over time. Canopy count data were analysed using a repeated measures linear general model (ANOVA) with a Fishers LSD post hoc test, after passing Levenes test for homogeneity. The results are interpreted with a degree of caution because both datasets failed Mauchly's test of Sphericity (pitfall trap Mauchly's W $=0.251 \mathrm{df}=5$ Greenhouse - Geisser $=0.659 ;$ canopy counts Mauchly's $\mathrm{W}=0.606 \mathrm{df}=14$ Greenhouse - Geisser $=0.852)$. A general linear model $($ ANOVA) was used to compare the available canopy space between the different groups.

\subsection{Results}

\subsubsection{Initial conditions}

Argentine ants had been observed to be very abundant within the experimental area in the four years prior to establishment of the experiment, and this was confirmed by our initial pitfall trapping. No significant difference (ANOVA: $\mathrm{df}=4 ; \mathrm{F}=0.801 ; \mathrm{p}=0.530$ ) was found for Argentine ant density in the initial assessment amongst the set-up locations (Fig. 4.2).

We compared the amount of available 'canopy space' within each treatment group by measuring the length of the longest cane of each plant (Mean $1.24 \mathrm{~m} \pm 0.39 \mathrm{~m}$ ) and found no significant difference for this factor (ANOVA: $\mathrm{df}=4 ; \mathrm{F}=0.691 ; \mathrm{p}=0.601$ ), therefore it was not included in further analysis.

\subsubsection{Ground assessments}

Argentine ant density was found to be significantly different between the external control (UE) and all treatments involving pheromones (Tab. 4.1), with a strong reduction of traffic around the treated vines (Fig. 4.2). We found no statistical difference amongst the three pheromone treatments (Tab. 4.1). Furthermore, no difference in Argentine ant activity on the ground was detected between the external (UE) and the internal control (UI). 


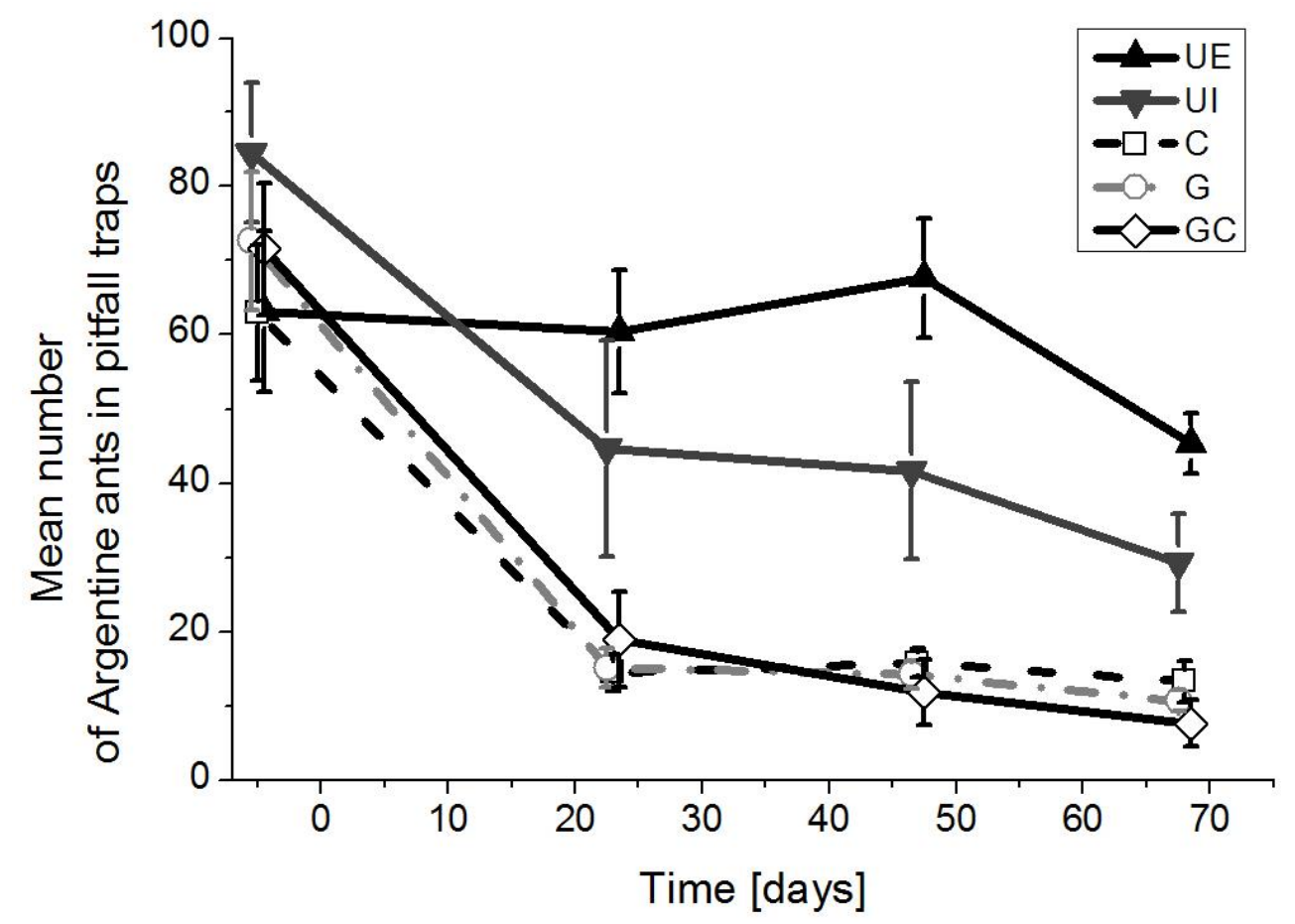

Figure 4.2: Mean ( \pm SEM) numbers of Argentine ants recorded in pitfall traps established in the Hawke's Bay vineyard study block. Assessments were undertaken between 15 February (before pheromone treatment) and 29 April 2013 ( $n=12$ pitfall traps next to $\mathrm{G} ; \mathrm{n}=11$ pitfall traps next to UE, $\mathrm{C}$ and $\mathrm{GC} ; \mathrm{n}=10$ pitfall traps next to UI). $\mathrm{C}$ = canopy; $\mathrm{G}=$ ground; $\mathrm{GC}=$ ground plus canopy; $\mathrm{UI}=$ untreated internal control; $\mathrm{UE}=$ untreated external control. 
Table 4.1: Mean difference, standard error, p-values and confidence intervals between treatments from the repeated measures linear model for the ground assessment (Games Howell post hoc test) and canopy assessment (Fishers LSD post hoc test). $\mathrm{C}=$ canopy; $\mathrm{G}=$ ground; $\mathrm{GC}=$ ground plus canopy; $\mathrm{UI}=$ untreated internal control; $\mathrm{UE}=$ untreated external control. Statistically significant differences between treatments during each assessment are denoted by one asterix $(\alpha=0.05)$.

\begin{tabular}{|c|c|c|c|c|c|c|c|}
\hline & & & \multirow[b]{2}{*}{ Mean Difference } & \multirow[b]{2}{*}{ Std. Error } & \multirow[b]{2}{*}{ Sig. } & \multicolumn{2}{|c|}{ 95\% Confidence Interval } \\
\hline & & & & & & Lower Bound & Upper Bound \\
\hline \multirow{8}{*}{$\begin{array}{l}\text { Ground assessment } \\
\text { (pitfall traps) }\end{array}$} & $\mathrm{UE}$ & $\mathrm{C}$ & $2.858^{*}$ & .562 & .001 & 1.073 & 4.643 \\
\hline & & G & $2.786^{*}$ & .535 & .001 & 1.060 & 4.512 \\
\hline & & $\mathrm{GC}$ & $3.201^{*}$ & .595 & .000 & 1.331 & 5.070 \\
\hline & & UI & 1.051 & .811 & .868 & -1.528 & 3.630 \\
\hline & $\mathrm{C}$ & $G$ & -.0721 & .390 & 1.000 & -1.287 & 1.143 \\
\hline & & GC & .342 & .469 & .997 & -1.122 & 1.808 \\
\hline & & UE & $-2.858^{*}$ & .562 & .001 & -4.643 & -1.073 \\
\hline & & UI & -1.807 & .723 & .206 & -4.204 & .589 \\
\hline \multirow{8}{*}{$\begin{array}{l}\text { Canopy assessment } \\
\text { (1-min counts) }\end{array}$} & $\mathrm{UE}$ & $\mathrm{C}$ & -.082 & .4907 & .868 & -1.065 & .901 \\
\hline & & G & $1.447^{*}$ & .4907 & .005 & .464 & 2.431 \\
\hline & & $\mathrm{GC}$ & $1.108^{*}$ & .4907 & .028 & .124 & 2.091 \\
\hline & & UI & .592 & .4907 & .233 & -.391 & 1.575 \\
\hline & $\bar{C} \mathrm{C}$ & $\bar{G}$ & "1.529* & (2.4907 & .003 & ב.546 & 2.513 \\
\hline & & GC & $1.190^{*}$ & .4907 & .019 & .206 & 2.173 \\
\hline & & UE & .082 & .4907 & .868 & -.901 & 1.065 \\
\hline & & UI & .673 & .4907 & .175 & -.309 & 1.657 \\
\hline
\end{tabular}

\subsubsection{Canopy assessments}

During the 1-min counts, Argentine ants were observed to be present on all the sentinel vines, independent of treatment (Fig. 4.3). However, we found significantly fewer ants on the ground (G) and ground plus canopy (GC) treatment on all assessment dates compared with either of the untreated controls (UI, UE) (Tab. 4.1). Most interestingly, we did not observe any significant difference in ant numbers in the vine canopy between the canopy treatment $(\mathrm{C})$ and either of the untreated controls (UI, UE) at any point during this study (Tab. 4.1). As during ground assessments, there was no difference between the ground $(\mathrm{G})$ and ground plus canopy (GC) treatments. Furthermore, we found no difference for Argentine ant numbers in the canopy between the external (UE) and the internal control (UI). 


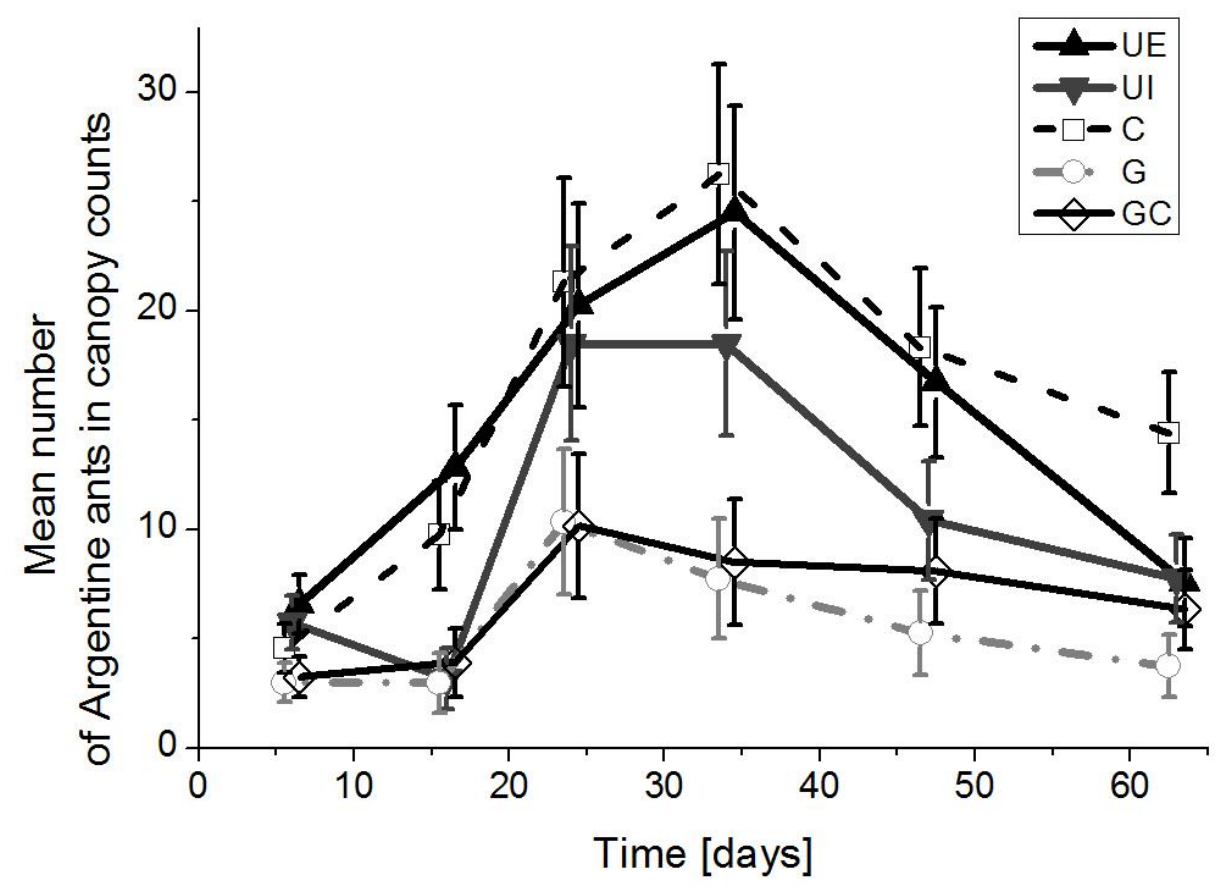

Figure 4.3: Mean ( \pm SEM) numbers of Argentine ants recorded during 1-min counts in the Hawke’s Bay vineyard study block ( $\mathrm{n}=12$ mealybug-inoculated Pinot Noir grapevines per treatment). Assessments were undertaken between 25 February and 29 April 2013. $\mathrm{C}$ = canopy; $\mathrm{G}=$ ground; $\mathrm{GC}=$ ground plus canopy; $\mathrm{UI}=$ untreated internal control; UE = untreated external control.

\subsection{Discussion}

Our study presents a successful demonstration that the application of trail pheromones can suppress Argentine ant activity in an agricultural environment. In our initial assessment, we found the Argentine ant evenly distributed across the experimental area. Therefore, it could be assumed that all the vines included in our experimental plot had an equal risk of ant incursions. The analysis of our data, however, suggests that Argentine ant activity was significantly reduced in some treatments and their access onto these vines decreased following the addition of pheromone dispensers.

We predicted that, placing the dispenser near the ground would have the most suppressive effect on Argentine ant ground activity. While we observed a significant drop in ant abundance compared with controls, which was similar to previous reports by Tanaka et al. (2008), there was no effect between the dispenser locations on the ground traffic. The number of workers on 
the ground decreased by 73 to $79 \%$ after the establishment of the trial compared with their initial abundance, and activity continued to stay at a similar level in following weeks. This result suggests that the pheromone filaments and meandering plumes lowered random ground traffic and scouting independently of the exact location of the dispensers. More interestingly, an increased number of dispensers in the ground plus canopy (GC) treatment did not result in a further reduction in ant density, which suggests that the pheromone quantity distributed by the dispensers during our experiment was sufficiently high to achieve trail disruption, and within expectations of what had been previously used in pheromone disruption experiments on ants (Westermann et al. 2014). Since no difference in activity was found between our external and internal control, either in pitfall traps, or in 1-min counts, we assume that the impact of the pheromone was limited to the immediate area of the dispensers and reduced quickly with increased distance from the source. Indeed another study (Suckling et al. 2008) has suggested that the impact on Argentine ants is of short duration and they recover quickly once outside the area of effect.

We expected pheromone dispensers placed in the vine canopy would have the strongest suppressive effect on Argentine ant numbers in the vine canopy. Ant counts in the canopy confirmed that Argentine ant abundance was reduced under the influence of the pheromone dispenser, with distinct differences depending on the positioning of the pheromone dispenser. Most surprisingly, dispensers placed in the canopy did not appear to have any effect on the ability of the Argentine ant to access the canopy and therefore the mealybugs located therein. These results indicated that ground-placed dispensers, close to the base of a crop or fruit plant, may be more effective for Argentine ant control than treatment of the canopy. It seems likely that this placement would restrict or at least limit ant access onto the whole plant, as long as no other physical access points allow access to upper parts of the plant. It seems reasonable to assume that at least one reason for the difference in effectiveness between ground $(\mathrm{G})$, ground 


\section{Pheromone control of an invasive ant}

plus canopy (GC) and canopy only (C) treatments was the ability of Argentine ants to use visual cues for orientation. Therefore, a ground treatment may reduce the ability of Argentine ants to recruit a continuous trail towards the trunk of the plant. However, once access to the plant has been established, we speculate that ants could use visual cues and or sense of gravity (Khuong et al. 2013) to navigate up and down the plant and around the branches, which could severely decrease the effectiveness of pheromone applications.

Pheromones have shown a growing potential for integrated pest management (Witzgall et al. 2010), can be tailored to crops/pests (Zehnder et al. 2007) and adapted to local or area wide application (Brockerhoff et al. 2012). In our study, ant traffic was significantly reduced in the canopy of ground pheromone treated vines, therefore we conclude that the treatments likely altered normal ant foraging behaviour sufficiently to impede their ability to find and protect mealybugs, which offer honeydew. If so, this might result in major advantages for pest management. Firstly, it may be beneficial for mealybugs' natural enemies, particularly parasitoids, as a previous study has suggested that mealybug biological control may be negatively influenced by the presence of the Argentine ant (Mgocheki \& Addison 2010). Conversely, this could also severely limit Argentine ants spread, as they depend on the access to honeydew to produce large enough numbers of workers to overcome other ant species (Shik \& Silverman 2013). However, the target concentration of trail pheromone required for suppression of an entire population on a large scale is yet unknown, and thus it is too early to consider the feasibility of this control method. Earlier studies using higher pheromone concentrations achieved up to 90\% reduction in foraging (Suckling et al. 2008, 2010), measured as trail presence after application of microencapsulation (as opposed to discrete dispensers), which was higher than the current study. The fast rate of recovery of normal trail response of the ants which has been reported previously (Suckling et al. 2011) suggests that 
any ants in clean air may be able to trail normally, which would allow for uninterrupted foraging outside our experimental trial.

\subsection{Conclusions}

Our study presents a successful demonstration that the application of trail pheromones can suppress Argentine ant activity in an agricultural environment, which may also reduce the numbers of mealybugs. Our results are consistent with previous observations (Tanaka et al. 2008, 2009; Nishisue et al. 2010). Trail pheromone disruption is a target-specific and potentially more environmentally friendly control technique than the current area-wide use of insecticides, which have been shown to negatively impact other beneficial insect species (Whitehorn et al. 2012).

The next step in the process is to progress our experimental design to a large-scale level. In our future studies we plan to assess the extent to which pheromone dispensers can successfully impede Argentine ant recruitment on mature agricultural crops, and therefore reduce its ability to interact with and protect mealybugs. 



\section{Chapter 5: The long term effects of reduced competitive ability on foraging success of an invasive species}

\subsection{Abstract}

Invasive ant species like Pheidole megacephala, Solenopsis invicta and the Argentine ant, Linepithema humile have repeatedly been reported to be strongly associated with honeydew-producing arthropods like aphids, scale insects and mealybugs, effectively protecting them from biological control agents like parasitoids. These honeydew producing insects are frequently vectors of plant pathogens. Here we report the results of a successful trial using pheromone dispensers to suppress Argentine ant activity over large sections in a commercial vineyard over a period of two months and preventing ant access into and foraging within the vine canopy.

We found Argentine ant activity to be significantly reduced in pheromone-treated plots for the duration of the trial period compared with control plots. Our results showed a significant reduction in the numbers of Argentine ant workers recruited to randomly placed food resources within treated plots compared with untreated plots. Furthermore, spatial distribution of Argentine ants alongside transects in untreated plots remained relatively continuous, while increasing sharply beyond the borders of treated plots. Furthermore, we measured the body fat content of workers and found a significant reduction in fat among workers from treated plots compared with untreated plots, suggesting an adverse effects on nest fitness. Additionally, we provide an initial assessment of the feasibility of the presented approach. 


\section{Effects of reduced foraging success on an invasive ant}

Our results showed that it is possible to control Argentine ant, preventing them access to and foraging within the vine canopy, thereby potentially depriving mealybugs of their protection, while at the same time reducing Argentine ants access' to honeydew.

\subsection{Introduction}

The spread of invasive species can have a detrimental effect on ecosystems and economies (Pimentel et al. 2000, 2005; Mack et al. 2000), with increasing impact over the last century due to expanding international trade and traffic (Kaluza et al. 2010). Invasive species can disrupt ecosystem functions (Pejchar \& Mooney 2009) and services such as pollination (Stout \& Morales 2009) or promote the spread of existing pathogens (Bowen-Walker, Martin \& Gunn 1999). In response, considerable efforts and research have been made to understand and mitigate the impact of invasive species (for example MacDougall \& Turkington 2005; Pejchar \& Mooney 2009).

Invasive ant species like Pheidole megacephala (Fabricius), Solenopsis invicta (Buren) and the Argentine ant, Linepithema humile (Mayr) have repeatedly been reported to be strongly affiliated with honeydew-producing arthropods like aphids, scale insects or mealybugs (Johnson et al. 2001; Helms \& Vinson 2002; Holway et al. 2002a). These pest insects are frequently vectors of plant pathogens like the virus causing Mealybug wilt of pineapple (MWP) (Jahn et al. 2003; Sether et al. 2005) or the Grapevine leafroll-associated virus 3 (GLRaV-3) (Tsai et al. 2008; Maree et al. 2013). Such plant pathogens can lead to significant economic losses, with estimates from a study in South Africa on GLRaV-3 ranging from $\$ 25,000$ to $\$ 40,000$ per hectare for scenarios of yield reduction and quality penalty (Atallah et al. 2012). Several studies have shown that the most effective approach to manage these pathogens and mitigate the damage, is not necessarily to target the vector directly, but controlling the invasive ants associated with the respective pest species. For example, no MWP infected plants were 
found in plots in Hawaii where P. megacephala was controlled, while the number of infected plants increased sharply in blocks where ants were not controlled (Su 1979). Similarly mealybug numbers on grapevines were found to be significantly reduced simply by controlling the abundance of the invasive Argentine ants (Phillips \& Sherk 1991).

The invasive Argentine ant L. humile, native to South America, has successfully spread through Mediterranean regions worldwide (Suarez et al. 2001; Holway et al. 2002a; Wild 2004; Roura-Pascual et al. 2006). It is considered to be a serious pest species (Harris et al. 2002a; Holway et al. 2002a) with its success being partly attributed to its strong association with honey-dew producing insect species (Shik \& Silverman 2013). Since the Argentine ant tends mealybugs in a variety of horticultural crops (Lester et al. 2003), which in turn are vectors of viruses like GLRaV-3 (Daane et al. 2012), its management is an important strategy to reduce the spread and impact of plant pathogens.

While insecticides can be successfully used to manage invasive ants ( $\mathrm{Su} 1979)$, they frequently have negative effects on non-target species (Brown 1978; Matsumura 1985; Cresswell 2011) and may even facilitate certain invasive species (Barbieri et al. 2013b). Therefore, more target specific management options like pheromones are being investigated to reduce the negative effects of pest control treatments on the environment (Witzgall et al. 2010). Pheromones provide significant advantages over pesticides, as they can be used on organic crops without leaking into the food chain (Zehnder et al. 2007). Recent advances have also shown that pheromones can be used successfully to manipulate invasive ant species like Monomorium pharaonis (Robinson et al. 2005) or the Argentine ant (Nishisue et al. 2010).

The synthetic pheromone (Z)-9-hexadecenal (Z9-16:Ald) disrupts Argentine ant trail following behaviour (Suckling et al. 2008, 2010, 2011; Nishisue et al. 2010) and has been shown to limit their foraging success. Previous experiments have also demonstrated that trail disruption may provide competitive advantages for other resident ant species due to reduced 


\section{Effects of reduced foraging success on an invasive ant}

hostility of the Argentine ant workers (Westermann et al. 2014). A variety of different application methods to distribute the pheromone in the field has been investigated (Suckling et al. 2008, 2010; Westermann et al. 2014), with the most successful approach so far, being a rope dispenser (Tatsuki et al. 2005; Chapter 4), which can be deployed at a location for a longer duration of time to distribute the pheromone.

Our previous work found ground-based pheromone dispensers to be most effective in preventing the Argentine ant from recruiting to the vine canopy (Westermann et al. 2015). This treatment may therefore prevent Argentine ants from harvesting honey dew and protecting mealybugs from predators and parasitoids (Mgocheki \& Addison 2010). Here we report the results of a $7168 \mathrm{~m}^{2}$ large trial to determine if the rope pheromone would reduce Argentine ants in a commercial agricultural environment using synthetic pheromone.

Our first aim was to determine if the use of synthetic trail pheromones could reduce the Argentine ants' abundance and its ability to access the vine canopy. Secondly, we assessed the Argentine ants ability to locate and recruit to randomly placed food sources within the vine canopy in order to evaluate the impact of the treatment on their chances to tend mealybugs. Thirdly, we investigated the spatial distribution of Argentine ants towards and beyond the boundaries of the pheromone treated plots in order to achieve a better understanding of the range of the pheromone effects. We also used the body fat content of ant workers as a surrogate measurement to evaluate whether the pheromone induced decreased foraging activity of Argentine ants translates into a measurable fitness effect in nests, within the area of effect of the pheromone treatment. Finally, we have calculated the potential cost of the presented treatment to allow evaluation of its feasibility. 


\subsection{Materials and methods}

\subsubsection{Study site.}

The study was conducted between 4 February and 25 March 2014 (Southern Hemisphere summer) on a commercial vineyard in Hawke's Bay (-39.63, 176.81), a winegrowing region on the east coast of New Zealand's North Island. Established in 2003, the study block was planted in Cabernet Sauvignon grapevines grown on vertical shoot positioned trellis with two cordons. The Argentine ant had serendipitously been discovered in the block in February 2009, with its distribution throughout the block confirmed during subsequent monitoring (Bell, unpublished data, 2009). Insecticide usage was recorded in the block but the last input was three months prior to the study commencing. Insecticide inputs to the vines were limited to targeting mealybugs only, and included prothiofos (e.g. Tokuthion® and JMS StyletOil/Oil-Mate II®, 1,000 L/ha) applied on 12 September 2013 (Southern Hemisphere spring), and two mealybug-specific insecticides applied on 30 October (buprofezin, e.g. Mortar ${ }^{\mathrm{TM}}, 300$ L/ha) and 11 November (spirotetramat, e.g. Movento®, 350 L/ha). As prothiofos was applied five months before this study commenced it would have limited its potential to adversely influence Argentine ant mortality in and around the study block. The other mealybug specific insecticides applied to the vines have no known effects on ants.

Argentine ants had been observed to be abundant within the experimental area prior to establishment, which was confirmed in our preliminary pitfall trapping in January 2014 as well as in our pre-trial counts and food source counts on the day of trial establishment. We found no significant differences in neither ant activity (GLMM: $\mathrm{SE}=0.079, \mathrm{t}=0.513, \mathrm{p}=0.609$ ) nor recruitment to food sources (GLMM: $\mathrm{SE}=0.193, \mathrm{t}=-0.097, \mathrm{p}=0.924)$ between plots designated to be treated and plots designated to be control, prior to the establishment of the trial. However, results of our preliminary pitfall trapping indicated that the ant population may not be evenly distributed across the trial area, which was accounted for in the experimental 


\section{Effects of reduced foraging success on an invasive ant}

design. However this spatial gradient across the experimental area was not confirmed as Block ID was a not a significant factor in the model for the initial 1 minute counts (GLMM: SE = $0.410, \mathrm{Z}=1.201, \mathrm{p}=0.230$ ) and initial baiting (GLMM: $\mathrm{SE}=0.211, \mathrm{Z}=1.018, \mathrm{p}=0.308$ ).

\subsubsection{Experimental design.}

Eight plots with each individual plot measuring $28 \mathrm{~m}$ x $32 \mathrm{~m}$ encompassing an area of $896 \mathrm{~m}^{2}$ were marked with flagging tape. Each plot included approximately 280 mature vine plants arranged in 14 rows and 4 bays. Plots had a distance of 32 meters between them on the vertical (North-South) axis and 18 meters in the horizontal (East-West) axis to utilize the maximum spatial separation possible. The total experimental area of the trial, including spacing, therefore summed up to approximately $18944 \mathrm{~m}^{2}$. Preliminary pitfall trapping indicated that Argentine ant abundance followed a spatial gradient and increasing towards the southern end of the experimental site. As a completely random trial design could have resulted in having more or less control plots in areas with higher ant abundance and thus possibly artificially creating differences between treatment and control groups, we decided to use a BACI (Before-After-Control-Impact) (Smith 2002) experimental design and arranged plots in 2 x 4 rows, similar to a Latin Square (Gomez \& Gomez 1984) alternating treated and untreated plots (Fig. 5.1). 


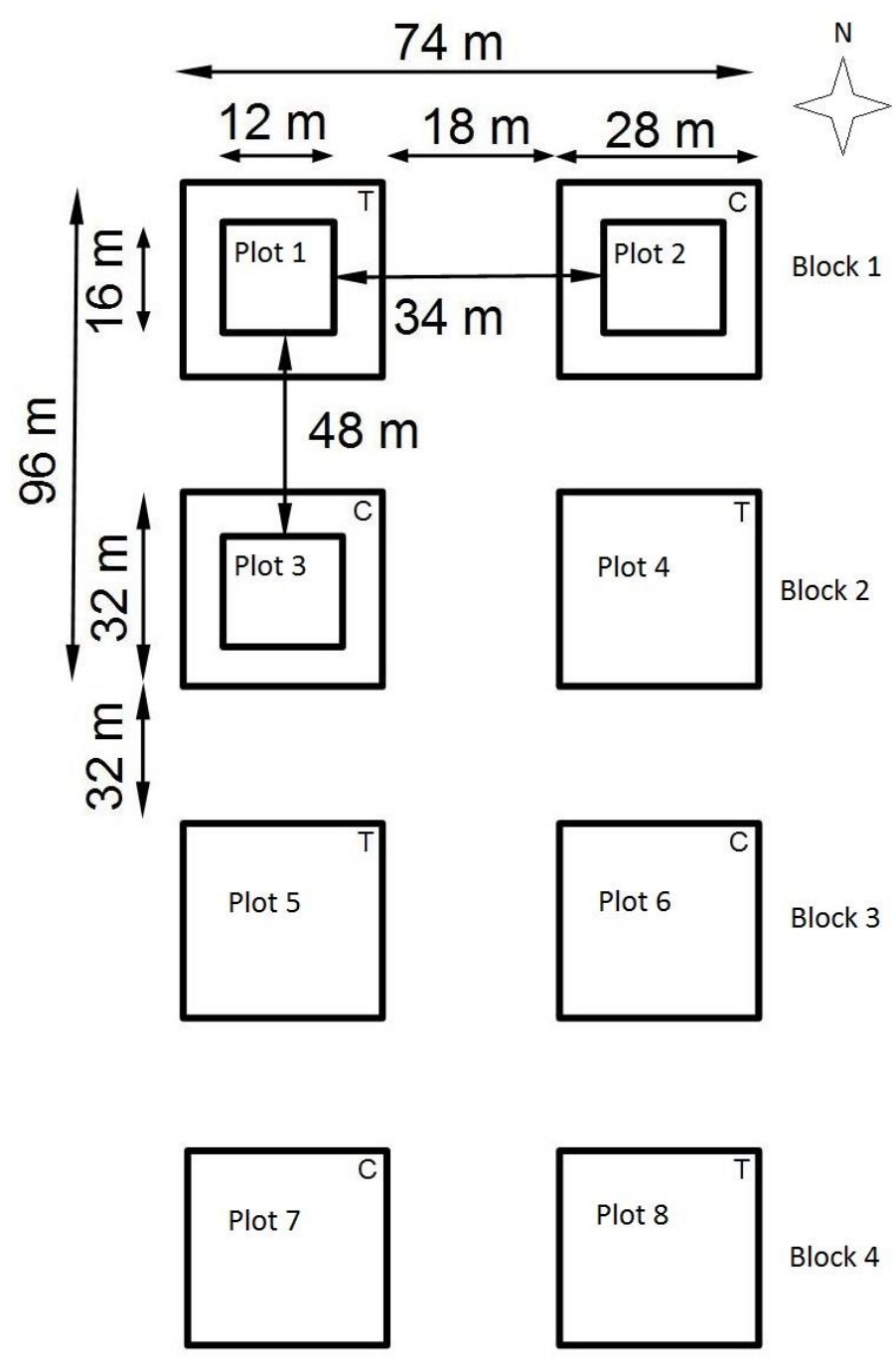

Figure 5.1: Schematic representation (not to scale) of the experimental layout. Each square represents one experimental plot with $\mathrm{T}=$ Treated and $\mathrm{C}=$ Control plots with the dimensions of $28 \times 32 \mathrm{~m}$. Each plot contained a monitoring area with $12 \times 16 \mathrm{~m}$.

We used a rope pheromone dispenser supplied by Shin-Etsu (Shin-Etsu Chemical, Tokyo, Japan; see details in Tanaka et al. 2009), which visually somewhat resembles brown electrical wire with a diameter of approximately $0.5 \mathrm{~cm}$. The dispenser rope was applied to four plots, by leading it through the existing anchor points of the irrigation line at a height of 5-10 $\mathrm{cm}$ above the ground, as this had been shown to be the most effective setup in previous trials (Westermann et al. 2015), and fixed by winding it around the anchor points. Thus $448 \mathrm{~m}$ of rope were applied on each replicate treated plot. Since pre-existing anchor points were used, 


\section{Effects of reduced foraging success on an invasive ant}

no physical obstruction or barrier was created along the trunks of the vine plants which could have influenced or hindered the free access of Argentine ants to the vine canopy. The rope contained approximately $375 \mathrm{mg}$ of (Z)-9-hexadecanal per meter in a permeable polyethylene plastic tube, therefore an amount of $168 \mathrm{~g}$ per plot or $187.5 \mathrm{mg} / \mathrm{m}^{2}$ was available to be distributed in each of the treated areas. Assuming a constant release rate over the duration of the trial, the estimated maximum delivery rate of pheromone was $3.83 \mathrm{mg} / \mathrm{m}^{2} / \mathrm{day}$, which is comparable to earlier studies (Westermann et al. 2015). However, it should be noted that delivery rates are likely to have undergone fluctuations depending on temperature and wind, which however would have affected all plots equally. The four control plots were left undisturbed.

We established monitoring areas within each of the plots. Each monitoring area was located exactly in the middle of one of the eight plots and had the dimensions of $12 \mathrm{~m} \times 16 \mathrm{~m}$ (6 rows and 2 bays), encompassing 60 mature vines. This provided a buffer zone of 6 and $8 \mathrm{~m}$ to the side of the respective plot to account for possible edge effects, for example Argentine ants from untreated areas walking into treated plots, or pheromone being dispersed by wind into an untreated plot.

\subsubsection{Canopy Traffic.}

To investigate the Argentine ants' abundance and its ability to access the vine canopy, we conducted 1-minute counts of ant traffic on vines within each monitoring area. The visual search encompassed all parts of the vine, going methodically from bottom to top (trunk, crown, canes and leaves) and counting every ant seen within the given timeframe. To reduce the risk of double counting ants, which sometimes moved quickly through the canopy of adjunct vines when high traffic was found, we only counted the ants on every second vine, resulting in $\mathrm{n}=$ 
30 per plot for each monitoring. The first 1-minute counts were undertaken on the same day as the trial was established, directly before the deployment of the pheromone rope $\left(4^{\text {th }}\right.$ of February). Subsequent counts were conducted approximately weekly $\left(13^{\text {th }}, 18^{\text {th }}, 27^{\text {th }}\right.$ February, $7^{\text {th }}, 12^{\text {th }}, 19^{\text {th }}$ and $25^{\text {th }}$ March) during the trial period. All monitoring was conducted midday during warm (mean temperature $21.07^{\circ} \mathrm{C} \pm 2.66$ ), dry and sunny days, with no rain occurring for at least 24 hours before and during monitoring.

\subsubsection{Food sources recruitment.}

To assess the Argentine ants ability to locate and recruit to food sources within the vine canopy, we placed one small droplet of honey $(\sim 0.1 \mathrm{~g})$ as a food source during each monitoring on four vine leaves within each plot. Vines were randomly selected during each monitoring interval, using a random number generator and placing the food source in the canopy of the corresponding vine. Food sources were subsequently left for one hour and then revisited to count all ants present at the food source. Food source monitoring was conducted on the same days as the 1 minute counts.

\subsubsection{Edge Effects.}

To achieve a better understanding of the range of the pheromone effects, we extended 1-minute counts using the same protocol as described in the canopy traffic assessments, on vines alongside rows to form transects beyond the monitoring and treatment area. Rows were randomly chosen using a random number generator set to produce $8 x 1$ numbers between 1-6 and continuing counts on every second vine along the corresponding row. Those counts were continued for an additional two bays in both directions (one inside the plot and one beyond the border of the plot), thereby adding an additional 10 vines to the respective row. The first 


\section{Effects of reduced foraging success on an invasive ant}

transect counts were undertaken on the same day as the trial was established, directly before the deployment of the pheromone rope ( $4^{\text {th }}$ of February). Subsequent transect counts were conducted on the (18 ${ }^{\text {th }}$ February, $7^{\text {th }}$ and $19^{\text {th }}$ March).

\subsubsection{Fat analysis.}

Ant workers within a nest share resources through their social stomach, and food availability translates into reproductive success, through emerging workers. Therefore, we decided to use the body fat content of ant workers as a surrogate measurement to evaluate the potential fitness effects of the pheromone treatment on the Argentine ants within the trial area. We used a similar methodology as has been described in Heinze et al. 2003 and Weissel et al. 2011 for the measurement of ant body fat content. We collected four haphazardly selected nests within the perimeter of each plot. The nests were excavated and transferred into boxes, which were frozen at $-20{ }^{\circ} \mathrm{C}$ to kill and preserve the ants. Each sample consisted of 250 ant workers which we randomly picked from each nest and were sorted into glass vials. Each sample was dried to constant weight for at least 48 hours at $65{ }^{\circ} \mathrm{C}$ over silica gel pearls and was then weighed using a Mettler AM100 microscale. Each sample was weighed four times on two different days. Subsequently, each sample was soaked in $2 \mathrm{ml}$ petroleum ether (Sigma-Aldrich) for 5 days at room temperature to extract the body fat from the ant workers. At the end of this time, we carefully decanted the petroleum ether to remove the dissolved fat and dried the samples again for at least 48 hours at $65{ }^{\circ} \mathrm{C}$ over silica gel. Each sample was then weighed again four times. Fat content was estimated as mean dry weight after fat extraction subtracted from mean dry weight before fat extraction. 


\subsubsection{Statistical analysis}

Each experimental plot was assigned a number (Plot ID) which was kept with every count and bait data to be able to trace back every measurement. For analysis purposes, we also assigned a Block ID to each plot pair (one treated, one control). Each count taken or bait placed was furthermore associated with a number (Plant ID/ Bait ID), to be used as identifier for repeated measuring. Similarly for our transects, each sample was given a number (Transect ID), which reflected the relative position of the sample on the corresponding transect.

Statistical analyses were performed in IBM SPSS Statistics 22.00. We analysed the initial conditions of the canopy traffic and recruitment to food sources before the establishment of the pheromone dispensers ( $4^{\text {th }}$ of February), to test if there were any differences in Argentine ant abundance between the plots designated to be treated and the plots designated to be control. We used a Generalized Linear Mixed Effects Model, with the following settings: Ant count (1minute counts, food source counts) as target set to a Poisson loglinear distribution, treatment as fixed effect and Block ID as a random effect.

To investigate the Argentine ants' abundance and its ability to access the vine canopy we used a Generalized Linear Mixed Effect Model with the following parameters: Block ID and Plant ID as the subject variable, time $\left(13^{\text {th }}, 18^{\text {th }}, 27^{\text {th }}\right.$ February, $7^{\text {th }}, 12^{\text {th }}, 19^{\text {th }}$ and $25^{\text {th }}$ March) as the repeated messure variable, 1-minute counts as the target set to a Poisson loglinear distribution and treatment as fixed factor. Block ID was treated as a random factor.

To assess the Argentine Ants ability to locate and recruit to food sources within the vine canopy we used a Generalized Linear Mixed Effect Model with the following parameters: Block ID and Bait ID as the subject variable food source counts as the target set to a Poisson loglinear distribution and treatment as fixed factor. Block ID was treated as a random factor.

To compare the initial spatial distribution of Argentine ants along transects between treated and untreated plots we used a General Estimating Equation as a Poisson loglinear model 


\section{Effects of reduced foraging success on an invasive ant}

with the following parameters: Transect ID as the subject variable, Transect Position (Spatial Position of the vine on the transect) as the within-subject variable, 1-minute counts as the dependent variable and treatment as factor.

To analyse potential impacts of the pheromone treatment on nest fitness, we used a General Linear Model with the following settings: Ant fat content as dependent variable, treatment as fixed factor and Block ID as a random factor.

\subsection{Results}

\subsubsection{Canopy Traffic.}

Our first aim in this study was to reduce the Argentine ants' abundance and its ability to access the vine canopy, in treated plots. We found Argentine ant activity to be significantly reduced in treated plots for the whole duration of the trial period, compared to the control plotsGLMM: $\mathrm{SE}=0.135, \mathrm{t}=-11.775, \mathrm{p}<0.001)$, with mean worker counts dropping about $89 \%$ from control plots. The random factor Block ID did not contribute significantly to the model (GLMM: $\mathrm{SE}=0.030, \mathrm{Z}=0.878, \mathrm{p}=0.380)$. Argentine ants in untreated plots often formed continuously streaming trails, sometimes covering the complete trunk/vine. While we are unclear what triggered it, the differences between untreated and treated plots became particularly apparent during a period of heightened activity at mid-summer (end of February and the beginning of March), where a maximum of 96 ants could be counted on a single vine in an untreated plot within one minute (Fig. 5.2). 


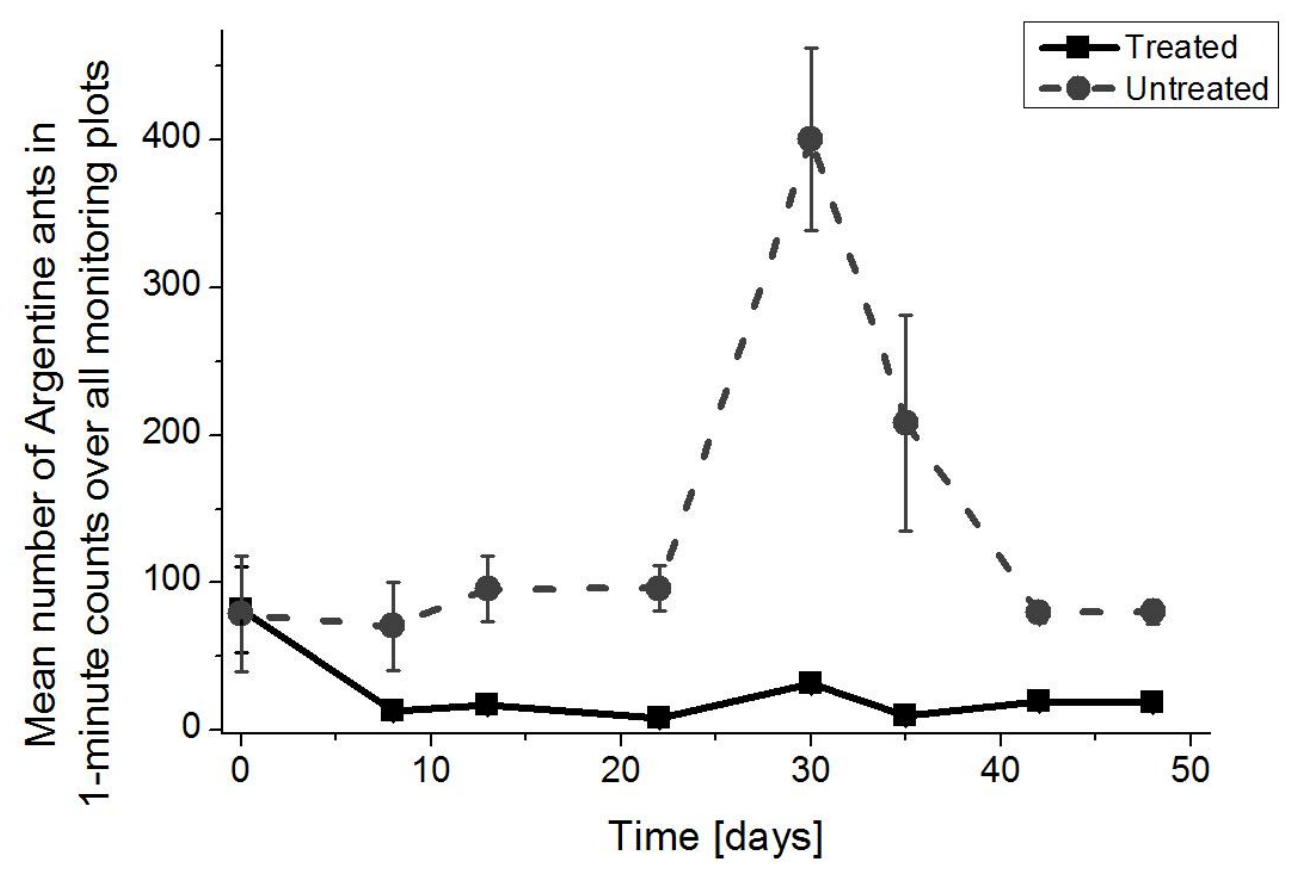

Figure 5.2: Mean $( \pm$ SEM) numbers of Argentine ants recorded during 1-minute counts in the canopy of grapevines in treated and untreated monitoring plots. Assessments were undertaken between $4^{\text {th }}$ February (before pheromone treatment) and $25^{\text {th }}$ March 2014 (with $n=30$ per plot and monitoring interval).

Continuous ant trails were never observed in treated plots. At numerous occasions during our counts, we observed individual Argentine ant workers inside treated plots behaving, in what we interpreted to be a "disorientated" manner, for example walking up $10-20 \mathrm{~cm}$ along the trunk, then standing still, antennating at its surroundings and subsequently turning around to walk back down again only to stop near the base and repeat the process. At other times individuals would continuously run in small circles on the side of the trunk. These behaviours were observed for up to 10 minutes without any changes. An increase in activity simultanously to the one in untreated plots, was observed in treated plots during the same time period, it was however, only a comparatively small increase. 


\section{Effects of reduced foraging success on an invasive ant}

\subsubsection{Food source recruitment.}

Our second aim was to assessed the Argentine Ants ability to locate and recruit to randomly placed food sources within the vine canopy in order to evaluate the impact of the treatment on their chances to tend mealybugs. Our results showed a significant reduction of the number of Argentine ant workers recruited to randomly placed food sources within treated plots compared with untreated plots (GLMM: $\mathrm{SE}=0.313, \mathrm{t}=-7.941, \mathrm{p}<0.001)$, with mean worker counts at baits dropping by an average of $81 \%$. Again, the random factor Block ID did not significantly contribute to the model (GLMM: $\mathrm{SE}=0.129, \mathrm{Z}=0.439, \mathrm{p}=0.661)$. As with the 1-minute counts, we observed a heightened ant activity between the end of February and the beginning of March around food sources in untreated plots, with a smaller spike in the treated plots (Fig. 5.3).

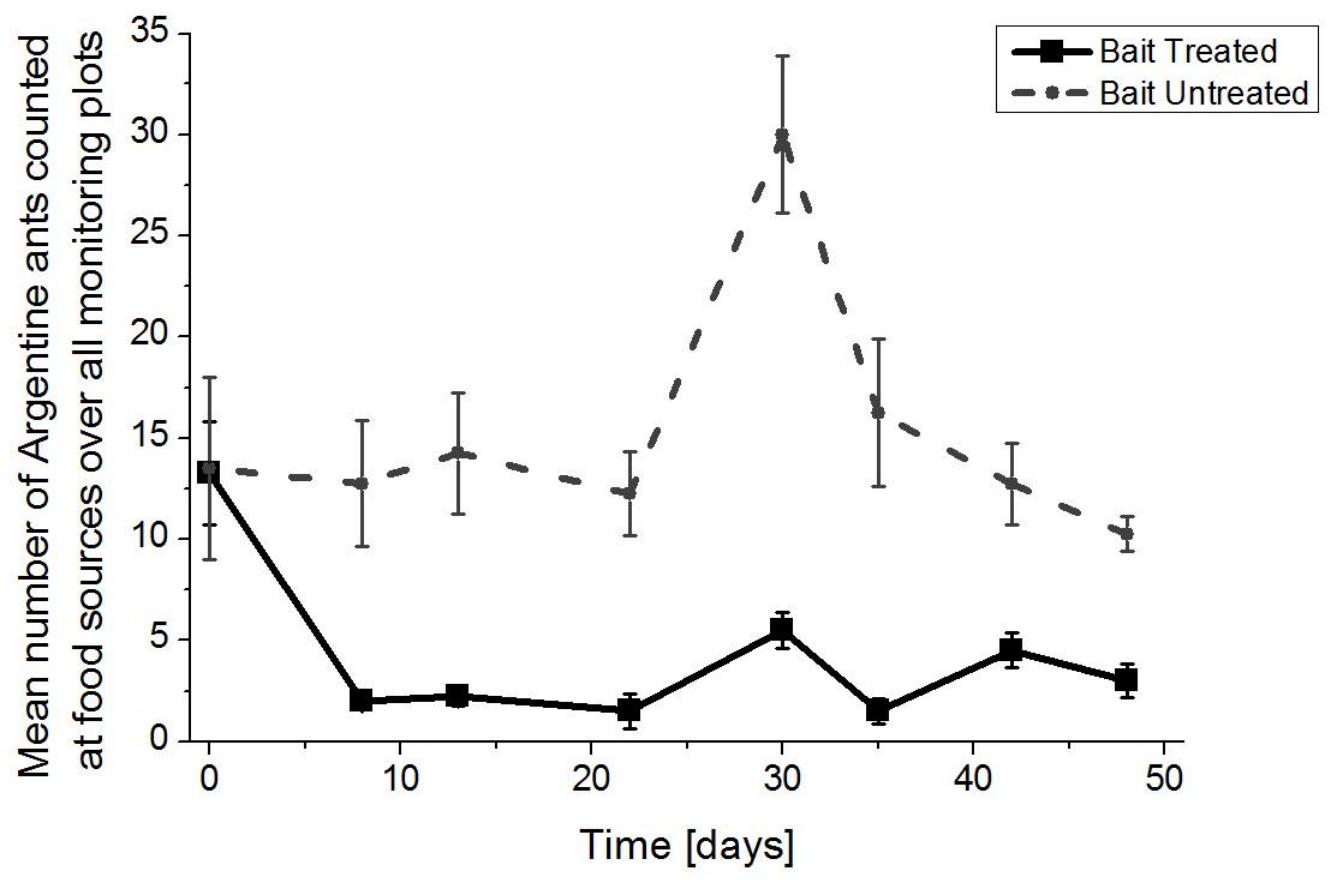

Figure 5.3: Mean $( \pm$ SEM) numbers of Argentine ants recorded at randomly placed food sources in the canopy of grapevines after 1 hour in treated and untreated monitoring plots. Assessments were undertaken between $4^{\text {th }}$ February (before pheromone treatment) and $25^{\text {th }}$ March 2014 (with $n=4$ per plot and monitoring interval). 


\section{Effects of reduced foraging success on an invasive ant}

\subsubsection{Edge Effects.}

Here, our aim was to investigate the spatial distribution of Argentine ants towards and beyond the boundaries of the pheromone treated plots in order to achieve a better understanding of the range of the pheromone effects. We found no difference in the initial distribution of Argentine ants along transects (GEE: $\mathrm{B}=-0.334$; Wald Chi-Square $=2.55 ; \mathrm{df}=1 ; \mathrm{p}=0.110$ ) between plots designated to be treated and plots designated to be control, prior to the establishment of the trial. Over the duration of the experiment, the spatial distribution alongside the transects in untreated plots remained relatively continuous. Argentine ant activity increased by $301 \%$ at a distance of approximately $3.2 \mathrm{~m}$ beyond the last counts within the treated plot (Fig. 5.4). Subsequent increases were another $180.5 \%$ at $6.4 \mathrm{~m}$ and an additional $108 \%$ at 9.6 m. However, it should be noted that despite this strong increase, this activity only made up 56.4, 60 and finally $90.1 \%$ of the activity found around the borders of untreated trials. Pooling the data of all treated transects allowed us to fit a sigmoid function describing the increase of Argentine ant activity relative to the one in untreated plots $\left(y=215.926 /\left(1+\mathrm{e}^{(-0.205 \times(\mathrm{x}-24.246)}\right)\right.$; $\mathrm{R}^{2}=0.852$ ). Solving this fitted equation for the distance at which Argentine ant activity reaches $50 \%$ relative to untreated plot provides an estimate of the "half-life distance" of the pheromone effect. This point would be at approximately $18.4 \mathrm{~m}$ from the centre of the plot, which is a distance of 2.4 meters away from the last pheromone dispenser. 


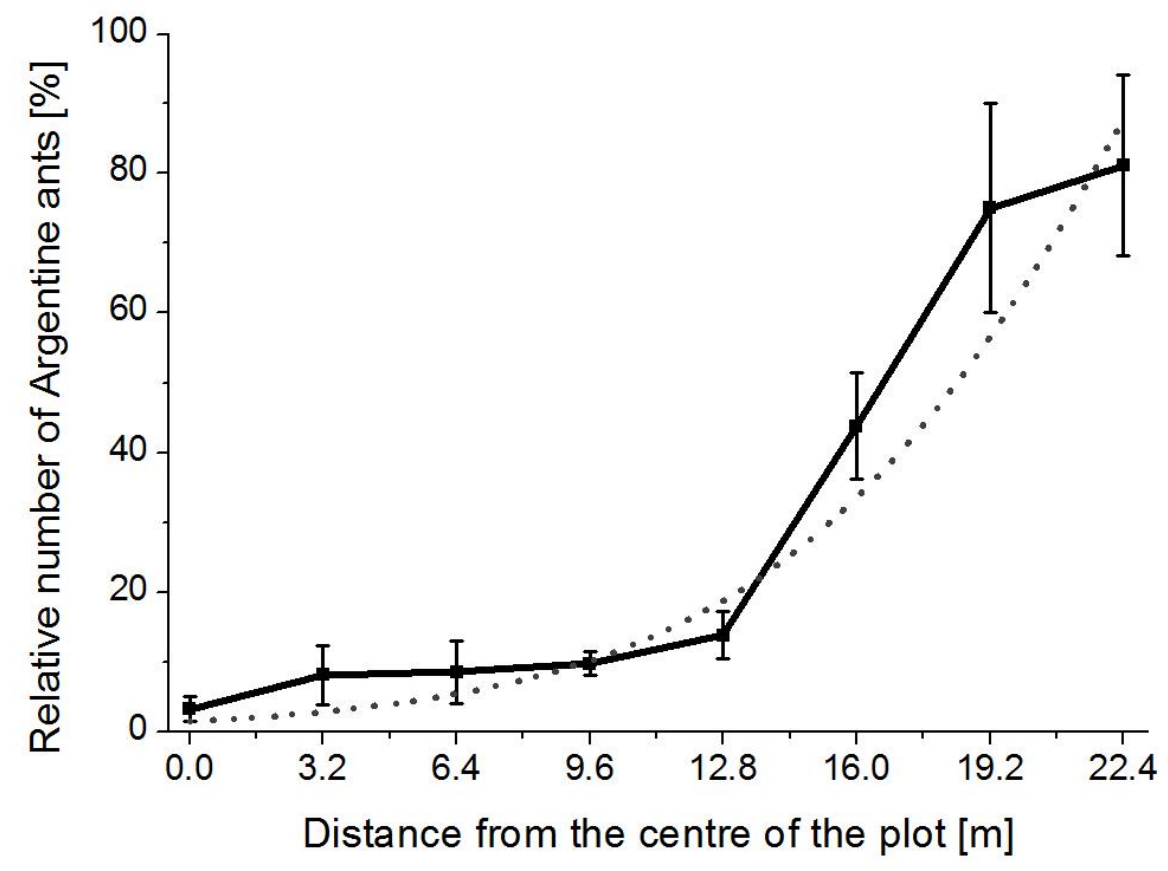

Figure 5.4: Argentine ant activity along transects. Mean \% ( \pm SEM) of Argentine ants recorded during 1 -minute counts along transects through treated monitoring plots, relative to the mean number $(10.27 \pm 1.15)$ of Argentine ants counted during 1-minute counts along transects through untreated monitoring plots. The x-Axis represents the distance from the centre of the plot in meters, with the edge of the monitoring plot after the 6.4 meter mark and the edge of the treated plot, where the last dispensers were located, after the 12.8 meter mark. The dotted line represents a fitted curve with the function $y=215.926 /\left(1+\mathrm{e}^{(-0.205 \times(\mathrm{x}-24.246)}\right)$. Assessments were undertaken between $4^{\text {th }}$ February (before pheromone treatment) and $25^{\text {th }}$ March 2014 (with $n=15$ per plot and monitoring interval).

\subsubsection{Fat analysis.}

We used the body fat content of ant workers as a surrogate measurement to evaluate whether the impaired foraging activity of Argentine ants translates into a measurable fitness effect in nests within the area of effect of the pheromone treatment. We found a significant weight difference between the mean amount of extracted fat from ant samples taken from untreated and treated plots at the end of our trial duration (GLM: $\mathrm{df}=1 ; \mathrm{F}=5.5 ; \mathrm{p}=0.028)$. The mean weight difference of the samples retrieved from untreated plots before and after the fat extraction was $9.62 \mathrm{mg} \pm 1.09 \mathrm{mg}$, while the difference found in treated plots was $6.57 \mathrm{mg}$ $\pm 0.56 \mathrm{mg}$. This result indicates that on average the fat bodies of individual ant workers captured within untreated plots had a weight of $38.48 \mu \mathrm{g}$, while workers from nests within 
treated plots had an average weight of $26.28 \mu \mathrm{g}$, which is a reduction of $31.7 \%$. The random factor Block ID was not significant (GLM: $d f=1 ; F=0.677 ; p=0.575)$.

\subsection{Discussion}

Our study demonstrates that pheromones can successfully disrupt Argentine ant activity and foraging on mature agricultural crops, which results in fitness consequences for the ants. Argentine ant activity was significantly reduced in all treated experimental plots following the addition of pheromone dispensers. Our results showed that it is possible to control Argentine ant activity over large areas in a commercial vineyard over a period of two months, preventing them access to and foraging in the vine canopy.

Our first aim of this study was to reduce the Argentine ants' abundance and its ability to access the vine canopy. Previous experiments have suggested that pheromone dispensers are likely to have the most disruptive effect on Argentine ant trail-following behaviour when placed at the trunk of vine plants, compared to placements in the plant canopy (Westermann et al. 2015). We found Argentine ant activity to be significantly reduced in treated plots, which in our observations appeared to be particularly prominent along the trunks and vines. As has been reported in previous studies (Suckling et al. 2008; Westermann et al. 2014) ants displayed signs which we interpreted to be disorientation. The overload with the synthetic trail pheromone deteriorates trail coherence (Suckling et al. 2008, 2011), which may result in a negative feedback loop as difficulties to follow trails leads to less workers reinforcing the trails, which makes them even more difficult to follow. It also complicates the establishment of new trails for individual workers, as other workers can't easily detect their trail, while the scouts themselves, possibly can't even detect their own trail to return. 


\section{Effects of reduced foraging success on an invasive ant}

We aimed to assess the ability of Argentine Ants to locate and recruit to randomly placed food sources within the vine canopy, in order to estimate the likely impact of the treatment on their chances to tend to mealybugs. As individual Argentine ant workers scout the environment and discover food sources, they are usually able to quickly recruit large numbers of nest mates to maximise the exploitation of a food source (Deneubourg et al. 1990; Human \& Gordon 1996; Holway 1999; Flanagan et al. 2013). Our results showed that Argentine ants experienced significant difficulties in finding and recruiting high numbers of workers to our food sources in treated compared with untreated plots. This is potentially due to three factors. Firstly there are likely to be fewer individuals scouting the different parts of the plant, due to the reduced general traffic, thereby reducing the likelihood of workers finding the food source. Secondly, if an individual discovers a food source, it would usually recruit directly from the nearest active trail (Flanagan et al. 2013), thereby rapidly diverting workers to exploit the resource. However, due to the trail disruption, almost no trails are formed, which leaves the scout no other option then running all the way back to the nest to recruit other individuals to the food source from there (Franks \& Richardson 2006; Fernandez \& Deneubourg 2011) which is likely to increases recruitment time substantially. Lastly, recruitment is likely to be limited by the pheromone, by directly preventing the formation of a trail to the food source.

While ants could still use visual cues and/or sense of gravity (Khuong et al. 2013) to navigate up and down the plant and around the branches, our data in combination with other studies, indicate that pheromone management may significantly reduce the ability of Argentine ants to recruit to food sources like aphids, scale insects or mealy bugs, leaving these honeydew producers more vulnerable to biological control agents like parasitoids (Phillips \& Sherk 1991; Mgocheki \& Addison 2010). While previous studies have shown that the trail disruption may also provide opportunities for other ant community species (Westermann et al. 2014), we did not observe other species recruiting to baits during this trial. One likely explanation is that there 
weren't other ant species in the immediate vicinity to take advantage of the food sources, as the Argentine ant has been dominant in the area for several years. The only other ant species, which was encountered approximately $400 \mathrm{~m}$ away from the experimental site, was Pheidole rugosula which, while very active on the ground on that location, was not observed to access grapevines, leaving the Argentine ant to forage in the canopy unchallenged.

We also wanted to investigate the spatial distribution of Argentine ants towards and beyond the boundaries of the pheromone treated plots in order to achieve a better understanding of the range of the pheromone effects. Interestingly, our data suggests that the provision of the pheromone did influence the population beyond its original deployment, but the $50 \%$ effective activity was only for a relatively short distance of up to $2.4 \mathrm{~m}$. While it has been previously found (Suckling et al. 2008) that the impact of pheromones on Argentine ants are of short duration and they recover quickly once outside the area of effect, it was not entirely clear how far the effect of the pheromone might extend. Our results indicate that a continuous application of the pheromone may be necessary to provide reliable disruption, as the effect quickly decreased over distance.

Lastly, we used the body fat content of ant workers as a surrogate measurement to evaluate whether the impaired foraging activity of Argentine ants translates into a measurable fitness effect in nests, within the area of effect of the pheromone treatment. We found a significant difference in the amount of body fat, between workers collected from treated and untreated plots. This indicates that our treatments had an impact on the foraging success over the whole duration of the trial and starved the ants of food resources. It also shows that it may be possible to eradicate Argentine ants by continuously denying them access to food sources and eventually lead them to the point of colony collapse. However ants in treated areas did retain some body fat, it could therefore be speculated that the ants may have still been able to forage to some degree. As our plots were of limited size and the Argentine ant is known to 


\section{Effects of reduced foraging success on an invasive ant}

forage over distances of more than $50 \mathrm{~m}$ (Vega \& Rust 2001; Cooper et al. 2008), a possible explanation is that workers from treated plots either found some food inside the treated areas or were able to forage outside of the treated plots and return. It is also possible that the ants kept a number of scale insects in underground tunnels on roots of grapevine plants (Daane et al. 2012). This could have provided a food source which would not have been affected by the pheromone. However, only treatment of significantly larger areas would allow to separate those effects.

We have calculated the potential cost of the presented treatment to allow evaluation of its feasibility. We deployed $\sim 448 \mathrm{~m}$ of pheromone dispensers per plot which contained an amount of $168 \mathrm{~g}$ per plot or $187.5 \mathrm{mg} / \mathrm{m}^{2}$. With this setup and an approximate cost of US\$ 50 per $100 \mathrm{~m}$ of pheromone dispenser $\left(=\mathrm{US} \$ 0.5 \times \mathrm{m}^{-1}\right)$, we calculated that $5000 \mathrm{~m}$ of rope dispenser would be needed on 1 hectare to reach similar pheromone concentrations, resulting in a material cost of US\$ 2500 (calculation excludes the cost of labour to deploy the pheromone). Therefore the cost can also be stated as $13.3 \mathrm{US} \$ / \mathrm{mg} / \mathrm{ha}$. The optimal concentration of trail pheromone required for suppression of the Argentine ant on a wide scale area and the potential management benefits still require further investigation. Particularly the actual effects on mealybug, parasitoid populations and crop quality need comparison with other management methods, to properly assess economic cost/benefits. However, it is apparent that the application of the pheromone as used in this study cannot be considered feasible, as insecticide treatments which aim to control mealybugs are therefore comparable, if this was the main aim of the treatment, have an estimated cost of about 120 US\$ per hectare (Bell V., personal communication). Further adjustments and optimizations to the delivery mechanism and production are required to allow a more cost effective deployment.

Our results showed that it is possible to control Argentine ant activity over large areas in a commercial vineyard over a period of two months and preventing them access to and 
foraging in the vine canopy. Target specific management options like pheromones are being investigated to reduce the negative effects of anti-pest treatments on the environment (Witzgall et al. 2010) and have shown a growing potential for integrated pest management over pesticides (Zehnder et al. 2007; Witzgall et al. 2010; Brockerhoff et al. 2012). This deprives mealybugs of their protection (Mgocheki \& Addison 2010), while at the same time leaving Argentine ants without access to honey dew, which is an important factor driving their spread (Shik \& Silverman 2013). Further research could focus on the effects of this treatment on mealybug population or arthropod communities to more accurately calculate the economic and ecological benefits of this approach. Furthermore, improving upon the formula of the pheromone by identifying additional components (Choe et al. 2012), to provide complete disruptions with lower concentrations, and optimizing the delivery mechanism to allow easier, yet similarly resistant to water and wind, deployment of the pheromone, may greatly increase the benefitcost-ratio of this management method. 



\section{Chapter 6: General Discussion}

\subsection{Summary}

Chemical communication is an important factor in the ecology of many animal species, but is of particular importance for social insects. Chemical communication may even help to explain why certain species resist the impact of an invasive species while others fail to do so. In this thesis I investigated the effects of natural and synthetic semiochemicals on Argentine ants. My overall aim was to gain a better understanding of the influences of semiochemicals on interactions between Argentine ants and other ant species, and to determine whether pheromone recruitment mechanisms which control ant communities, can be used as tools to manage Argentine ants. I investigated four factors contributing to this aim. 1) Different venom utilization methods and venom toxicity of four Monomorium species in aggressive interactions with the invasive Argentine ant; 2) How the disruption of foraging via the use of synthetic trail pheromones reduces the competitive ability of the invasive Argentine ant and how this disruption could benefit other community species to increase their own foraging activity; 3) By experimenting with placements of synthetic pheromone dispensers at different locations around grapevines, I investigated how such dispensers could be used as a management technique in a commercial setting and which arrangement is the most likely to prevent the Argentine ants' access to vine canopy; and 4) I tested the effects of the pheromone disruption, on the ants foraging success within the vine canopy and used the body fat content of ant workers as a surrogate measurement to evaluate whether the impaired foraging activity of Argentine ants translates into a measurable fitness effect in nests, within the area of effect of the pheromone treatment. 


\section{General Discussion}

In Chapter 2, I found the toxicity of venom to be significantly higher in Monomorium species co-occurring with the invasive Argentine ants compared to the toxicity of the species which do not, but found no correlation between venom toxicity and Monomorium survival in laboratory arenas. Venom utilization had a significant effect on Monomorium mortality in $M$. antipodum where Gaster flagging was $81 \%$ higher in trials which resulted in high mortality. Aggression towards Argentine ants was found to be positively correlated with an increase in M. antarcticum and $M$. antipodum mortality rates.

I showed that Argentine ants' foraging success could be reduced with a synthetic trail pheromone application (Chapter 3). The reduced foraging success of Argentine ants also had a positive effect on the foraging of three resident species. I found behavioural variation provided an explanation for observed differences in foraging success of these resident species and the relative increase in their foraging if the competitive ability as the Argentine ant's foraging success was decreased. I concluded that the mechanism for the observed increase in resource acquisition of resident species appeared to be the decrease in aggressive behaviour displayed by the Argentine ant, which allowed the other ants to forage with significantly reduced harassment.

Chapter 4 investigated if it is possible to suppress Argentine ants in grape vines using ant pheromone dispensers, and what the most effective placement of such dispensers would be. I observed a significant decrease in Argentine ant activity in the canopy under the influence of synthetic pheromone dispensers placed at ground level compared with untreated controls. However, placing dispensers only in the canopy did not reduce the numbers of ants within the canopy compared with untreated controls.

During my field experiment in a vineyard (Chapter 5) I found Argentine ant activity to be significantly reduced at randomly placed food sources within plots treated with the synthetic 
trail pheromone. I was also able to show that there may be an effect on ant fitness, by comparing the body fat content of workers in treated and untreated areas. Furthermore, I calculated the approximate distance of the pheromone effect, but showed that this method may currently not be cost-effective in an agricultural environment.

\subsection{Synthesis}

Chemical communication is an important aspect in many animal interactions, particularly in insects. The results of my trials with venom utilization and ant survival in arena competitions (Chapter 2) have shown that at least some ants, in my case M. antipodum, can benefit from an adaptive utilization of venom, which is concurrent with a range of previous studies in ants (Sorrells et al. 2011; Lebrun et al. 2014). In my Introduction (Chapter 1) I asked "what allows one species to resist the impact of an invasive species when others fail to do so?" The possible answers probably involve combinations from a range of factors such as size, physical strength, utilization of semiochemicals (Chapter 2), behavioural traits (Chapter 3), reproductive capabilities or foraging efficiency (Chapters 3-5), likely with different possible peak solutions in a conceivable data landscape. Such solutions may consist of subordinate species, with little to no aggression display or usage of repellent strategies, active avoidance behaviour and possibly divergent food niches or opportunistic foraging strategies. An example for this may be M. antipodum (Chapter 2) or O. glaber (Chapter 3). Other solutions to this problem may include sub-dominant or dominant species which become sub-dominant after the establishment of an invasive species and are able to illicit avoidance behaviour in the invader, as occasionally observed with Argentine ants when meeting M. antarcticum (Chapter 3), or defending themselves through physical strength or venom application (Chapter $2 \& 3$ ), thereby allowing co-occurrence of the species. 


\section{General Discussion}

Other factors which may contribute to the co-occurrence patterns between species, could involve aspects which are currently not possible to predict. For instance, LeBrun et al. (2014) found that the Tawny Crazy ant (Nylanderia fulva) is capable of detoxifying venom of the Red Imported Fire ant (Solenopsis invicta). They further speculated that this behaviour may have evolved in their common native range in South America. The Tawny Crazy ant also utilizes this behaviour to defend itself successfully against other ants. It is conceivable, that other ant species may also have evolved particular defensive or optimized venom strategies (Morgenstern \& King 2013), which are yet undiscovered but will allow them to resist a particular invasive species.

While I found that the use of synthetic pheromones for the control of Argentine ants may not be economically feasible (Chapter 5) in its current form, it has nonetheless been shown to be a promising approach for the management of invasive ants. The detrimental effect on foraging I observed (Chapters 3 and 5) in combination with the reduced body fat contents measured in workers taken from nests after two months of treatment, suggest that a pheromone treatment could be suitable for long term management or may even be useful to support eradication programs. The negative effects on Argentine ants could be intensified by the fact that resident ant species have been observed to take advantage of the reduced foraging of Argentine ants (Chapter 3) and can increase their own success to a varying degree. Interestingly, $M$. antarcticum which strongly benefitted from the pheromone application was also found to be able to withstand the Argentine ant during my arena experiments (Chapter 2). This result could suggests that ant species which have been previously categorized as subdominant in the ant hierarchy (Vepsäläinen \& Pisarski 1982; Savolainen \& Vepsäläinen 1989) may benefit the most from this kind of foraging disruption.

While still mostly speculative at this point, I would propose that the suppression or reduction of a competitive advantage of a dominant invasive species, in this case through means 
of a pheromone treatment, may provide support to induce restorative effect on the community system from an ant invasion, by introducing a positive feedback cycle (Fig. 6.1). Herein, the invasive ants experience reduced foraging, resulting in less available biomass within the colony (supported by the reduced worker body fat measured in Chapter 5). This would be expected to lead to a reduction in egg production, surviving larvae and/or emerging workers. In combination with the decrease in aggression towards other species (Chapter 3), this would further decrease their ability to dominate other ants and monopolize food sources. This ability to monopolize food, has been described as an important factor among invasive ant species (Holway 1999; Barton et al. 2001; Holway et al. 2002a; Ricciardi et al. 2013) and has therefore been considered an important competitive advantage and one of the main driving forces in ant invasions. Conversely, the reduction in aggression towards competing community species enables these species to increase their food intake, which could increase their worker production, further enabling them to resist the Argentine ant. However, this proposed mechanism would depend on certain conditions, such as the presence of at least one ant community species (preferably native) which actively competes with the Argentine ant through interference and/or exploitation competition. 


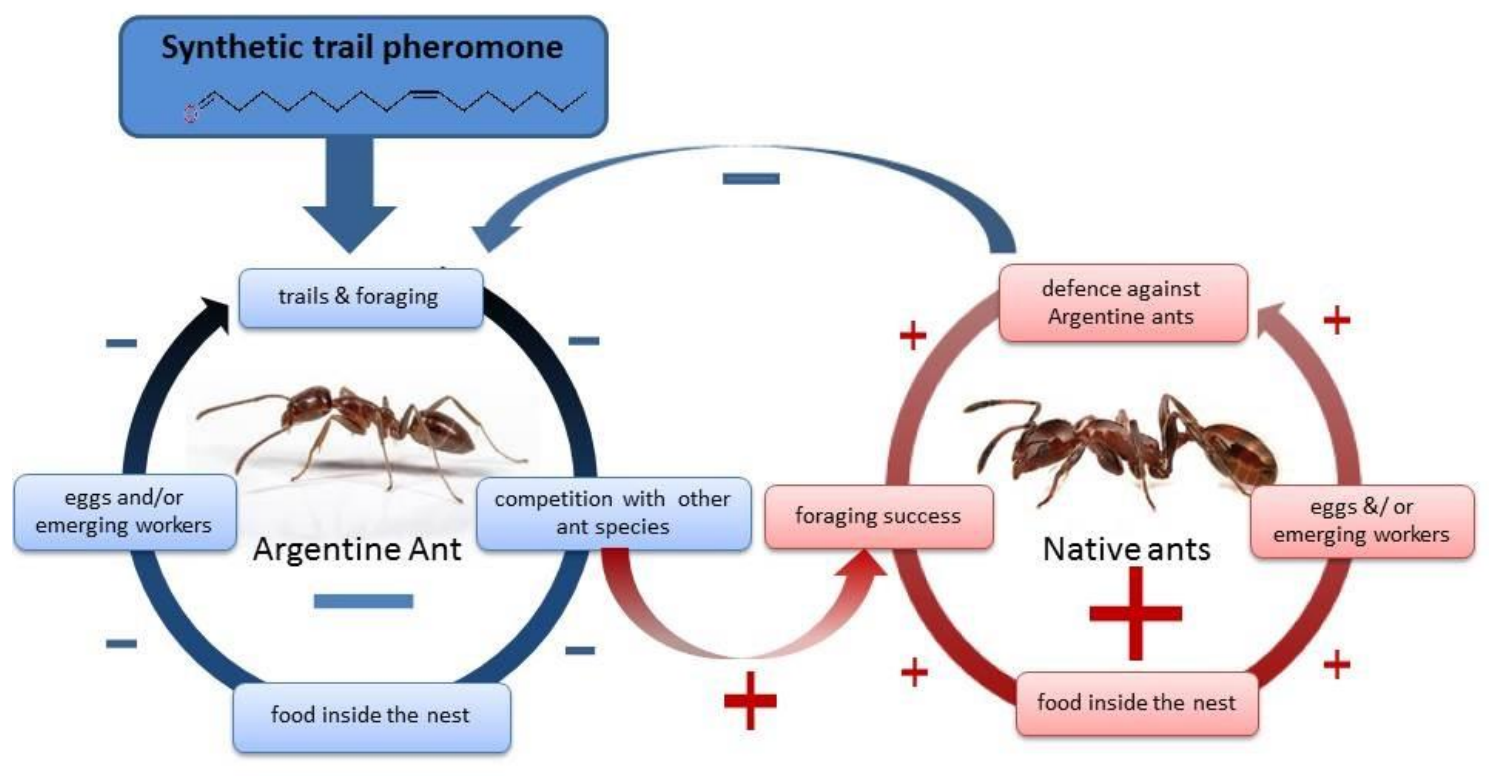

Figure 6.1: Proposed feedback cycle initiated and supported by the application of synthetic Argentine ant trail pheromone in an environment with at least one sub dominant ant community species competing with the Argentine ant for food sources. Minus-signs represent a negative feedback i.e. a reduction of the following descriptor by the previous one for instance "reduction of trails and foraging of the Argentine ant by synthetic pheromone". Plus-signs represent a positive feedback i.e. an increase of the following descriptor by the previous one in the same manner.

Picture credit: Argentine ant by Pedro Moura Pinheiro (https://www.flickr.com/photos/pedromourapinheiro/5838641363) under the CC BY-NC-SA 2.0 License. Monomorium antarcticum by George Novak.

Although there have been reports of invasive species populations collapsing after successful establishment after a certain time (Simberloff \& Gibbons 2004; Cooling et al. 2012), it is currently not possible to predict to which species this will happen or explain the mechanisms behind these collapses, therefore making a 'sit and wait' management approach a dangerous gamble. With the rise in international trading (Kaluza et al. 2010), further introductions of non-native species are a problem which is only likely to grow, despite the increasing awareness and biosecurity efforts. While some invasive ant species might only be passengers of human disturbance (King \& Tschinkel 2006, 2008; King, Tschinkel \& Ross 
2009) it is still desirable to control their spread, even if only for the impacts they have on human wellbeing (Pejchar \& Mooney 2009). A number of invasive ants, however, also expand into natural environments (Holway et al. 2002a; O’Dowd et al. 2003; Bos et al. 2008). While not economically feasible in an agricultural environment in its current form, pheromone management of invasive ants in more natural environments may be a desirable option, as largescale insecticide deployments affect a large number of arthropods indiscriminately. While my research provides a proof of concept, further improvements to the efficacy of the pheromone may be desirable, before dispersion in natural environments can be considered.

The concept of lowering a species dominance in an ecological system, by specifically targeting and reducing a particular trait which gives it a competitive advantage over others (Chapter 3), may be transferable to other species. The exploitation of sex pheromones has been investigated for many years, and has resulted in a variety of applications (Nesbitt et al. 1975; Witzgall et al. 2010; Brockerhoff et al. 2012). The use of sex pheromones has recently gained particular interest for its possibilities to manage invasive arthropods such as the Asian long horned beetle (Anoplophora glabripennis M.) as well as a variety of other forest damaging beetles and insect pests (Brockerhoff et al. 2006; El-Sayed et al. 2006, 2009; Haack et al. 2010). However, the exploitation of other pheromone systems to change behaviours or species interactions, such as with influencing mealy bugs by interfering with the ants that tend to them (Chapter 4,5 ) or supporting native species by lowering the competitive ability of an invader (Chapter 3), is only slowly developing.

For the management of ants, it is conceivable that different pheromones could be used to achieve other outcomes, besides impacting foraging efficiency, which may result in interesting effects, such as the dispersion of propaganda pheromones which can be found in certain slave making ants (Lenoir et al. 2001). Propaganda pheromones trigger infighting within an ant colony of a specific species and could therefore be used to create disturbance in 


\section{General Discussion}

an invasive ant species to the degree where its workers may kill each other (Akino 2008). The utilization of trail pheromones might be an interesting line of research for termite pest species, which rely on a similar communication system and might be disrupted in a comparable fashion (Stuart 1967; Matsumura, Coppel \& Tai 1968; Birch et al. 1972; Traniello 1982; Hall \& Traniello 1985). Pheromone disruption might also be transferred to a certain extent to other invasive Hymenoptera, including wasps (Ruther et al. 2002; Steinmetz, Schmolz \& Ruther 2003).

Altering species fitness with the aim of changing its abundance within an environment has been conducted to some extent in other systems. For example, genetically altered mosquitoes which possess increased resistance to Malaria (Plasmodium falciparum) thereby reproducing more successfully and outcompete natural mosquito populations (Marrelli et al. 2007). Other opportunities to change the interactions in biological systems towards desirable outcomes are likely to be found through ongoing research. However, all large scale applications of any pheromone or alterations of the equilibrium between competing species by interfering with specific aspects of one species by whatever means, must necessarily be considered a form of ecosystem-engineering. Therefore a careful risk assessment is warranted to evaluate possible side effects.

\subsection{Constraints and further research}

During my experiments I faced several constraints which prevented me from further expanding certain experiments and data chapters, therefore leaving some interesting unexplored avenues for additional research. Some of these research directions would require longer term research, access to overseas field sites and samples or particular constellations on field sites which, despite my best efforts, have not been met during the course of my studies. 
In Chapter 2, I investigated the effects of venom toxicity on interactions between Monomorium species and the Argentine ant. As only four Monomorium species are present in New Zealand and were available for experiments, my work was constrained to those four species. Further experiments would have required the introduction of additional Monomorium species to New Zealand or access to overseas sites. While I was unable to establish any correlation between the factors 'Venom toxicity' and 'survival in competitions', it is possible that, if the study were to be repeated with a larger diversity of ants and additional factors like body size were to be included in the analysis, the results may yet show a more profound impact of venom toxicity. Similar experiments could also be performed with other invasive species, like the Yellow Crazy Ant (Anoplolepis gracilipes) or the Red Imported Fire Ant (Solenopsis invicta) to explore if venom toxicity may be a factor which allows a more universal explanation of why certain ants resist certain invaders. This idea is particularly appealing, since LeBrun, Jones \& Gilbert (2014) showed that ants might be able to detoxify the venoms of another ant species with their own. The identification of the natural ant venom components and their synthesis could also be considered a limiting factor to a certain degree, as only small quantities of the synthetic venoms were available. Limited amounts of synthesized venom may also be a constraint in further experiments, as the venoms of additional species to be tested also first need to be identified and synthesized in sufficient quantities.

During the preliminary samplings for Chapter 3, I was only able to utilize a limited number of locations, where I found other ant species to be attracted to the baits at the same time as Argentine ants. It would have been beneficial to have access to additional locations and/or other ant community species to expand the work to some extent. Perhaps the establishment of a global dominance hierarchy network structure in ant communities could help to provide a better overview over the factors which govern these interactions. However, this would require an enormous amount of experimental data and the creation of a large 


\section{General Discussion}

database, which could be analysed for behavioural traits or physical characteristics to better understand which species outcompete which and under what circumstances. At the very least this experiment would require testing of a large number of ant species in standardized aggression tests in the field or in laboratory environments, as well as measuring physical characteristics and behaviours.

I originally intended to examine whether the synthetic pheromone can be used to alter the invasion front of the Argentine ant and move the boundary in favour of a competing species for Chapter 4. Such work would expand on my findings from Chapter 3 on interspecific competition under the influence of synthetic trail pheromone and further examine factors that may contribute to invasion success. In November/December 2012 Dr. Vaughn Bell and I had identified an invasion front of the Argentine ant, bordering an area which was most dominantly being occupied by Pheidole rugosula (Forel), in the Hawkes Bay area. We placed a transect of alternating four treated and four untreated plots along the identified invasion border, with each plot encompassing 3 rows and 2 bays $(6 \mathrm{~m} \times 16 \mathrm{~m})$. Treated plots where sprayed with a liquid formula of $1.406 \mathrm{mg} / \mathrm{m}^{2}(\mathrm{Z})-9-$ Hexadecanal on the vine canopy and approximately $0.5 \mathrm{~m}$ on the ground on either side of the grapevines every second week between $4^{\text {th }}$ December 2012 and $15^{\text {th }}$ March 2013, with pitfall trapping undertaken over 48 hours on four occasions and 1-minute ant counts being conducted by Dr. Vaughn Bell. Additionally leaf assessments of mealy bug activities were undertaken to investigate the impacts of reduced Argentine ant activity, if the invasion front were to be pushed back during the experiment, as the pheromone had been hypothesized to give a competitive advantage to Pheidole rugosula. However, Argentine ant abundance turned out to be very patchily distributed, with almost no Argentine ants appearing in the canopy of treated and untreated plots, making comparisons impossible. Furthermore, while baiting on the ground appeared to indicate that $P$. rugosula could be superior at baits, we found no indication of $P$. rugosula ever accessing the vine canopy, leaving it difficult to 
evaluate if actual competition between those species existed and to what extent. Lastly, we were unable to assess the effect duration of the sprayed pheromone, which was likely strongly influenced by rain, wind and heat (as there was no resupply once the sprayed application was evaporated). This result eventually led us to the use of rope pheromone dispensers in the experimental design of Chapter 4, which were more likely to have a more continuous release rate. Therefore, despite all of the before mentioned effort, the project had to be abandoned in favour of a more agricultural applied setup (Chapter 4) when we were able to secure access to pheromone dispensers and young vines which could be used in an area with increased Argentine ant abundance. This outcome leaves an interesting and unexplored opportunity for future research to investigate if and to what extent an invasion front could be manipulated by using synthetic pheromones in favour of other ant community species which usually do not cooccur with an invader due to competitive exclusion.

In the design of Chapter 4, which developed to replace the originally planned experiment, the experimental setup could have been optimized, if access to other field sites would have been available and we would have known the exact area of effect of the pheromone dispensers from the beginning. The potted vines could have been placed further apart, which would have excluded any potential of interference between vines treatments due to pheromone residue. Furthermore, a better strategy to simultaneously investigate the effects on the mealy bug population we introduced on the vines would have enhanced the experiment.

Additional sampling was undertaken for Chapter 5 in order to to precisely assess the effects of reduced Argentine ant activity on mealy bug populations and biological control agents which were hypothesized to benefit from the pheromone treatment. These sampling, however, did not yield sufficient information to provide informative results. Specifically, we undertook numerous leaf assessments of 20 leaves per plot to investigate whether more mealy bugs would be found in untreated plots, compared to treated plots. Additionally, we planned to 


\section{General Discussion}

keep the sampled mealy bugs alive to determine if parasitoids would emerge and evaluate if differences in the success of infecting them could be found between treated and untreated plots. We also had pheromone traps in place in each plot to catch parasitoids to see if there is any effect on parasitoid populations due to the decreased ant traffic. Lastly, it may have even been possible to monitor new infections of Grapevine leafroll-associated virus 3 (GLRaV-3) in the year after the treatment and compare new infection rates in treated and untreated plots. Unfortunately, all of these assessments did not lead to any results, as mealy bug populations were simply too small and no parasitoids were found. It is possible that the insecticide program in operation within the experimental vineyard has reduced mealy bug activity substantially. Consequently, Chapter 5 could have been further expanded, if access to an area without mealybug control and high Argentine ant abundance would have been available. These results leave another opportunity for a future expansion of this study, which would also be highly beneficial in order to assess cost benefits of this treatment.

Lastly, it would be interesting to see if similar substances can be identified for other ant species and these results can be replicated, as for instance has already been shown for the Red Imported Fire ant (Suckling et al. 2012). It would also be essential to improve upon the formula of the pheromone by including additional components (Choe et al. 2012), to provide complete disruptions with lower concentrations, and optimizing the delivery mechanism to allow an easier, yet similarly resistant to water and wind, deployment of the pheromone. Also the cost would have to be significantly reduced to make this approach more feasible. Lastly, it would be essential to undertake tests to determine any potential toxicity or side effects of the pheromone, for instance effects on water- or soil organisms, before any large scale operation can be recommended. 


\section{Conclusions}

Chemical communication is an important aspect in the interactions between invasive ant species and the native ant community (Adams \& Traniello 1981; Andersen et al. 1991; Sorrells et al. 2011; Lebrun et al. 2014) and may also be a key factor in the invasion success (Dussutour et al. 2009; Lizon à l'Allemand \& Witte 2010; Flanagan et al. 2013), which can be exploited for management efforts. Understanding the influence chemical interactions in a community have on the overall community structure, has important ramifications for the prediction of the outcomes of ant invasions. While the importance of venom chemistry had been reported previously, not many studies thus far have attempted to disentangle the factors of venom utilization, toxicity and their influence on survival in competitive interactions. Additionally this study offers a proof of concept of how the competitive ability, in this case foraging efficiency, of one otherwise dominant species could be lowered to the advantage of other community members. While the pheromone application may not be economically feasible in its current form, it offers an important insight in how the reduction of foraging, through the disruption of trail finding behaviour, could impact the fitness of an invasive species.

These findings suggest that targeting a specific trait or ability of an invasive species and altering it through an external cause, may be used to control or supress an invasive species, or at least reduce its impact. Ideally, this could support conservation efforts and induce a restorative effect in ecosystems which are impacted by an invasive species 



\section{References}

Abbott, K.L., Greaves, S.N.J., Ritchie, P.A. \& Lester, P.J. (2007) Behaviourally and genetically distinct populations of an invasive ant provide insight into invasion history and impacts on a tropical ant community. Biological Invasions, 9, 453-463.

Adams, E.S. \& Traniello, J.F.A. (1981) Chemical interference competition by Monomorium minimum (Hymenoptera: Formicidae). Oecologia, 51, 265-270.

Akino, T. (2008) Chemical strategies to deal with ants: a review of mimicry, camouflage, propaganda, and phytomimesis by ants (Hymenoptera: Formicidae) and other. Myrmecological News, 11, 173-181.

Albins, M. \& Hixon, M. (2008) Invasive Indo-Pacific lionfish Pterois volitans reduce recruitment of Atlantic coral-reef fishes. Marine Ecology Progress Series, 367, 233-238.

Ali, M.F. \& Morgan, E.D. (1990) Chemical communication in insect communities: a guide to insect pheromones with special emphasis on social insects. Biological Reviews, 65, 227 247.

Alonso, L. \& Vander Meer, R. (2002) Queen primer pheromone affects conspecific fire ant ( Solenopsis invicta ) aggression. Behavioral Ecology and Sociobiology, 51, 122-130.

Andersen, A.N. (1992) Regulation of "momentary" diversity by dominant species in exceptionally rich ant communities of the Australian seasonal tropics. The American Naturalist, 140, 401-420.

Andersen, M.C., Adams, H., Hope, B. \& Powell, M. (2004) Risk assessment for invasive species. Risk Analysis, 24, 787-793.

Andersen, A.N., Blum, M.S. \& Jones, T.H. (1991) Venom alkaloids in Monomorium "rothsteini" (Forel) repel other ants: Is this the secret to success by Monomorium in Australian ant communities? Oecologia, 88, 157-160.

Andersen, A.N. \& Patel, A.D. (1994) Meat ants as dominant members of Australian ant communities: an experimental test of their influence on the foraging success and forager abundance of other species. Oecologia, 98, 15-24.

Aneshansley, D.J., Eisner, T., Widom, J.M. \& Widom, B. (1969) Biochemistry at $100\{$ degrees\}C: Explosive secretory discharge of Bombardier Beetles (Brachinus). Science, 165, 61-63.

Aron, S., Pasteels, J.M. \& Deneubourg, J.L. (1989) Trail-laying behaviour during exploratory recruitment in the Argentine ant, Iridomyrmex humilis (Mayr). Biology of Behaviour, 14, 207-217. 


\section{References}

Atallah, S.S., Gomez, M.I., Fuchs, M.F. \& Martinson, T.E. (2012) Economic impact of grapevine leafroll disease on Vitis vinifera cv. Cabernet franc in Finger Lakes Vineyards of New York. American Journal of Enology and Viticulture, 63, 73-79.

Baltz, D. \& Moyle, P. (1993) Invasion resistance to introduced species by a native assemblage of California stream fishes. Ecological Applications, 3, 246-255.

Barbieri, R.F., Grangier, J. \& Lester, P.J. (2013a) Arrival sequence and diet mediate interspecific competition in an ant community. Insectes Sociaux, 60, 463-473.

Barbieri, R.F., Lester, P.J., Miller, A.S. \& Ryan, K.G. (2013b) A neurotoxic pesticide changes the outcome of aggressive interactions between native and invasive ants. Proceedings of the Royal Society B: Biological Sciences, 280, 20132157.

Barnosky, A.D., Matzke, N., Tomiya, S., Wogan, G.O.U., Swartz, B., Quental, T.B., Marshall, C., McGuire, J.L., Lindsey, E.L., Maguire, K.C., Mersey, B. \& Ferrer, E. a. (2011) Has the Earth's sixth mass extinction already arrived? Nature, 471, 51-57.

Barrows, E. (2011) Animal Behavior Desk Reference: A Dictionary of Animal Behavior, Ecology, and Evolution, 3rd ed. CRC Press.

Barton, K.E., Gordon, D.M. \& Sanders, N.J. (2001) Long-term dynamics of the distribution of the invasive Argentine ant, Linepithema humile, and native ant taxa in northern California. Oecologia, 127, 123-130.

Bauer, J.T. (2012) Invasive species: "back-seat drivers" of ecosystem change? Biological Invasions, 14, 1295-1304.

Belfroid, A.., van Drunen, M., Beek, M.., Schrap, S., van Gestel, C.A. \& van Hattum, B. (1998) Relative risks of transformation products of pesticides for aquatic ecosystems. Science of The Total Environment, 222, 167-183.

Birch, A.J., Brown, W. V., Corrie, J.E.T. \& Moore, B.P. (1972) Neocembrene-A, a termite trail pheromone. Journal of the Chemical Society, Perkin Transactions 1, 0, 2653.

Blackburn, T.M. \& Duncan, R.P. (2001) Determinants of establishment success in introduced birds. Nature, 414, 195-197.

Blacquière, T., Smagghe, G., Van Gestel, C.A.M. \& Mommaerts, V. (2012) Neonicotinoids in bees: A review on concentrations, side-effects and risk assessment. Ecotoxicology, 21, 973-992.

Blancafort, X. \& Gómez, C. (2005) Consequences of the Argentine ant, Linepithema humile (Mayr), invasion on pollination of Euphorbia characias (L.) (Euphorbiaceae). Acta Oecologica, 28, 49-55.

Blight, O., Provost, E., Renucci, M., Tirard, A. \& Orgeas, J. (2010) A native ant armed to limit the spread of the Argentine ant. Biological Invasions, 12, 3785-3793. 
Blum, M.S. (1985) Bioregulators for Pest Control (eds PA Hedin, HG Cutler, BD Hammock, JJ Menn, DE Moreland, and JR Plimmer). American Chemical Society, Washington, D.C.

Blum, M.S., Jones, T.H., Lloyd, H.A., Fales, H.M., Snelling, R.R., Lubin, Y. \& Torres, J. (1985) Poison gland products of Solenopsis and Monomorium. Journal of Entomological Science, 20, 254-257.

Bos, M.M., Tylianakis, J.M., Steffan-Dewenter, I. \& Tscharntke, T. (2008) The invasive Yellow Crazy Ant and the decline of forest ant diversity in Indonesian cacao agroforests. Biological Invasions, 10, 1399-1409.

Bowen-Walker, P., Martin, S. \& Gunn, A. (1999) The transmission of deformed wing virus between honeybees (Apis mellifera L.) by the ectoparasitic mite Varroa jacobsoni Oud. Journal of Invertebrate Pathology, 73, 101-106.

Brockerhoff, E.G., Jones, D.C., Kimberley, M.O., Suckling, D.M. \& Donaldson, T. (2006) Nationwide survey for invasive wood-boring and bark beetles (Coleoptera) using traps baited with pheromones and kairomones. Forest Ecology and Management, 228, 234240.

Brockerhoff, E.G., Suckling, D.M., Kimberley, M., Richardson, B., Coker, G., Gous, S., Kerr, J.L., Cowan, D.M., Lance, D.R., Strand, T. \& Zhang, A. (2012) Aerial application of pheromones for mating disruption of an invasive moth as a potential eradication tool. PLoS ONE, 7, e43767.

Brook, B.W., Sodhi, N.S. \& Bradshaw, C.J. a. (2008) Synergies among extinction drivers under global change. Trends in Ecology \& Evolution, 23, 453-460.

Brown, A. (1978) Ecology of Pesticides. John Wiley \& Sons., New York.

Buczkowski, G. \& Bennett, G.W. (2008) Aggressive interactions between the introduced Argentine ant, Linepithema humile and the native odorous house ant, Tapinoma sessile. Biological Invasions, 10, 1001-1011.

Carlin, N.F. \& Hölldobler, B. (1986) The kin recognition system of carpenter ants (Camponotus spp.). Behavioral Ecology and Sociobiology, 19, 123-134.

Carney, S.E., Byerley, M.B. \& Holway, D.A. (2003) Invasive Argentine ants (Linepithema humile) do not replace native ants as seed dispersers of Dendromecon rigida (Papaveraceae) in California, USA. Oecologia, 135, 576-582.

Causton, C.E., Sevilla, C.R. \& Porter, S.D. (2005) Eradication of the Little Fire Ant, Wasmannia auropunctata (Hymenoptera: Formicidae), from Marchena Island, Galapagos: on the Edge of Success? Florida Entomologist, 88, 159-168.

Cerdá, X., Angulo, E., Boulay, R. \& Lenoir, A. (2008) Individual and collective foraging decisions: a field study of worker recruitment in the gypsy ant Aphaenogaster senilis. Behavioral Ecology and Sociobiology, 63, 551-562. 


\section{References}

Cerdá, X., Retana, J. \& Cros, S. (1998) Prey size reverses the outcome of interference interactions of scavenger ants. Oikos, 82, 99-110.

Charles, J., Cohen, D. \& Walker, J. (2006) A review of the ecology of grapevine leafroll associated virus type 3 (GLRaV-3). New Zealand Plant Protection, 59, 330-337.

Choe, D.H., Villafuerte, D.B. \& Tsutsui, N.D. (2012) Trail Pheromone of the Argentine Ant, Linepithema humile (Mayr) (Hymenoptera: Formicidae). PLoS ONE, 7, e45016.

Colautti, R.I. \& MacIsaac, H.J. (2004) A neutral terminology to define "invasive" species. Diversity and Distributions, 10, 135-141.

Colautti, R.I., Ricciardi, A., Grigorovich, I. a. \& MacIsaac, H.J. (2004) Is invasion success explained by the enemy release hypothesis? Ecology Letters, 7, 721-733.

Colautti, R.I. \& Richardson, D.M. (2009) Subjectivity and flexibility in invasion terminology: Too much of a good thing? Biological Invasions, 11, 1225-1229.

Cole, F.R., Medeiros, A.C., Loope, L.L. \& Zuehlke, W.W. (1992) Effects of the Argentine ant on arthropod fauna of Hawaiian high- elevation shrubland. Ecology, 73, 1313-1322.

Cook, S.M., Khan, Z.R. \& Pickett, J.A. (2007) The use of push-pull strategies in integrated pest management. Annual Review of Entomology, 52, 375-400.

Cooling, M., Hartley, S., Sim, D. a \& Lester, P.J. (2012) The widespread collapse of an invasive species: Argentine ants (Linepithema humile) in New Zealand. Biology Letters, 8, 430433.

Cooper, M.L., Daane, K.M., Nelson, E.H., Varela, L.G., Battany, M.C., Tsutsui, N.D. \& Rust, M.K. (2008) Liquid baits control Argentine ants sustainably in coastal vineyards. California Agriculture, 62, 177-183.

Corin, S.E., Abbott, K.L., Ritchie, P. a. \& Lester, P.J. (2007) Large scale unicoloniality: The population and colony structure of the invasive Argentine ant (Linepithema humile) in New Zealand. Insectes Sociaux, 54, 275-282.

Cresswell, J.E. (2011) A meta-analysis of experiments testing the effects of a neonicotinoid insecticide (imidacloprid) on honey bees. Ecotoxicology, 20, 149-157.

D'Ettorre, P., Errard, C., Ibarra, F., Francke, W. \& Hefetz, A. (2000) Sneak in or repel your enemy: Dufour's gland repellent as a strategy for successful usurpation in the slave-maker Polyergus rufescens. Chemoecology, 10, 135-142.

Daane, K.M., Almeida, R.P.P., Bell, V.A., Walker, J.T.S., Botton, M., Fallahzadeh, M., Mani, M., Miano, J.L., Sforza, R., Walton, V.M. \& Zaviezo, T. (2012) Biology and management of mealybugs in vineyards. Arthropod management in Vineyards (eds N.J. Bostanian, C. Vincent \& R. Isaacs), pp. 271-307. Springer Netherlands, Dordrecht.

Davis, M. a, Chew, M.K., Hobbs, R.J., Lugo, A.E., Ewel, J.J., Vermeij, G.J., Brown, J.H., Rosenzweig, M.L., Gardener, M.R., Carroll, S.P., Thompson, K., Pickett, S.T. a, 
Stromberg, J.C., Del Tredici, P., Suding, K.N., Ehrenfeld, J.G., Grime, J.P., Mascaro, J. \& Briggs, J.C. (2011) Don't judge species on their origins. Nature, 474, 153-154.

Davis, N.E., O'Dowd, D.J., Green, P.T. \& Mac Nally, R. (2008) Effects of an alien ant invasion on abundance, behavior, and reproductive success of endemic island birds. Conservation Biology, 22, 1165-1176.

Davis, N.E., O’Dowd, D.J., Mac Nally, R. \& Green, P.T. (2010) Invasive ants disrupt frugivory by endemic island birds. Biology Letters, 6, 85-88.

Deneubourg, J.L., Aron, S., Goss, S. \& Pasteels, J.M. (1990) The self-organizing exploratory pattern of the Argentine ant. Journal of Insect Behavior, 3, 159-168.

DeRivera, C. \& Ruiz, G. (2005) Biotic resistance to invasion: native predator limits abundance and distribution of an introduced crab. Ecology, 86, 3364-3376.

Detrain, C. \& Deneubourg, J. (2006) Self-organized structures in a superorganism: do ants "behave" like molecules? Physics of Life Reviews, 3, 162-187.

Dicke, M., Sabelis, M.W., Takabayashi, J., Bruin, J. \& Posthumus, M.A. (1990) Plant strategies of manipulating predatorprey interactions through allelochemicals: Prospects for application in pest control. Journal of Chemical Ecology, 16, 3091-3118.

Didham, R.K., Tylianakis, J.M., Hutchison, M.A., Ewers, R.M. \& Gemmell, N.J. (2005) Are invasive species the drivers of ecological change? Trends in Ecology \& Evolution, 20, $470-474$.

Don, A.W., Jones, T.H., Flournoy, R.C. \& Zottig, V.E. (2001) Venom chemistry of Monomorium antipodum Forel (Hymenoptera: Formicidae) from New Zealand and its relevance to the taxonomy of the species. New Zealand Entomologist, 24, 49-52.

Duckworth, R. a \& Badyaev, A. V. (2007) Coupling of dispersal and aggression facilitates the rapid range expansion of a passerine bird. Proceedings of the National Academy of Sciences of the United States of America, 104, 15017-15022.

Dussutour, A., Nicolis, S.C., Shephard, G., Beekman, M. \& Sumpter, D.J.T. (2009) The role of multiple pheromones in food recruitment by ants. The Journal of Experimental Biology, 212, 2337-2348.

El-Sayed, A.M., Suckling, D.M., Byers, J.A., Jang, E.B. \& Wearing, C.H. (2009) Potential of "Lure and Kill" in Long-Term Pest Management and Eradication of Invasive Species. Journal of Economic Entomology, 102, 815-835.

El-Sayed, A.M., Suckling, D.M., Wearing, C.H. \& Byers, J.A. (2006) Potential of Mass Trapping for Long-Term Pest Management and Eradication of Invasive Species. Journal of Economic Entomology, 99, 1550-1564.

Fellers, J.H. (1987) Interference and exploitation in a guild of woodland ants. Ecology, 68, 1466-1478. 


\section{References}

Fernandez, A.A. \& Deneubourg, J.L. (2011) On following behaviour as a mechanism for collective movement. Journal of Theoretical Biology, 284, 7-15.

Flanagan, T.P., Pinter-Wollman, N.M., Moses, M.E. \& Gordon, D.M. (2013) Fast and Flexible: Argentine Ants Recruit from Nearby Trails. PLoS ONE, 8, e70888.

Foster and, S.P. \& Harris, M.O. (1997) Behavioral manipulation methods for insect pestmanagement. Annual Review of Entomology, 42, 123-146.

Franks, N.R. \& Richardson, T. (2006) Teaching in tandem-running ants. Nature, 439, 153.

Games, P.A. \& Howell, J.F. (1976) Pairwise Multiple Comparison Procedures with Unequal N's and/or Variances: A Monte Carlo Study. Journal of Educational and Behavioral Statistics, 1, 113-125.

Gibb, H. (2005) The effect of a dominant ant, Iridomyrmex purpureus, on resource use by ant assemblages depends on microhabitat and resource type. Australian Journal of Ecology, 30, 856-867.

Gomez, K. \& Gomez, A. (1984) Statistical Procedures for Agricultural Research, 2nd ed. Wiley-Interscience, New York.

Gómez, C. \& Oliveras, J. (2003) Can the Argentine ant (Linepithema humile Mayr) replace native ants in myrmecochory? Acta Oecologica, 24, 47-53.

Green, O.R. (1990) Entomologist sets new record at Mt. Smart, or Iridomyrmex humilis established in New Zealand. Weta, 13, 14-16.

Green, P.T., O’Dowd, D.J. \& Lake, P.S. (2001) From resistance to meltdown: secondary invasion of an island rain forest. International Conference on Tropical Ecosystems Oxfors IBH, New Delhi, Bangalore, India.

Greenberg, L., Kabashima, J.N., Allison, C.J., Rust, M.K., Klotz, J.H., Hurvois, J.-P. \& Paine, T.D. (2008) Lethality of Red Imported Fire Ant Venom to Argentine Ants and Other Ant Species. Annals of the Entomological Society of America, 101, 1162-1168.

Gurevitch, J., Fox, G. a., Wardle, G.M., Inderjit \& Taub, D. (2011) Emergent insights from the synthesis of conceptual frameworks for biological invasions. Ecology Letters, 14, 407418.

Haack, R. a, Hérard, F., Sun, J. \& Turgeon, J.J. (2010) Managing invasive populations of Asian longhorned beetle and citrus longhorned beetle: a worldwide perspective. Annual Review of Entomology, 55, 521-546.

Hall, P. \& Traniello, J. (1985) Behavioral bioassays of termite trail pheromones. Journal of chemical ecology, 11, 1503-1513.

Halstead, B. \& Courville, D. (1988) Poisonous and Venomous Marine Animals of the World, 2nd rev. e. Darwin Press, Princeton, NJ. 
Harris, R. (2002) Potential Impact of the Argentine Ant (Linepithema Humile) in New Zealand and Options for Its Control. Science for Conservation 196: 36 p., Department of Conservation, Wellington, NZ. (Available online at http//www.doc.govt.nz/publications/index/asp).

Harris, R.J., Rees, J.S. \& Toft, R.J. (2002a) Trials to eradicate infestations of the argentine ant, Linepithema humile (Hymenoptera: Formicidae), in New Zealand. Proceedings of the 4th International Conference on Urban Pests (eds S.C. Jones, J. Zhai \& W.H. Robinson), pp. 67-74. Pocahontas Press, VA.

Harris, R.J., Ward, D. \& Sutherland, M.A. (2002b) A survey of the current distribution of agentine ants, Linepithema humile, in native habitats in New Zealand, and assessment of future risk of establishment.

Heinze, J., Foitzik, S., Fischer, B., Wanke, T. \& Kipyatkov, V.E. (2003) The significance of latitudinal variation in body size in a holarctic ant, Leptothorax acervorum. Ecography, 26, 349-355.

Hejda, M., Pyšek, P. \& Jarošík, V. (2009) Impact of invasive plants on the species richness, diversity and composition of invaded communities. Journal of Ecology, 97, 393-403.

Heller, N.E. \& Gordon, D.M. (2006) Seasonal spatial dynamics and causes of nest movement in colonies of the invasive Argentine ant (Linepithema humile). Ecological Entomology, 31, 499-510.

Heller, N.E., Ingram, K.K. \& Gordon, D.M. (2008) Nest connectivity and colony structure in unicolonial Argentine ants. Insectes Sociaux, 55, 397-403.

Helms, K.R. \& Vinson, S.B. (2002) Widespread association of the invasive ant Solenopsis invicta with an invasive mealybug. Ecology, 83, 2425-2438.

Heth, G., Todrank, J. \& Johnston, R. (1998) Kin recognition in golden hamsters: evidence for phenotype matching. Animal behaviour, 56, 409-417.

Hodgson, E. (2012) Toxins and venoms. Toxicology and Human Environments, 1st ed (ed E. Hodgson), pp. 373-415. Elsevier.

Hoffmann, B.D. \& Parr, C.L. (2008) An invasion revisited: The African big-headed ant (Pheidole megacephala) in northern Australia. Biological Invasions, 10, 1171-1181.

Holldobler, B. (1983) Territorial behavior in the green tree ant (Oecophylla smaragdina). Biotropica, 15, 241-250.

Holldobler, B. \& Wilson, E. (1994) Journey to the Ants: A Story of Scientific Exploration. Harvard University Press, Cambride, MA.

Holway, D. A. (1999) Competitive mechanisms underlying the displacement of native ants by the invasive argentine ant. Ecology, 80, 238-251. 


\section{References}

Holway, D. A., Lach, L., Suarez, A. V., Tsutsui, N.D. \& Case, T.J. (2002a) The Causes and Consequences of Ant Invasions. Annual Review of Ecology and Systematics, 33, 181-233.

Holway, D.A., Suarez, A. V \& Case, T.J. (2002b) Role of abiotic factors in governing susceptibility to invasion: A test with argentine ants. Ecology, 83, 1610-1619.

Horan, R., Perrings, C., Lupi, F. \& Bulte, E. (2002) Biological pollution prevention strategies under ignorance: the case of invasive species. American Journal of Agricultural Economy, 84, 1303-1310.

Howell, G., Butler, J., Deshazo, R.D., Farley, J.M., Liu, H.-L., Nanayakkara, N.P.D., Yates, A., Yi, G.B. \& Rockhold, R.W. (2005) Cardiodepressant and neurologic actions of Solenopsis invicta (imported fire ant) venom alkaloids. Annals of allergy, asthma \& immunology: official publication of the American College of Allergy, Asthma, \& Immunology, 94, 380-386.

Human, K.G. \& Gordon, D.M. (1996) Exploitation and interference competition between the invasive Argentine ant, Linepithema humile, and native ant species. Oecologia, 105, 405412.

Jahn, G.C., Beardsley, J.W. \& Gonzalez-Hernandez, H. (2003) A review of the association of ants with mealybug wilt disease of pineapple. Proceedings of the Hawaiian Entomological Society, 36, 9-28.

Jeanson, R. \& Weidenmüller, A. (2014) Interindividual variability in social insects - proximate causes and ultimate consequences. Biological Reviews, 89, 671-687.

Johnson, C., Agosti, D., Delabie, J.H., Dumpert, K., Williams, D.J., Tschirnhaus, M. von \& Maschwitz, U. (2001) Acropyga and Azteca Ants (Hymenoptera: Formicidae) with Scale Insects (Sternorrhyncha: Coccoidea): 20 Million Years of Intimate Symbiosis. American Museum Novitates, 3335, 1-18.

Jones, T.H., Andersen, A.N. \& Kenny, J.C. (2009) Venom alkaloid chemistry of Australian species of the Monomorium rothsteini complex, with particular reference to taxonomic implications. Chemistry and Biodiversity, 6, 1034-1041.

Jones, T.H., Blum, M.S., Fales, H.M. \& Thompson, C.R. (1980a) (5Z,8E)-3-Heptyl-5methylpyrrolizidine from a thief ant. The Journal of Organic Chemistry, 45, 4778-4780.

Jones, T.H., Franko, J.B., Blum, M.S. \& Fales, H.M.M. (1980b) Unsymmetrical 2,5dialkylpyrrolidines via reductive amination of 1,4-diketones. Tetrahedron Letters, 21, 789-792.

Jones, T.H., Laddago, A., Don, A.W. \& Blum, M.S. (1990) A novel (5E,9Z)dialkylindolizidine from the ant Monomorium smithii. Journal of Natural Products, 53, $375-381$.

Jones, T.H., Stahly, S.M., Don, A.W. \& Blum, M.S. (1988) Chemotaxonomic implications of the venom chemistry of some Monomorium "antarcticum" populations. Journal of Chemical Ecology, 14, 2197-212. 
Kabashima, J.N., Greenberg, L., Rust, M.K. \& Paine, T.D. (2007) Aggressive interactions between Solenopsis invicta and Linepithema humile (Hymenoptera: Formicidae) under laboratory conditions. Journal of Economic Entomology, 100, 148-154.

Kaluza, P., Kölzsch, A., Gastner, M.T. \& Blasius, B. (2010) The complex network of global cargo ship movements. Journal of the Royal Society, Interface / the Royal Society, 7, 1093-1103.

Keane, R. (2002) Exotic plant invasions and the enemy release hypothesis. Trends in Ecology \& Evolution, 17, 164-170.

Keller, R.P., Lodge, D.M. \& Finnoff, D.C. (2007) Risk assessment for invasive species produces net bioeconomic benefits. Proceedings of the National Academy of Sciences of the United States of America, 104, 203-207.

Keller, L. \& Nonacs, P. (1993) The role of queen pheromones in social insects: queen control or queen signal? Animal Behaviour, 45, 787-794.

Kent, D.S. \& Simpson, J.A. (1992) Eusociality in the beetle Austroplatypus incompertus (Coleoptera: Curculionidae). Naturwissenschaften, 79, 86-87.

Kenward, R.E. \& Holm, J.L. (1993) On the replacement of the red squirrel in Britain: a phytotoxic explanation. Proceedings. Biological sciences / The Royal Society, 251, 18794.

Khuong, A., Lecheval, V., Fournier, R., Blanco, S., Weitz, S., Bezian, J.-J. \& Gautrais, J. (2013) How do ants make sense of gravity? A Boltzmann Walker analysis of Lasius niger trajectories on various inclines. PloS ONE, 8, e76531.

King, J.R. \& Tschinkel, W.R. (2006) Experimental evidence that the introduced fire ant, Solenopsis invicta, does not competitively suppress co-occurring ants in a disturbed habitat. Journal of Animal Ecology, 75, 1370-1378.

King, J.R. \& Tschinkel, W.R. (2008) Experimental evidence that human impacts drive fire ant invasions and ecological change. Proceedings of the National Academy of Sciences of the United States of America, 105, 20339-20343.

King, J.R., Tschinkel, W.R. \& Ross, K.G. (2009) A case study of human exacerbation of the invasive species problem: Transport and establishment of polygyne fire ants in Tallahassee, Florida, USA. Biological Invasions, 11, 373-377.

De Kock, A. (1990) Interactions between the introduced Argentine ant, Iridomyrmex humilis Mayr, and two indigenous fynbos ant species. Journal of the Entomological Society of Southern Southern Africa, 53, 107-108.

Kreuger, J. (1998) Pesticides in stream water within an agricultural catchment in southern Sweden, 1990-1996. Science of The Total Environment, 216, 227-251. 


\section{References}

Krushelnycky, P.D. \& Gillespie, R.G. (2008) Compositional and functional stability of arthropod communities in the face of ant invasions. Ecological Applications, 18, 15471562.

Krushelnycky, P. \& Holway, D. (2010) Invasion processes and causes of success. Ant Ecology (eds L. Lach, C.L. Parr \& K.L. Abbott), pp. 245-260. Oxford University Press, Oxford.

Lach, L. (2007) Argentine ants displace floral arthropods in a biodiversity hotspot. Diversity and Distributions, 14, 281-290.

Lebrun, B. \& Cattaert, D. (1997) Slow inhibition of Na+ current in crayfish axons by 2-(1non8enyl)-5-(1non-8enyl)pyrrolidine (Pyr9), a synthetic derivative of an ant venom alkaloid. The Journal of Experimental Biology, 200, 2097-2106.

Lebrun, E.G., Jones, N.T. \& Gilbert, L.E. (2014) Chemical warfare among invaders: A detoxification interaction facilitates an ant invasion. Science, 89, 1824-1836.

Lebrun, E.G., Tillberg, C. V., Suarez, A. V., Folgarait, P.J., Smith, C.R. \& Holway, D.A. (2007) An experimental study of competition between fire ants and Argentine ants in their native range. Ecology, 88, 63-75.

Lenoir, A., D'Ettorre, P., Errard, C. \& Hefetz, A. (2001) Chemical ecology and social parasitism in ants. Annual Review of Entomology, 46, 573-599.

Lester, P.J., Baring, C.W., Longson, C.G. \& Hartley, S. (2003) Argentine and other ants (Hymenoptera: Formicidae) in New Zealand horticultural ecosystems: distribution, hemipteran hosts, and review. New Zealand Entomologist, 26, 79-89.

Lester, P.J. \& Longson, C.G. (2002) Argentine Ant Distribution Investigation: Horticultural Areas. Report to MAF Biosecurity, Victoria University of Wellington.

Leung, B., Lodge, D.M., Finnoff, D., Shogren, J.F., Lewis, M. a \& Lamberti, G. (2002) An ounce of prevention or a pound of cure: bioeconomic risk analysis of invasive species. Proceedings. Biological sciences / The Royal Society, 269, 2407-2413.

Lin, N. \& Michener, C. (1972) Evolution of sociality in insects. Quarterly Review of Biology, 47, 131-159.

Lind, N.K. (1982) Mechanism of action of fire ant (Solenopsis) venoms. I. Lytic release of histamine from mast cells. Toxicon, 20, 831-840.

Littrell, E. (1990) Effects of field vertebrate pest control on nontarget wildlife (with emphasis on bird and rodent control). Proceedings of the Fourteenth Vertebrate Pest Conference 1990 pp. 3-6.

Lizon à l'Allemand, S. \& Witte, V. (2010) A sophisticated, modular communication contributes to ecological dominance in the invasive ant Anoplolepis gracilipes. Biological Invasions, 12, 3551-3561. 
Lockwood, J.L., Hoopes, M.F. \& Michael P. Marchetti. (2007) An Introduction to Invasion Ecology. Invasion Ecology pp. 1-17. Blackwell Sci. Publ., Malden.

Longson, C. \& Joss, J. (2006) Optimal toxicity in animals: predicting the optimal level of chemical defences. Functional Ecology, 20, 731-735.

Lövei, G.L., Lewinsohn, T.M., Dirzo, R., Elhassan, E.F.M., Ezcurra, E., Freire, C.A. de O., Gui, F.-R., Halley, J.M., Tibazarwa, J.M., Jiang, M.-X., Katebaka, R., Kinyamario, J., Kymanywa, S., Liu, F.-Q., Liu, S.-S., Liu, W.-X., Liu, Y.-Q., Lu, B.-R., Minot, E.O., Qiang, S., Qiu, B.-L., Shen, H., Soberon, J., Sujii, E.R., Tang, J.-W., Uludag, A., Vitule, J.R.S., Wan, F.-H., Wang, F.-H., Yang, G.-Q., Zhang, X.-Y. \& You, M.-S. (2012) Megadiverse developing countries face huge risks from invasives. Trends in Ecology \& Evolution, 27, 2-3.

Lovell, S., Stone, S. \& Fernandez, L. (2006) The economic impacts of aquatic invasive species: a review of the literature. Agricultural and Resource Economics Review, 35, 195-208.

Lowe, S., Browne, M. \& Boudjelas, S. (2000) 100 of the world's worst invasive alien species. Aliens, 12, 2-12.

Lubin, Y.D. (1984) Changes in the native fauna of the Galápagos Islands following invasion by the little red fire ant, Wasmannia auropunctata. Biological Journal of the Linnean Society, 21, 229-242.

MacDougall, A.S. \& Turkington, R. (2005) Are invasive species the drivers or passengers of change in degraded ecosystems? Ecology, 86, 42-55.

Mack, R.N., Simberloff, D., Mark Lonsdale, W., Evans, H., Clout, M. \& Bazzaz, F.A. (2000) Biotic Invasions: Causes, Epidemiology, Global Consequences, and Control. Ecological Applications, 10, 689-710.

Maree, H.J., Almeida, R.P.P., Bester, R., Chooi, K.M., Cohen, D., Dolja, V. V, Fuchs, M.F., Golino, D. a, Jooste, A.E.C., Martelli, G.P., Naidu, R. a, Rowhani, A., Saldarelli, P. \& Burger, J.T. (2013) Grapevine leafroll-associated virus 3. Frontiers in Microbiology, 4, 82 .

Marrelli, M.T., Li, C., Rasgon, J.L. \& Jacobs-Lorena, M. (2007) Transgenic malaria-resistant mosquitoes have a fitness advantage when feeding on Plasmodium-infected blood. Proceedings of the National Academy of Sciences, 104, 5580-5583.

Matsumura, F. (1985) Toxicology of Insecticides. Plenum Press, New York.

Matsumura, F., Coppel, H.C. \& Tai, A. (1968) Isolation and Identification of Termite Trailfollowing Pheromone. Nature, 219, 963-964.

McGlynn, T.P. (1999) The worldwide transfer of ants: geographical distribution and ecological invasions. Journal of Biogeography, 26, 535-548. 


\section{References}

McGrannachan, C.M. \& Lester, P.J. (2013) Temperature and starvation effects on food exploitation by Argentine ants and native ants in New Zealand. Journal of Applied Entomology, 137, 550-559.

McNatty, A., Abbott, K.L. \& Lester, P.J. (2009) Invasive ants compete with and modify the trophic ecology of hermit crabs on tropical islands. Oecologia, 160, 187-194.

Mebs, D. (2001) Toxicity in animals. Trends in evolution? Toxicon: official journal of the International Society on Toxinology, 39, 87-96.

Mebs, D. (2002) Venomous and Poisonous Animals: A Handbookfor Biologists, Toxicologists and Toxinologists, Physicians and Pharmacists. CRC Press, Boca Raton, FL.

Mgocheki, N. \& Addison, P. (2010) Spatial distribution of ants (Hymenoptera: Formicidae), vine mealybugs and mealybug parasitoids in vineyards. Journal of Applied Entomology, 134, 285-295.

Michael Crossland \& Alford, R.A. (1998) Evaluation of the toxicity of eggs, hatchlings and tadpoles of the introduced toad Bufo marinus (Anura: Bufonidae) to native Australian aquatic predators. Australian Journal of Ecology, 23, 129-137.

Mitchell, C.E. \& Power, A.G. (2003) Release of invasive plants from fungal and viral pathogens. Nature, 421, 625-627.

Morgenstern, D. \& King, G.F. (2013) The venom optimization hypothesis revisited. Toxicon, 63, 120-128.

Morrison, L.W. (1996) Community organization in a recently assembled fauna: the case of Polynesian ants. Oecologia, 107, 243-256.

Nesbitt, B.F., Beevor, P.S., Hall, D.R., Lester, R. \& Dyck, V.A. (1975) Identification of the female sex pheromones of the moth, Chilo suppressalis. Journal of Insect Physiology, 21, 1883-1886.

Nishisue, K., Sunamura, E., Tanaka, Y., Sakamoto, H., Suzuki, S., Fukumoto, T., Terayama, M. \& Tatsuki, S. (2010) Long-term field trial to control the invasive Argentine Ant (Hymenoptera: Formicidae) with synthetic trail pheromone. Journal of Economic Entomology, 103, 1784-1789.

Nowak, M.A., Tarnita, C.E. \& Wilson, E.O. (2010) The evolution of eusociality. Nature, 466, 1057-1062.

O'Dowd, D.J., Green, P.T. \& Lake, P.S. (2001) Invasional meltdown in island rainforest. Tropical ecosystems. Structure, diversity and human welfare (eds K.N. Ganeshaiah, R.U. Shaanker \& K.S. Bawa), pp. 447-450. Oxford and IBH, New Delhi.

O’Dowd, D.J., Green, P.T. \& Lake, P.S. (2003) Invasional "meltdown" on an oceanic island. Ecology Letters, 6, 812-817. 
Occhipinti-Ambrogi, A. \& Galil, B.S. (2004) A uniform terminology on bioinvasions: A chimera or an operative tool? Marine Pollution Bulletin, 49, 688-694.

Olson, L. (2006) The economics of terrestrial invasive species: a review of the literature. Agricultural and Resource Economics Review, 35, 178-194.

Parker, I.M., Simberloff, D., Lonsdale, W.M., Goodell, K., Wonham, M., Kareiva, P.M., Williamson, M.H., Holle, B. von, Moyle, P.B., Byers, J.E., Goldwasser, L. (1999) Impact: toward a framework for understanding the ecological effects of invader. Biological Invasions, 1, 3-19.

Pedersen, J.S., Krieger, M.J.B., Vogel, V., Giraud, T. \& Keller, L. (2006) Native supercolonies of unrelated individuals in the invasive Argentine ant. Evolution, 60, 782-791.

Pejchar, L. \& Mooney, H. a. (2009) Invasive species, ecosystem services and human wellbeing. Trends in Ecology \& Evolution, 24, 497-504.

Phillips, P.A. \& Sherk, C.J. (1991) To control mealybugs, stop honeydew-seeking ants. California Agriculture, 45, 2-4.

Pimentel, D., Lach, L., Zuniga, R. \& Morrison, D. (2000) Enviromental and economic costs associated with nonindigenous species in the United States. BioScience, 50, 53-65.

Pimentel, D., Zuniga, R. \& Morrison, D. (2005) Update on the environmental and economic costs associated with alien-invasive species in the United States. Ecological Economics, 52, 273-288.

Pimm, S.L., Jenkins, C.N., Abell, R., Brooks, T.M., Gittleman, J.L., Joppa, L.N., Raven, P.H., Roberts, C.M. \& Sexton, J.O. (2014) The biodiversity of species and their rates of extinction, distribution, and protection. Science, 344, 1246752.

Pimm, S.L., Russell, G.J., Gittleman, J.L. \& Brooks, T.M. (1995) The Future of Biodiversity. Science, 269, 347-350.

Pintor, L.M., Sih, A. \& Kerby, J.L. (2009) Behavioral correlations provide a mechanism for explaining high invader densities and increased impacts on native prey. Ecology, 90, 581587.

Porter, S.D. \& Savignano, D.A. (1990) Invasion of polygyne fire ants decimates native ants and disrupts arthropod community. Ecology, 71, 2095-2106.

Pratt, S., Mallon, E., Sumpter, D. \& Franks, N. (2002) Quorum sensing, recruitment, and collective decision-making during colony emigration by the ant Leptothorax albipennis. Behavioral Ecology and Sociobiology, 52, 117-127.

Rabitsch, W. (2011) The hitchhiker's guide to alien ant invasions. BioControl, 56, 551-572.

Race, M. (1982) Competitive displacement and predation between introduced and native mud snails. Oecologia, 54, 337-347. 


\section{References}

Ravary, F., Lecoutey, E., Kaminski, G., Châline, N. \& Jaisson, P. (2007) Individual experience alone can generate lasting division of labor in ants. Current Biology, 17, 1308-1312.

Regnier, F. \& Wilson, E. (1971) Chemical communication and“ propaganda” in slave-maker ants. Science, 172, 267-269.

Ricciardi, A., Hoopes, M.F., Marchetti, M.P. \& Lockwood, J.L. (2013) Progress toward understanding the ecological impacts of nonnative species. Ecological Monographs, 83, $263-282$.

Richardson, D.M. \& Pyšek, P. (2008) Fifty years of invasion ecology - the legacy of Charles Elton. Diversity and Distributions, 14, 161-168.

Robinson, E.J.H., Jackson, D.E., Holcombe, M. \& Ratnieks, F.L.W. (2005) Insect communication: "no entry" signal in ant foraging. Nature, 438, 442.

Rodriguez, L.F. (2006) Can invasive species facilitate native species? Evidence of how, when, and why these impacts occur. Biological Invasions, 8, 927-939.

Ross, K.G. \& Keller, L. (1995) Ecology and Evolution of Social Organization: Insights from Fire Ants and Other Highly Eusocial Insects. Annual Review of Ecology and Systematics, 26, 631-656.

Roura-Pascual, N., Suarez, A. V, McNyset, K., Gómez, C., Pons, P., Touyama, Y., Wild, A.L., Gascon, F. \& Peterson, a T. (2006) Niche differentiation and fine-scale projections for Argentine ants based on remotely sensed data. Ecological Applications, 16, 1832-1841.

Rowles, A.D. \& O'Dowd, D.J. (2007) Interference competition by Argentine ants displaces native ants: Implications for biotic resistance to invasion. Biological Invasions, 9, 73-85.

Rowles, A.D. \& O'Dowd, D.J. (2009a) Impacts of the invasive Argentine ant on native ants and other invertebrates in coastal scrub in south-eastern Australia. Australian Journal of Ecology, 34, 239-248.

Rowles, A.D. \& O'Dowd, D.J. (2009b) New mutualism for old: Indirect disruption and direct facilitation of seed dispersal following Argentine ant invasion. Oecologia, 158, 709-716.

Ruther, J., Sieben, S. \& Schricker, B. (2002) Nestmate recognition in social wasps: manipulation of hydrocarbon profiles induces aggression in the European hornet. Naturwissenschaften, 89, 111-114.

Sagata, K. \& Lester, P.J. (2009) Behavioural plasticity associated with propagule size, resources, and the invasion success of the Argentine ant Linepithema humile. Journal of Applied Ecology, 46, 19-27.

Samways, M., Nel, M. \& Prins, A. (1982) Ants (Hymenoptera: Formicidae) foraging in citrus trees and attending honeydew-producing Homoptera. Phytophylactica, 14, 155-157.

Sanders, N.J., Gotelli, N.J., Heller, N.E. \& Gordon, D.M. (2003) Community disassembly by an invasive species. Proceedings of the National Academy of Sciences, 100, 2474-2477. 
Savage, A.M., Johnson, S.D., Whitney, K.D. \& Rudgers, J.A. (2011) Do invasive ants respond more strongly to carbohydrate availability than co-occurring non-invasive ants? A test along an active Anoplolepis gracilipes invasion front. Australian Journal of Ecology, 36, $310-319$.

Savolainen, R. (1991) Interference by wood ant influences size selection and retrieval rate of prey by Formica fusca. Behavioral Ecology and Sociobiology, 28, 1-7.

Savolainen, R. \& Vepsäläinen, K. (1989) Niche differentiation of ant species within territories of the wood ant Formica polyctena. Oikos, 56, 3-16.

Sbarbati, A. \& Osculati, F. (2006) Allelochemical Communication in Vertebrates: Kairomones, Allomones and Synomones. Cells Tissues Organs, 183, 206-219.

Schmidt, J.O. (1978) Ant Venoms: Study of Venom Diversity. Pesticide and Venom Neurotoxicity (eds D.L. Shankland, R.M. Holligworth \& T. Smyth Jr.), pp. 247-263. Plenum Press, New York, 283 p.

Schulz, S. (2005) The Chemistry of Pheromones and Other Semiochemicals II, 2nd ed (ed S Schulz). Springer.

Sether, D.M., Melzer, M.J., Busto, J., Zee, F. \& Hu, J.S. (2005) Diversity and Mealybug Transmissibility of Ampeloviruses in Pineapple. Plant Disease, 89, 450-456.

Shaffer, Z., Sasaki, T. \& Pratt, S.C. (2013) Linear recruitment leads to allocation and flexibility in collective foraging by ants. Animal Behaviour, 86, 967-975.

Sherbrooke, W.C. \& Middendorf, G.A. (2004) Responses of Kit Foxes (Vulpes macrotis) to Antipredator Blood-Squirting and Blood of Texas Horned Lizards (Phrynosoma cornutum). Copeia, 2004, 652-658.

Shik, J.Z. \& Silverman, J. (2013) Towards a nutritional ecology of invasive establishment: Aphid mutualists provide better fuel for incipient Argentine ant colonies than insect prey. Biological Invasions, 15, 829-836.

Sih, A., Bell, A. \& Johnson, J.C. (2004) Behavioral syndromes: An ecological and evolutionary overview. Trends in Ecology \& Evolution, 19, 372-378.

Sih, A., Cote, J., Evans, M., Fogarty, S. \& Pruitt, J. (2012) Ecological implications of behavioural syndromes. Ecology Letters, 15, 278-289.

Simberloff, D. (2003) Confronting introduced species: A form of xenophobia? Biological Invasions, 5, 179-192.

Simberloff, D. (2006) Invasional meltdown 6 years later: Important phenomenon, unfortunate metaphor, or both? Ecology Letters, 9, 912-919.

Simberloff, D. \& Gibbons, L. (2004) Now you see them, now you don't! - Population crashes of established introduced species. Biological Invasions, 6, 161-172. 


\section{References}

Simberloff, D., Simberloff, D., Holle, B. Von \& Holle, B. Von. (1999) Positive interactions of nonindigenous species: invasional meltdown? Biological Invasions, 1, 21-32.

Simberloff, D. \& Vitule, J.R.S. (2014) A call for an end to calls for the end of invasion biology. Oikos, 123, 408-413.

Smith, E.P. (2002) BACI design. Encyclopedia of Environmetrics (eds A.H. El-Shaarawi \& W.W. Piegorsch), pp. 141-148. John Wiley \& Sons Ltd, Chichester.

Smith, A.A., Hölldober, B. \& Liebig, J. (2009) Cuticular Hydrocarbons Reliably Identify Cheaters and Allow Enforcement of Altruism in a Social Insect. Current Biology, 19, 7881.

Sol, D., Timmermans, S. \& Lefebvre, L. (2002) Behavioural flexibility and invasion success in birds. Animal Behaviour, 63, 495-502.

Sorrells, T.R., Kuritzky, L.Y., Kauhanen, P.G., Fitzgerald, K., Sturgis, S.J., Chen, J., Dijamco, C. a, Basurto, K.N. \& Gordon, D.M. (2011) Chemical defense by the native winter ant (Prenolepis imparis) against the invasive argentine ant (Linepithema humile). PLoS ONE, 6, e18717.

Speight, M.R., Hunter, M.D. \& Watt, A.D. (2008) Ecology of Insects: Concepts and Applications. Wiley-Blackwell, Chichester.

Steinmetz, I., Schmolz, E. \& Ruther, J. (2003) Cuticular lipids as trail pheromone in a social wasp. Proceedings. Biological sciences / The Royal Society, 270, 385-391.

Stout, J.C. \& Morales, C.L. (2009) Ecological impacts of invasive alien species on bees. Apidologie, 40, 388-409.

Stringer, L.D., Haywood, J. \& Lester, P.J. (2007) The influence of temperature and fine-scale resource distribution on resource sharing and domination in an ant community. Ecological Entomology, 32, 732-740.

Stuart, a M. (1967) Alarm, defense, and construction behavior relationships in termites (Isoptera). Science, 156, 1123-1125.

Stuart, A. (1981) The role of pheromones in the initiation of foraging, recruitment and defence by the soldiers of a tropical termite, Nasutitermes corniger (Motschulsky). Chemical Senses, 6.

Su, T.H. (1979) The Biology and Control of the Big-Headed Ant and Its Associated Mealybugs in Hawaiian Pineapple Fields. University of Hawaii at Manoa.

Suarez, A. V \& Case, T.J. (2002) Bottom-up effects on persistence of a specialist predator: Ant invasions and horned lizards. Ecological Applications, 12, 291-298.

Suarez, A. V, Holway, D.A. \& Case, T.J. (2001) Patterns of spread in biological invasions dominated by long-distance jump dispersal: Insights from Argentine ants. Proceedings of the National Academy of Sciences of the United States of America, 98, 1095-1100. 
Suarez, A. V, Holway, D.A. \& Tsutsui, N.D. (2008) Genetics and behavior of a colonizing species: the invasive Argentine ant. The American naturalist, 172 Suppl , S72-S84.

Suarez, A. V, Yeh, P. \& Case, T.J. (2005) Impacts of Argentine ants on avian nesting success. Insectes Sociaux, 52, 378-382.

Suckling, D.M., Peck, R.W., Manning, L.M., Stringer, L.D., Cappadonna, J. \& El-Sayed, A.M. (2008) Pheromone disruption of Argentine Ant trail integrity. Journal of Chemical Ecology, 34, 1602-1609.

Suckling, D.M., Peck, R.W., Stringer, L.D., Snook, K. \& Banko, P.C. (2010) Trail Pheromone Disruption of Argentine Ant Trail Formation and Foraging. Journal of Chemical Ecology, 36, 122-128.

Suckling, D.M., Stringer, L.D. \& Corn, J.E. (2011) Argentine ant trail Pheromone disruption is mediated by trail concentration. Journal of Chemical Ecology, 37, 1143-1149.

Suckling, D.M., Stringer, L.D., Corn, J.E., Bunn, B., El-Sayed, A.M. \& Vander Meer, R.K. (2012) Aerosol delivery of trail pheromone disrupts the foraging of the red imported fire ant, Solenopsis invicta. Pest Management Science, 68, 1572-1578.

Suter, R.B. \& Stratton, G.E. (2009) Spitting performance parameters and their biomechanical implications in the spitting spider, Scytodes thoracica. Journal of Insect Science, 9, 1-15.

Tanaka, Y., Nishisue, K. \& Sunamura, E. (2009) Trail-following disruption in the invasive Argentine ant with a synthetic trail pheromone component (Z)-9-hexadecenal. Sociobiology, 1, 139-152.

Tanaka, Y., Sunamura, E., Nishisue, K., Terayama, M., Sakamoto, H., Suzuki, S., Fukumoto, T. \& Tatsuki, S. (2008) Response of the invasive Argentine ant to high concentration of a synthetic trail pheromone component suggests a potential control strategy of pest ants. Ari, 31, 43-50.

Tatsuki, S., Terayama, M. \& in- ventors; Shin-Etsu Chemical, Co., Ltd., A. (2005) Behaviordisrupting agent and behavior-disrupting method of Argentine ant. U.S. patent 0209344 A1, 2, 6-9.

Thomas, C.D., Cameron, A., Green, R.E., Bakkenes, M., Beaumont, L.J., Collingham, Y.C., Erasmus, B.F.N., De Siqueira, M.F., Grainger, A., Hannah, L., Hughes, L., Huntley, B., Van Jaarsveld, A.S., Midgley, G.F., Miles, L., Ortega-Huerta, M. a, Peterson, a T., Phillips, O.L. \& Williams, S.E. (2004) Extinction risk from climate change. Nature, 427, $145-148$.

Thorne, B. (1982) Polygyny in termites: Multiple primary queens in colonies of Nasutitermes corniger (Motschuls) (Isoptera: Termitidae). Insectes Sociaux, 29, 102-117.

Thorne, B.L. (1997) Evolution of eusociality in termites. Annual Review of Ecology and Systematics, 28, 27-54. 


\section{References}

Torchin, M.E. \& Mitchell, C.E. (2004) Parasites, pathogens, and invasions by plants and animals. Frontiers in Ecology and the Environment, 2, 183-190.

Towns, D.R. \& Broome, K.G. (2003) From small Maria to massive Campbell: Forty years of rat eradications from New Zealand islands. New Zealand Journal of Zoology, 30, 377398.

Traniello, J. (1982) Recruitment and orientation components in a termite trail pheromone. Naturwissenschaften, 343-345.

Traniello, J.F.A. (1989) Foraging Strategies of Ants. Annual Review of Entomology, 34, 191210.

Tsai, C.-W., Chau, J., Fernandez, L., Bosco, D., Daane, K.M. \& Almeida, R.P.P. (2008) Transmission of grapevine leafroll-associated virus 3 by the vine mealybug (Planococcus ficus). Phytopathology, 98, 1093-1098.

Tsutsui, N.D. \& Suarez, A. V. (2003) The Colony Structure and Population Biology of Invasive Ants. Conservation Biology, 17, 48-58.

Tsutsui, N.D., Suarez, A. V, Holway, D.A. \& Case, T.J. (2000) Reduced genetic variation and the success of an invasive species. Proceedings of the National Academy of Sciences of the United States of America, 97, 5948-5953.

Valéry, L., Fritz, H. \& Lefeuvre, J.-C. (2013) Another call for the end of invasion biology. Oikos, 122, 1143-1146.

Vega, S. \& Rust, M. (2001) The Argentine Ant- A Significant Invasive Species in Agricultural, Urban and Natural Environments. Sociobiology, 37, 3-26.

Vepsäläinen, K. \& Pisarski, B. (1982) Assembly of island ant communities. Annales Zoologici Fennici, 19, 327-335.

Vonshak, M., Dayan, T. \& Hefetz, A. (2012) Interspecific displacement mechanisms by the invasive little fire ant Wasmannia auropunctata. Biological Invasions, 14, 851-861.

Walters, A.C. \& Mackay, D.A. (2005) Importance of large colony size for successful invasion by Argentine ants (Hymenoptera: Formicidae): Evidence for biotic resistance by native ants. Australian Journal of Ecology, 30, 395-406.

Ward, D.F. (2007) Modelling the potential geographic distribution of invasive ant species in New Zealand. Biological Invasions, 9, 723-735.

Ward, D.F., Beggs, J.R., Clout, M.N., Harris, R.J. \& O’Connor, S. (2006) The diversity and origin of exotic ants arriving in New Zealand via human-mediated dispersal. Diversit Distributions, 12, 601-609.

Ward, D.F., Green, C., Harris, R.J., Hartley, S., Lester, P.J., Stanley, M.C., Suckling, D.M. \& Toft, R.J. (2010) Twenty years of Argentine ants in New Zealand: past research and future priorities for applied management. New Zealand Entomologist, 33, 68-78. 
Ward, D.F., Harris, R.J. \& Stanley, M.C. (2005) Human-mediated range expansion of Argentine ants Linepithema humile (Hymenoptera: Formicidae) in New Zealand. Sociobiology, 45, 401-407.

Warrell, D. a. (2007) Venomous animals. Medicine, 35, 659-662.

Weissel, N., Mitesser, O., Poethke, H.-J. \& Strohm, E. (2011) Availability and depletion of fat reserves in halictid foundress queens with a focus on solitary nest founding. Insectes Sociaux, 59, 67-74.

Westermann, F.L., Bell, V. a, Suckling, D.M. \& Lester, P.J. (2015) Synthetic pheromones as a management technique - dispensers reduce Linepithema humile activity in a commercial vineyard. Pest Management Science, n/a-n/a.

Westermann, F.L., Suckling, D.M. \& Lester, P.J. (2014) Disruption of foraging by a dominant invasive species to decrease its competitive ability. PLoS ONE, 9, e90173.

Westhoff, G., Tzschätzsch, K. \& Bleckmann, H. (2005) The spitting behavior of two species of spitting cobras. Journal of Comparative Physiology A: Neuroethology, Sensory, Neural, and Behavioral Physiology, 191, 873-881.

Weston, D.P., You, J. \& Lydy, M.J. (2004) Distribution and Toxicity of Sediment-Associated Pesticides in Agriculture-Dominated Water Bodies of California's Central Valley. Environmental Science \& Technology, 38, 2752-2759.

Wetterer, J.K. \& Porter, S.D. (2003) The little fire ant, Wasmannia auropunctata: Distribution, impact, control. Sociobiology, 42, 1-41.

Whitehorn, P.R., O’Connor, S., Wackers, F.L. \& Goulson, D. (2012) Neonicotinoid Pesticide Reduces Bumble Bee Colony Growth and Queen Production. Science, 336, 351-352.

Wigger, E., Kuhn-Nentwig, L. \& Nentwig, W. (2002) The venom optimisation hypothesis: a spider injects large venom quantities only into difficult prey types. Toxicon, 40, 749-752.

Wild, A.L. (2004) Taxonomy and Distribution of the Argentine Ant, Linepithema humile (Hymenoptera: Formicidae). Annals of the Entomological Society of America, 97, 12041215.

Van Wilgenburg, E., Torres, C.W. \& Tsutsui, N.D. (2010) The global expansion of a single ant supercolony. Evolutionary Applications, 3, 136-143.

Wilson, E. (1971) The Insect Societies. Belknap Press of Harvard University Press, Cambride, MA.

Wilson, E.O. (1975) Enemy specification in the alarm-recruitment system of an ant. Science, 190, 798-800.

Wilson, E.O. \& Hölldobler, B. (2005) Eusociality: origin and consequences. Proceedings of the National Academy of Sciences of the United States of America, 102, 13367-13371. 


\section{References}

Wilson, E.O., Jr, F.R. \& Regnier Jr., F.E. (1971) The evolution of the alarm-defense system in the formicine ants. American Naturalist, 105, 279-289.

Witzgall, P., Kirsch, P. \& Cork, A. (2010) Sex pheromones and their impact on pest management. Journal of Chemical Ecology, 36, 80-100.

Worm, B., Barbier, E.B., Beaumont, N., Duffy, J.E., Folke, C., Halpern, B.S., Jackson, J.B.C., Lotze, H.K., Micheli, F., Palumbi, S.R., Sala, E., Selkoe, K. a, Stachowicz, J.J. \& Watson, R. (2006) Impacts of biodiversity loss on ocean ecosystem services. Science, 314, 787790.

Yan, X., Zhenyu, L., Gregg, W.P. \& Dianmo, L. (2001) Invasive species in China - An overview. Biodiversity and Conservation, 10, 1317-1341.

Zavaleta, E.S., Hobbs, R.J. \& Mooney, H. a. (2001) Viewing invasive species removal in a whole-ecosystem context. Trends in Ecology \& Evolution, 16, 454-459.

Zehnder, G., Gurr, G.M., Kühne, S., Wade, M.R., Wratten, S.D. \& Wyss, E. (2007) Arthropod pest management in organic crops. Annual Review of Entomology, 52, 57-80.

Zimma, B.O., Ayasse, M., Tengö, J., Ibarra, F., Schulz, C. \& Francke, W. (2003) Do social parasitic bumblebees use chemical weapons? (Hymenoptera, Apidae). Journal of Comparative Physiology A: Neuroethology, Sensory, Neural, and Behavioral Physiology, 189, 769-775. 
..for though it cannot hope to be useful or informative on all matters, it does at least make the reassuring claim, that where it is inaccurate it is at least definitively inaccurate. In all cases of major discrepancy it's always reality that's got it wrong.

- Douglas Adams, The Hitchhikers Guide to the Galaxy

Ditto.

- Fabian Westermann, The influence of semiochemicals on the cooccurrence patterns of a global invader and native species 